Maastricht Graduate School of Governance (MGSoG)

\title{
INCREASED OPPORTUNITY TO MOVE UP THE ECONOMIC LADDER? EARNINGS MOBILITY IN EU: 1994-2001
}

\author{
Denisa Sologon \\ Cathal O'Donoghue
}

Work in Progress

July 2009

Working Paper

MGSoG/2009/WP003

\section{Maastricht Graduate School of Governance (MGSoG)}




\section{Maastricht Graduate School of Governance}

The 'watch dog' role of the media, the impact of migration processes, health care access for children in developing countries, mitigation of the effects of Global Warming are typical examples of governance issues - issues to be tackled at the base; issues to be solved by creating and implementing effective policy.

The Maastricht Graduate School of Governance, Maastricht University, prepares students to pave the road for innovative policy developments in Europe and the world today.

Our master's and $\mathrm{PhD}$ programmes train you in analysing, monitoring and evaluating public policy in order to strengthen democratic governance in domestic and international organisations. The School carefully crafts its training activities to give national and international organisations, scholars and professionals the tools needed to harness the strengths of changing organisations and solve today's challenges, and more importantly, the ones of tomorrow.

\section{Authors}

\section{Denisa Maria Sologon}

Maastricht University, Maastricht Graduate School of Governance

Harvard University, Harvard Kennedy School of Government

Email: denisa.sologon@maastrichtuniversity.n.

\section{Cathal O'Donoghue}

Teagasc Rural Economy Research Centre; NUI Galway; IZA and ULB

Email: Cathal.ODonoghue@teagasc.ip

Mailing address

Universiteit Maastricht

Maastricht Graduate School of Governance

P.O. Box 616

6200 MD Maastricht

The Netherlands

Visiting address

Kapoenstraat 2, $6211 \mathrm{KW}$ Maastricht

Phone: +31 433884650

Fax: +31433884864

Email: info-governance@maastrichtuniversity.n 


\section{ABSTRACT \\ INCREASED OPPORTUNITY TO MOVE UP THE ECONOMIC LADDER? EARNINGS MOBILITY IN EU: 1994-2001}

Do EU citizens have an increased opportunity to improve their position in the distribution of earnings over time? This question is answered by exploring short and long-term wage mobility for males across 14 EU countries between 1994 and 2001 using ECHP. Mobility is evaluated using rank measures which capture positional movements in the distribution of earnings. All countries recording an increase in cross-sectional inequality recorded also a decrease in shortterm mobility. Among countries where inequality decreased, short-term mobility increased in Denmark, Spain, Ireland and UK, and decreased in Belgium, France and Ireland. Long-term mobility is higher than short-term mobility, but long-term persistency is still high in all countries. The lowest long-term mobility is found in Luxembourg followed by four clusters: first, Spain, France and Germany; second, Netherlands, and Portugal; third, UK, Italy and Austria; forth, Greece, Finland, Belgium and Ireland. The highest long-term mobility is recorded in Denmark.

JEL Classification: C23, D31, J31, J60

Keywords: panel data, wage distribution, inequality, mobility

Corresponding Author:

Denisa Maria Sologon

Maastricht Graduate School of Governance

Maastricht University

Kapoenstraat 2, KW6211

Maastricht

The Netherlands

Email: denisa.sologon@maastrichtuniversity.nl 


\section{INTRODUCTION}

Do EU citizens have an increased opportunity to improve their position in the distribution of earnings over time? This question is relevant in the context of the EU labour market policy changes that took place after 1995 under the incidence of the 1994 OECD Jobs Strategy, which recommended policies to increase wage flexibility, lower non-wage labour costs and allow relative wages to reflect better individual differences in productivity and local labour market conditions. (OECD, 2004) Following these reforms, the labour market performance improved in some countries and deteriorated in others, with heterogeneous consequences for cross-sectional earnings inequality and earnings mobility. Averaged across OECD, however, gross earnings inequality increased after 1994. (OECD, 2006)

Some people argue that rising annual inequality does not necessarily have negative implications. This statement relies on the "offsetting mobility" argument, which states that if there has been a sufficiently large simultaneous increase in mobility, the inequality of income measured over a longer period of time, such as lifetime income or permanent income - can be lower despite the rise in annual inequality, with a positive impact on social welfare. This statement, however, holds only under the assumption that individuals are not averse to income variability, future risk or multi-period inequality. (Creedy and Wilhelm, 2002; Gottschalk and Spolaore, 2002) Therefore, there is not a complete agreement in the literature on the value judgement of income mobility. (Atkinson, Bourguignon, and Morrisson, 1992)

Those that value income mobility positively perceive it in two ways: as a goal in its own right or as an instrument to another end. The goal of having a mobile society is linked to the goal of securing equality of opportunity in the labour market and of having a more flexible and efficient economy. (Friedman, 1962; Atkinson et al., 1992) The instrumental justification for mobility takes place in the context of achieving distributional equity: lifetime equity depends on the extent of movement up and down the earnings distribution over the lifetime. (Atkinson et al., 1992) In this line of thought, Friedman (1962) underlined the role of social mobility in reducing lifetime earnings differentials between individuals, by allowing them to change their position in the income distribution over time. Thus earnings mobility is perceived in the literature as a way out of poverty. In the absence of mobility the same individuals remain stuck at the bottom of the earnings distribution, hence annual earnings differentials are transformed into lifetime differentials. 
This paper explores earnings mobility across 14 EU countries over the period 1994-2001 using ECHP to identify the possible consequences of the labour market changes occurred across Europe after 1995. We are interested in mobility as the degree of opportunity to better ones position in the earnings distribution over time. The second aspect of mobility mentioned above - as equalizer of lifetime earnings differentials - is left for future research. The comparative perspective aims to shed light on the link between the evolution of earnings mobility and cross-sectional earnings inequality.

The question regarding the degree of wage mobility is vitally important from a welfare perspective, particularly given the large variation in the evolution of cross-sectional wage inequality across Europe over the period 1994-2001. It is highly relevant to understand what the source of this variation is. Did the increase in cross-sectional wage inequality observed in some countries result from greater transitory fluctuations in earnings and individuals facing a higher degree of earnings mobility? Or is this rise reflecting increasing permanent differences between individuals with mobility remaining constant or even falling? What about countries which recorded a decrease in cross-sectional earnings inequality? Can increased mobility be a factor behind shrinking earnings differentials? In some countries, earnings distribution might not change to a large extent over a period of one or two years, and the core question is what happens in different parts of the distribution. Are the same people stuck at the bottom of the earnings distribution or are low earnings largely transitory? How mobile are people in earnings distribution over different time horizons? Did mobility patterns change over time? Are there common trends in earnings inequality and mobility across different countries? What lessons can we learn from the different mobility approaches?

Mobility is assumed to be exogenous and is measured using two approaches based on rank measures which capture positional movements in the distribution of earnings. The first one is based on estimating transition probabilities between earnings quintiles and the second one on the changes in the individual ranks in the earnings distribution between different time periods.

\section{LITERATURE REVIEW}

The number of comparative studies on earnings mobility is limited because of the lack of sufficiently comparable panel cross-country data. Most of the existing studies focus on comparison between the US and a small number of European countries. 
Aaberge, Bjorklund, Jantti, Palme, Pedersen, Smith, and Wannemo (2002) compared income (family income, disposable income and earnings) inequality and mobility in the Scandinavian countries and the United Stated during 1980-1990. They measured mobility as the proportionate reduction of inequality when the accounting period of income is extended and found low mobility levels for all countries. Independent of the accounting period, they found that earnings inequality is higher in the US than in the Scandinavian countries. Mobility is higher for the US only for long accounting periods. They also found evidence of greater dispersion of first differences of relative earnings and income in the United States.

Brukhauser and Poupore (1997) and Brukhauser, Holtz-Eakin, and Rhody (1998) found that, the US, in spite of having a higher earnings or disposable income dispersion than Germany, its mobility is similar with Germany between 1983 and 1988.

Fritzell (1990) studied mobility in Sweden using mobility tables from 1973 and 1980 and compared them with Duncan and Morgan (1981) for the US for the period 1971 and 1978, and found remarkable similarities between the two countries.

OECD $(1996,1997)$ presented a variety of comparisons of earnings inequality and mobility across OECD countries over the period 1986-1991. The results vary depending on the definition and measure of mobility.

At the EU level, no study attempted to analyse and to understand in a comparative manner earnings mobility and its link with earnings inequality over a more recent period and covering a longer time frame than six years. By exploiting the eight years of panel in ECHP, our paper aims to fill part of that gap and to make a substantive contribution to the literature on crossnational comparisons of mobility at the EU level.

\section{Methodology}

There are many approaches to measuring mobility.(Fields and Ok, 1999; Fields, Leary, and Ok, 2003) We focus on two rank measures, which capture positional movements in the distribution of earnings. The first one is derived from the transition matrix approach between income quintiles and other labour market states, and the second one is based on individual ranks, as derived by Dickens (1999).

We estimate two types of mobility measures: 
- short-term mobility $\mathrm{M}(\mathrm{t}, \mathrm{t}+1)$ - defined as mobility between periods one year apart, meaning between year $t$ and year $t+1$. This is used to assess the pattern of short-term mobility over time, between $\mathrm{M}(1994,1995)$ and $\mathrm{M}(2000,2001)$.

- longer period mobility $\mathrm{M}(\mathrm{t}, \mathrm{t}+7)$ - defined as mobility between periods $\operatorname{seven}^{1}$ years apart, meaning between year $t$ and year $t+7$. This will be compared with short-term mobility to assess the extent to which mobility increases with the time span.

Finally, we explore the link between short and long-term mobility and the evolution of yearly inequality: first, the link between the relative change in $\mathrm{M}(\mathrm{t}, \mathrm{t}+1)^{2}$ and in $\mathrm{I}(\mathrm{t}+1)^{3}$ over the sample period; second the link between the relative difference between mobility the first land last wave, $M(t, t+7)$, and the relative change in inequality between the first and last wave . $^{4}$

\subsection{Transition Matrix Approach to Mobility}

Mobility measures derived from transition probabilities between different earnings ranges (e.g. quintiles) or between different labour market states are purely relative. For example, in the case of earnings transition probabilities, in a country with a low level of cross-sectional earnings inequality, a modest increase in earnings could cause a large change in an individual's relative position. The same quintile transition in a second country, with high cross-sectional inequality, would require a larger percentage increase in earnings. Thus, equal transition probabilities indicate similar relative mobility, meaning that the frequency of changes in the earnings rankings is the same in both countries, but earnings volatility is higher in the second country. The extent of relative mobility has important implication for long-period or lifetime inequality.(OECD, 1996)

The information contained in the transition matrices can be summarized by several immobility indices, which allows one to create mobility rankings. Two of them are selected for summarizing the transitions between the earnings quintiles: the immobility ratio and the average jump. (Atkinson et al., 1992)

\footnotetext{
${ }^{1} 6$ for Luxembourg and Austria and 5 for Finland.

${ }^{2} \mathrm{M}(1994,1995)$ to $\mathrm{M}(2000,2001)$

${ }^{3} \mathrm{I}(1995)$ to $\mathrm{I}(2001)$

${ }^{4}$ The link between M(1994,2001) and the relative difference between I(1994) and I(2001)
} 
The immobility ratio measures the percentage of people staying in the same quintile or entering the quintile immediately above/below. Because the immobility ratio focuses on the near-diagonal entries, it is insensitive to the movement outside the diagonal. (Atkinson et al., 1992). One popular alternative which circumvents this problem is the average jump $(\mathrm{AJ}): A j=\frac{\sum_{i=1}^{q} \sum_{j=1}^{q}|i-j| p_{i j}}{q}$

where $q$ is the number of quantiles, $p_{i j}$ is the transition rate located in row $i$ and column $j$. AJ represents the absolute value of the difference in rank, measured in quintiles, in one distribution compared to the other. One drawback of the AJ is that it is insensitive to purely exchange mobility.

In order to be interpretable, these measures of immobility need to be compared with the mobility achieved under "perfect mobility", meaning where the probability of occupying each rank is independent of the starting point. (Atkinson et al., 1992) For a transition matrix defined in terms of quintiles, perfect mobility means that the probability of moving into a particular rank from one period to the next is 0.2 . The Tmmobility ratio under the assumption

of perfect mobility for a transition matrix defined in terms of quintiles equals $0.52^{5}$ The expected $\mathrm{AJ}$ under the assumption of perfect mobility for a quintile transition matrix equals 1.6. Therefore, the value of the immobility ratio should be compared with $52 \%$ (base line for perfect mobility) and the value of the AJ should be compared with 1.6 (base line for perfect mobility).

\subsection{Alternative approach to mobility (Dickens 1997, 2000)}

The main limitation of the transition matrix approach to mobility is that it fails to capture the movement within each earnings quintile or income group. An alternative approach to the quintile transition matrices presented above is to compute the ranking of the individuals in the wage distribution for each year and examine the degree of movement in percentile ranking from one year to the next. (Dickens, 1999) For each mobility comparison only individuals that have earnings in both periods are considered.

${ }^{5}(2 * 0.2+3 * 0.2+3 * 0.2+3 * 0.2+2 * 0.2) / 5=0.52$ 
One way to give an indication of the level of mobility is to plot the percentile rankings for pairs of years. If there is no mobility, meaning that each individual preserves his/her rank in the income distribution from one period to the next, then the plot looks like a 45-degree line that starts at the origin. If there is no association between earnings from different years, then one would expect a random scatter.

Following Dickens (1999), the percentile rankings can be used to construct a measure of mobility based on the degree of change in ranking from one year to the other. The measure of mobility between year $t$ and year $s$ is:

$$
M=\frac{2 \sum_{i=1}^{N}\left|F\left(w_{i t}\right)-F\left(w_{i s}\right)\right|}{N}
$$

where $F\left(w_{i t}\right)$ and $F\left(w_{i s}\right)$ are the cumulative distribution function for earnings in year $\mathrm{t}$ and year $\mathrm{s}$ and $\mathrm{N}$ is the number of individuals that record positive earnings in both year $\mathrm{t}$ and year s. Based on this measure, the degree of mobility equals twice the average absolute change in percentile ranking between year $t$ and year $s$. When there is no mobility and people hold their position in the income distribution from year $t$ to year $s$, the difference between $F\left(w_{i t}\right)$ and $F\left(w_{i s}\right)$ is equal to 0 for all individuals, and therefore $\mathrm{M}$ is equal to 0 . The index takes a maximum value of 1 if earnings in the two years are perfectly negatively correlated, meaning that in the second period there is a complete reversal of ranks, and the value $2 / 3$ if earnings in the two periods are independent. The robustness of this measure of mobility was discussed in Dickens (1999).

\section{DATA}

The study is conducted using the European Community Household Panel (ECHP) ${ }^{6}$ over the period 1994-2001 for 14 EU countries. Not all countries are present for all waves. Luxembourg and Austria are observed over a period of 7 waves (1995-2001) and Finland over a period of 6 waves (1996-2001). Following the tradition of previous studies, the analysis focuses only on men.

${ }^{6}$ The European Community Household Panel provided by Eurostat via the Department of Applied Economics at the Université Libre de Bruxelles. 
A special problem with panel data is that of attrition over time, as individuals are lost at successive dates causing the panel to decline in size and raising the problem of representativeness. Several papers analysed the extent and the determinants of panel attrition in ECHP. A. Behr, E. Bellgardt, U. Rendtel (2005) found that the extent and the determinants of panel attrition vary between countries and across waves within one country, but these differences do not bias the analysis of income or the ranking of the national results. L.Ayala, C. Navrro, M.Sastre (2006) assessed the effects of panel attrition on income mobility comparisons for some EU countries from ECHP. The results show that ECHP attrition is characterized by a certain degree of selectivity, but only affecting some variables and some countries. Moreover, the income mobility indicators show certain sensitivity to the weighting system.

In this paper, the weighting system applied to correct for the attrition bias is the one recommended by Eurostat, namely using the "base weights" of the last wave observed for each individual, bounded between 0.25 and 10. The dataset is scaled up to a multiplicative constant $^{7}$ of the base weights of the last year observed for each individual.

For this study we use real net ${ }^{8}$ hourly wage adjusted for CPI of male workers aged 20 to 57 , born between 1940 and 1981. Only observations with hourly wage lower than 50 Euros and higher than 1 Euro were considered in the analysis. The resulting sample for each country is an unbalanced panel. Details on the number of observations, inflows and outflows of the sample by cohort over time for each country are provided in Table 1 .

\section{CHANGES IN THE CROSS-SECTION EARNINGS DISTRIBUTION OVER TIME}

This section presents the changing shape of the cross-sectional distribution of earnings for men over time. Figure 1 illustrates the frequency density estimates for the first wave ${ }^{9}, 1998$ and 2001 earnings distributions and Table 2 illustrates the evolution of the other moments of the earnings distribution over time. The evolution of mean net hourly wage shows that men in most countries got richer over time, except for Austria. Net hourly earnings became more dispersed in most countries, except for Austria, France and Denmark.

\footnotetext{
7 The multiplicative constant equals e.g. p*(Population above 16/Sample Population). The ratio p varies across countries so that sensible samples are obtained. It ranges between 0.001-0.01.

${ }^{8}$ Except for France, where wage is in gross amounts

${ }^{9}$ For Luxembourg and Austria, the first wave was recorded in 1995, whereas for Finland in 1996.
} 
Plotting the percentage change in mean hourly earnings between the beginning of the sample period and 2001 at each point of the distribution for each country (Figure 2), revealed that, in most countries, the relationship between the quantile ${ }^{10}$ rank and growth in real earnings is negative and nearly monotonic: the higher the rank, the smaller the increase in earnings. This shows that in most countries, over time, the situation of the low paid people improved to a larger extent than for the better off ones. In Austria, people at the top of the distribution experience a decrease in mean hourly wage over time, which might explain the decrease in the overall mean.

Netherlands, Germany, Greece and Finland diverge in their pattern from the other EU countries experiencing a higher relative increase in earnings the higher the rank. Netherlands is the only country where men at the bottom of the income distribution recorded a deterioration of their work pay. For these countries, the increase in the overall mean might be the result of an increase in the earnings position of the better off individuals, not the low paid ones.

To complete the descriptive picture of the cross-sectional earnings distribution over time, we provide also inequality measures. Inequality indices differ with respect to their sensitivity to income differences in different parts of the distribution. Therefore they illustrate different sides of the earnings distribution. The year-to-year changes in earnings inequality are captured by computing the ratio between the mean earnings in the 9th decile and the 1st decile (Figure 3), the Gini index, the GE indices - the Theil Index (GE(1)) -, and the Atkinson inequality index evaluated at an the aversion parameter equal to 1 (Table 3). ${ }^{11}$

The ratio between the mean earnings in the 9th decile and the 1st deciles focuses only on the two ends of the distribution. The Gini index is most sensitive to income differences in the middle of the distribution (more precisely, the mode). The GE with a negative parameter is sensitive to income differences at the bottom of the distribution and the sensitivity increases the more negative the parameter is. The GE with a positive parameter is sensitive to income differences at the top of the distribution and it becomes more sensitive the more positive the parameter is. For the Atkinson inequality indices, the more positive the "inequality aversion

\footnotetext{
10100 Quantiles

${ }^{11}$ Besides these indices, several others were computed (GE(-1); GE(0), GE(2), Atkinson evaluated at different values of the aversion parameter) and can be provided upon request from the authors. They support the findings shown by the reported indices.
} 
parameter" is, the more sensitive the index is to income differences at the bottom of the distribution.

The level and pattern of inequality over time as measured by the ratio between the mean earnings in the 9th decile and the 1st decile differs to a large extent between the EU14 countries. Two clusters can be identified. The first one is comprised of Netherlands, Begium, Italy, Finland, Austria and Denmark and is characterized by a small relative distance between the bottom and top of the distribution. The other cluster identifies countries with a higher level of inequality, with ratios between 2.75 and 4 .

In 1994, based on the Gini index, Portugal is the most unequal, followed by Spain, France, Ireland, UK, Greece, Germany, Italy, Belgium, Netherlands and Denmark. In general, the other two indices confirm this ranking. However, using the Theil index, France appears to be more unequal than Spain, whereas using the Atkinson index, Ireland appears to be more unequal than France and as equal as Spain.

In 2001, based on the Gini index, Portugal is still the most unequal, followed by France, Greece, Luxembourg, Spain, UK, Germany, Ireland, Netherlands, Italy, Finland, Belgium, Austria and Denmark. In general, the other two indices confirm this ranking. Based on Theil, however, Greece is more unequal than France, and Spain than Luxembourg. Based on Atkinson, Luxembourg is more unequal than Greece.

For most countries, all indices show a consistent story regarding the evolution of inequality over the sample period, except for Germany, France and Portugal, where the evolution of the Gini, Theil and Atkinson index is opposite to the one observed for the D9/D1. Based on Gini, Theil and Atkinson, Netherlands, Greece, Finland, Portugal, Luxembourg, Italy and Germany recorded an increase in yearly inequality, and the rest a decrease.

The relative evolution over the sample period is captured in Figure 4, which illustrates for each country, the change in inequality as measured by Gini, Theil, Atkinson index and the D9/D1. Based on Gini, the highest increase in inequality was recorded by Netherlands (around 15\%), followed by Greece, Finland, Portugal, Luxembourg, Italy and Germany. The highest decrease was recorded in Ireland (around 20\%), followed by Austria, Denmark, Belgium, Spain, France and UK. Based on the Theil index, Portugal records a higher increase than Finland, Italy a higher increase than Luxembourg and Spain a higher decrease than 
Belgium. Based on Atkinson index, Portugal records a higher increase than Finland and UK a higher decrease than France.

For Netherlands, Finland and Greece the increase in the distance between the top and bottom of the distribution and in the overall level of inequality can be explained by the improved earnings position of the better off individuals. Hence in these countries, the economic growth benefitted the high income people and leaded to an increase in earnings inequality.

Luxembourg and Italy recorded an increase in inequality based on all indices, but the situation at the bottom improved to a larger extent than for the top. Thus the increase in inequality might be the result of other forces affecting the distribution, such as mobility in the bottom and top deciles.

For France, the relative distance between the top and the bottom 10\% appears to increase over time, in spite of a higher relative increase in mean earnings at the bottom of the distribution compared with the top. This discrepancy could be explained by the presence of earnings mobility in the bottom and top $10 \%$ of the earnings distribution. The improved conditions for people in the bottom of the distributions could explain the decrease in earnings inequality as displayed by the other three indices.

Germany records opposite trends from France: the situation of the better off individuals improved to a larger extent than for low paid ones, which explains the increase in the overall inequality as captured by the Gini, Theil and Atkinson indices. The evolution of the ratio between mean earnings at the top and the bottom deciles is opposite to what was expected: the decrease might suggest that there are other forces at work, such as mobility in the top part of the distribution, which determined mean earnings to decrease for this group.

Portugal records similar trends with Germany, except for the negative correlation between the rank in the earnings distribution and the growth in earnings. Thus, the fact that low paid individuals improved their earnings position to a higher extent relative to high paid individuals, lowering the distance between the bottom and the top deciles of the earnings distribution did not have the expected effect of lowering overall earnings inequality as measured by the Gini, Theil and Atkinson indices. Mobility is expected to be the factor counteracting all these movements. 
For the rest of the countries, the increase in the overall mean, coupled with the higher relative increase in the earnings position of the low paid individuals compared with high earnings individuals can be an explanation for their decrease in inequality.

Besides the direction of evolution, also the magnitude of the change records differences among inequality indices. In general, the magnitude of the change is the highest for the index that is most sensitive to the income differences at the top of the distribution, followed by bottom and middle sensitive one, sign that most of the major changes happened at the top and the bottom of the distribution. There are a few exceptions. In UK, Spain, Belgium and Denmark the magnitude of the evolution is the highest for the bottom sensitive one, followed by the top and middle ones.

\section{LINKING EARNINGS INEQUALITY AND MOBILITY: INDIVIDUAL MOVEMENTS WITHIN THE DISTRIBUTION OVER TIME}

When analysing the change in the distribution of earnings, one has to pay attention to two basic characteristics. First, how far apart are individuals in terms of their wage and to what extent does the ranking of each individual change from one period to the next. Section 5 offered a broad overview of the first characteristic. This section focuses on the second one and analyses the intra-distributional mobility of earnings over the period $1994-2001$.

\subsection{Mobility among labour market states}

To understand mobility patterns over time, it is informative to inspect mobility both within the wage distribution and into and out of the distribution to other employment states. For this purpose, we compute the quintiles of the wage distribution and present short-term and longterm transitions both between quintiles and to other employment states. ${ }^{2}$

Table 4 presents one-year period transition matrices for men between the first and second wave and between 2000 and 2001. For all countries, one-year labour market transition matrices portray a picture of persistence, with little short-term mobility. The diagonal elements of these matrices are much higher than the off-diagonal elements, suggesting a low degree of mobility from one period to the next, both in terms of quintiles of the earnings distribution and in states outside of employment. The concentration around the diagonal

\footnotetext{
${ }^{12}$ Short-term transitions are defined as transitions from one year to the next. Long-term transitions are defined as transitions from the first to the last wave.
} 
decreases the further one moves from the diagonal, indicating that those individuals that do change their labour market position from one period to the next, do not move very far.

In most countries, individuals in the lowest two quintiles are more likely to enter unemployment and inactivity compared with the rest of the distribution. Netherlands is an exception, where the top and the bottom of the distribution have similar high rates of entering unemployment and inactivity. Similarly, those unemployed and inactive that managed to get a job in the next period are more likely to enter the lower quintiles of the distribution. These findings are consistent with previous findings, for example Dickens (2000) for UK over the period 1975-1994.

In the beginning of the sample period, the highest short-term persistence in unemployment was recorded in Ireland, Luxembourg, Italy, Finland, Belgium and Austria where between $62.45 \%$ and $50.63 \%$ kept their status from one year to the next, followed by Spain and Netherlands with $46 \%$ and $42.92 \%$, and Germany, UK, Greece, Portugal, France and Denmark with rates between $39.42 \%$ and $34 \%$. The highest persistency in inactivity was recorded in France, Belgium, Ireland and Portugal where more than half kept the same status in 1995. Over time, short-term mobility out of unemployment increased in Luxembourg, Ireland, Italy, Spain, Portugal, Austria and Finland, whereas short-term mobility out of inactivity increased only in Belgium, France and UK.

Looking at the pattern of mobility over a longer time span (Table 5), mobility measured over the whole sample period is higher than one-period mobility: the concentration along the diagonal is much less than when measured over one year. These trends are consistent with previous findings. (Atkinson et al., 1992; OECD, 1996; Dickens, 1999) The highest longterm persistency in unemployment is found in Belgium, UK, Italy, Germany and Spain, where between $23 \%$ and $12 \%$ maintained their status in 2001. The highest persistency in inactivity is in France, Belgium, Portugal, Spain, Netherlands and Ireland with rates between $29 \%$ and $23 \%$.

\subsection{The transition matrix approach to mobility among income quintiles}

Having introduced the general picture of mobility between different labour market states, the next step is to explore short and long-term mobility between income classes, as well as how short-term earnings mobility patterns changed over time. 
Short-term earnings transition matrices (Table 6) portray a picture of persistence, with little mobility over a one-year period: the diagonal elements of these matrices are much higher than the off-diagonal elements. All rows display high predictability and origin dependence (the transition probabilities are not equal) meaning that the position in the earnings distribution the next period depends heavily on the initial state. The concentration around the diagonal decreases the further one moves from the diagonal, indicating that those individuals that do change their income position from one period to the next, do not move very far. For all countries, short-term persistency appears to be the highest for the top quintile, followed by the bottom and middle ones.

Of those in the lowest quintile in the first wave, the highest percentage of people that were still in the lowest quintile one year later is recorded in Luxembourg (76.59\%), followed by Germany (71.28\%), Italy, France, Finland, Netherlands and Ireland, with values between $60 \%$ and $70 \%$, and Portugal, Austria, UK, Denmark, Spain, Belgium and Greece, with values between $50 \%$ and $60 \%$.

For the middle quintile, in the first wave, the highest mobility is observed in Austria, where $27.53 \%$ maintained their state from one year to the next, followed by Denmark $(32.22 \%)$, Greece, Finland, Spain, Italy, Belgium, Ireland and Germany with a persistency between $40 \%$ and 50\%, France, UK and Portugal with values between $50 \%$ and 55\%, and finally Luxembourg, where $68.15 \%$ of those in the middle quintile in the first wave maintained their earnings position until the next period.

For the top quintile, Portugal, followed by Germany, UK, Netherlands, Ireland, Spain record the highest persistency in the first wave, with a probability of over $80 \%$ of remaining in the same state one year later. Next follow Luxembourg, Belgium, Italy, France and Finland, with a probability between $80 \%$ and $70 \%$, Austria, Denmark and Greece, with a probability between $70 \%$ and $60 \%$.

Over time, short-term income mobility for individuals belonging to the first quintile decreased in all countries, with three exceptions: Luxembourg, Spain and Finland. Middle quintiles recorded a decrease in short-term mobility, except for UK, Belgium, and Ireland which did not change in mobility. Short-term mobility increased for the top quintile in Germany, Netherlands, Ireland, Spain and Portugal, and decreased in the rest. A decrease in short-term mobility over time suggests that in 2000-2001, low paid individuals find more 
difficult to move up the income distribution compared with the first two waves. For the middle quintile, mobility increased only in Belgium, UK and Portugal.

In 2000-2001, for the bottom quintile the highest persistency was recorded in Portugal, Germany, Austria, Belgium, Netherlands and Luxembourg where between $78 \%$ and $70 \%$ remained in the same income group, followed by Greece, France, Ireland, Denmark with probabilities between $69 \%$ and $60 \%$, and UK, Finland, Italy and Spain with rates between $59 \%$ and $49 \%$. For the middle quintile, the persistency is high in Luxembourg, Greece, Portugal, France, Austria, UK, Germany, Italy, and Netherlands with rates between $68 \%$ and $50 \%$, and the rest with rates between $47 \%$ (Spain) and 32\% (Denmark). For the top quintile, all countries have a high persistency: between $87 \%$ (Luxembourg) and 73\% (Finland) remained in the same earnings group.

As expected, for most countries and most income quintiles, long-term mobility (Table 7) appears to be higher compared with short-term mobility, but the persistency is still very high. The concentration along the diagonal is less than when measured over just one year.

For those in the bottom quintile in the first wave, the degree of long-term persistency is the highest in Germany, Austria, Finland, Portugal and France, where between 49\% and 41\% remained in the same earnings quintile in 2001, followed by Luxembourg, Netherlands, Spain, Belgium, Italy, Denmark, UK, Greece and Ireland, with values between $40 \%$ and $23 \%$ The mobility of the bottom quintile is higher than mobility of the middle quintile in Denmark, Luxembourg, UK, Ireland and Greece. From those in the middle quintile in the first wave, between $21 \%$ (Austria) and $45 \%$ (Luxembourg) are still in the middle quintile in the last wave. For those in the top quintile, the persistency is much higher, ranging between $88 \%$ and and $71 \%$ for Spain, Luxembourg, Portugal, Netherlands, Ireland, Germany, UK and Italy, and between $69 \%$ and $57 \%$ for Belgium, France, Finland, Austria, Greece and Denmark.

The decreasing degree of persistence with the time span is consistent with previous research which proved that the transitory component of earnings dies off after a certain number of years. The effects of the transitory shocks which might have affected earnings in one year are expected to diminish with time, determining people that experienced the transitory shocks to regain their pre-shock position in the earnings distribution. Exceptions from this trend are observed for the top quintile in Luxembourg and Greece, where long-term mobility is roughly equal to short-term mobility, suggesting the existence of high permanent differences between 
individual earnings, and in Spain, where long-term mobility decreased compared to shortterm mobility.

The information in the transition matrices can be summarized by the immobility ratio and the average jump. Figure 5, Figure 6 and Table 8 illustrate short and long-term immobility ratios and average jump (AJ) for the earnings quintiles transition matrices, both in absolute values and relative to the case of perfect mobility. For the interpretation, we use the ones relative to the case of perfect mobility.

Short-term immobility ratios for all countries over time (Figure 5) have values between 1.6 and 1.9 times the immobility ratio for the case of perfect mobility, suggesting a very high degree of persistency on or close the diagonal from one year to the next. In the first wave, Greece has the lowest persistency, followed by Austria, Belgium, Denmark, Italy and Finland, and, at a higher level, by Spain, France, Portugal, Ireland, UK, Germany, Netherlands and Luxembourg.

Short-term average jump over time (Figure 6 ) records values between 0.15 and 0.4 of the value under perfect mobility, suggesting a low to moderate degree of mobility outside the diagonal for all countries. In the first wave, the lowest average jump is recorded in Luxembourg (above 0.2), followed by Germany, Portugal and Netherlands (with values close to 0.3), UK, France, Ireland, Spain, Italy, Finland, Belgium and Denmark (with values between 0.3 and 0.4 ), and Austria and Greece (with values greater than 0.4).

As illustrated in Figure 5 and Figure 6, some countries recorded a decrease and others an increase in short-term mobility over time. In general, over time, the evolution of the immobility ratio appears to be negatively associated with the evolution of the average jump: the larger the increase in mobility on and close to the diagonal (decrease in immobility ratio), the larger the increase in mobility away from the diagonal (increase in average jump) and vice versa.

Greece, Austria, Belgium, France, Italy, Portugal, Germany, Luxembourg and Finland recorded a decrease in mobility close to the diagonal (increase in the immobility ratio) and a decrease in mobility away from the diagonal (decrease in the average jump). The magnitude of the evolution is the highest in the first five countries, ranging between $9 \%$ and $3 \%$ for the immobility ration, and $41 \%$ and $18 \%$ for the AJ. The relative decrease in mobility as measured by $\mathrm{AJ}$ is higher than the relative decrease in mobility as measured by the 
immobility ratio, suggesting that the off-diagonal short-term mobility increased to a higher extent than the mobility along the diagonal. An exception is Finland, where the reverse holds. Spain has the largest increase in mobility close or on the diagonal (a decrease of $4 \%$ in immobility ratio) and the largest increase in mobility away from the diagonal (16.8\%). In the same category are situated also Ireland and UK, but with a lower magnitude of the evolution (around $0.3 \%-1 \%$ for the immobility ratio and 3\%-4\% for AJ). Except Spain, the increase in the average jump is higher than the decrease in the immobility ratio.

Denmark and Netherlands represent an exception from this rule, recording both a decrease in immobility ratio and a decrease in the average jump, therefore an increase in mobility on the diagonal and a decrease in mobility away from the diagonal. Moreover, the decrease in offdiagonal mobility (11\% for Netherlands and 5\% for Denmark) is greater than the decrease of mobility on or close to the diagonal ( $0.4 \%$ in Netherlands and $0.8 \%$ in Denmark).

Mobility close to the diagonal appears to converge over time in five clusters: first, Luxembourg which records the highest immobility ratio in 2000-2001; second, Germany, France and Greece; third, UK, Belgium, Netherlands, Portugal, Italy and Austria; forth, Ireland and Finland, and lastly, with the lowest immobility ratio, Denmark and Spain. Similarly, mobility away from the diagonal appears to converge over time in four clusters: first, Luxembourg - the lowest average jump in 2000-2001; second, Germany, France, Austria, Netherlands, Belgium and Greece, Portugal; third, Italy, UK and Ireland; and lastly, Finland, Spain and Denmark, with the highest mobility away from the diagonal in 2000-2001. Overall, Luxembourg appears to diverge from the other EU countries.

In line with previous studies, the longer the period over which mobility is measured the higher the mobility, both close and away from the diagonal of the earnings transition matrix. (Table 8) Long-term immobility ratio records values between 1.4 and 1.7, whereas the average jump in the long run is between 0.3 and 0.6 , indicating a high degree of persistency close or on the diagonal and a high mobility away from the diagonal. Based on both indices, the lowest long-term mobility is recorded in Luxemboug ${ }^{13}$, followed by France, Spain, Germany, Netherlands and Portugal which record similar values. UK records a slightly higher

\footnotetext{
${ }^{13}$ The value for Luxembourg and Austria illustrated the mobility over a period of 6 years, and for Finland over 5 years.
} 
mobility, similar with Belgium, Italy and Greece. Denmark and Ireland record the highest mobility in the long run, confirmed both by the immobility and the average jump.

Figure 8 illustrates the relative difference between long and short-term mobility, based on the immobility ratio and average jump. For all countries, the longer the accounting period, the decrease in the immobility ratio is lower than the increase in the average jump, which suggests that mobility away from the diagonal increases to a higher extent compared with the mobility close to the diagonal. Thus the longer the time period, the more likely it is that people move away from their initial state.

The ranking of the countries based on the relative difference between long and short-term mobility reveals that the relative change in the average jump with the time horizon is negatively associated with the relative change in the immobility ratio with the time horizon. The first six countries which record the highest drop in the immobility ratio with the time horizon are among the first seven countries with the highest increase in the average jump. It is the case of Denmark, Ireland, UK, Germany, Netherlands and Portugal. Denmark appears to record the highest decrease in persistency close to the main diagonal (approximately 17\%), whereas the increase in the mobility away from the diagonal is of almost 55\%. Ireland, which has a similar decrease in the immobility ratio, has the highest increase in the average jump, almost 90\%. UK, Germany, Portugal and Netherlands record a relatively smaller reduction in the immobility ratio (between $11 \%$ and 14\%) than Denmark and Ireland and a higher increase in the average jump (over 60\%) than Denmark, but lower than Ireland.

These are followed by Italy, Spain, Finland, Belgium, Greece and France, which record a smaller decrease in the immobility ratio (between $6 \%$ and $11 \%$ ) and an increase of more than $40 \%$ in the average jump. Luxembourg records the lowest increase in mobility close to the main diagonal and among the highest increase in mobility away from the main diagonal, suggesting that the longer the period of time, the more likely it is that people move away from their initial position in the earnings distribution.

In the long run, Luxembourg appears to be the least mobile, and Denmark and Ireland the most mobile, both close to and away from the diagonal. Long-term immobility ratios are similar for the other countries, whereas for AJ more heterogeneity is observed. Overall, we observed less heterogeneity with respect to long-term mobility rates compared with shortterms, suggesting that over lifetime earnings mobility rates are expected to converge to 
similar levels in most countries. The convergence is expected to be more evident for the immobility ratio than for AJ.

\subsection{Alternative approach to mobility (Dickens 1997, 2000)}

Similar to the transition matrix approach, we look first at short-term mobility and then at long-term mobility. Figure 10 presents plots of percentile rankings of male earnings in 1994/1995 and 2000/2001, and. Figure 11 percentile plots for 1994/1995 and 1994/2001.

For the pair of years situated at 1 year time horizon a high earnings persistency is observed for all countries: most of the individuals are concentrated in a band around the 45-degree line, at different degrees across countries. The highest concentration is observed at the two extremes of the distribution, meaning that individuals situated at the bottom and top of the earnings distribution have a lower mobility compared to the ones in the middle of the distribution, which is in line with the findings from the transition matrix approach.

In the beginning of the sample period, the countries with the lowest overall short-term mobility (highest concentration along the 45-degree line) appear to be Germany, Netherlands, Luxembourg, France, UK, Ireland, Italy, Spain and Portugal. The most mobile appears to be Greece.

In order to understand better how the pattern of mobility changed over time we look at pairs of earnings rankings situated at the same time horizon (Figure 10 $)$. The concentration along the 45-degree line appears to increase over time, suggesting a decreasing degree of mobility from one year to the next, for most countries. Denmark, Ireland, Spain represent an exception, recording an apparent diminishing concentration along the 45-degree line and therefore an increase in mobility.

If one looks at the different parts of the distribution, diverging patterns appear. For those at the bottom of the distribution, mobility appears to increase in Denmark, Ireland, Spain and Finland, whereas for the other countries a higher concentration can be observed over time. These findings are in line with the ones from the transition matrix approach, except for Denmark, Ireland and Luxembourg, where the reversed in observed.

The concentration in the middle of the distribution increased over time, suggesting a decreasing degree of mobility from one year to the next, for most countries. Exceptions are Denmark, Belgium, UK, Ireland and Spain, where people situated in middle part of the 
distribution appear to become more mobile over time. Except for Denmark, Belgium, Ireland and Spain, these findings are confirmed also by the transition matrix approach.

In the top of the distribution, mobility appears to increase in Germany, Denmark, Netherlands, Belgium and Ireland. Except for Denmark, Belgium, Spain and Portugal, these results are confirmed also by the transition matrix approach.

These differences observed between the two approached can be explained by the main limitation of the transition matrix approach: it fails to capture the movement within each earnings quintile, and thus underestimates the true degree of mobility.

There are a few individuals that record a huge jump in their rank from one year to the next: some that start at the bottom and jump to the top in the next period, and vice versa. This indicates the presence of a limited measurement error in hourly earnings in all countries.

Looking at mobility across different time horizons (Figure 11), we observe that the longer the time span between the pair of earnings rankings, the less concentrated the scatter becomes along the 45-degree line, suggesting an increase in mobility with the time span. This trend is valid for all years and for all countries, and reconfirms previous findings.

The information in the rank scatter plots is summarised by the mobility index in 0.2 . Figure 12 and Table 9 illustrate the evolution of the mobility index in (0.2) for different time horizons over the sample period for all countries. The values from all time horizons are below the value expected if earnings were independent in both years.

Figure 13 illustrates the evolution of short-term mobility over time for all countries. Shortterm mobility in the beginning of the sample period was the highest in Greece, followed by Austria, Belgium, Denmark and Finland with values over 0.25. Next follows Italy, France, Spain, Ireland, UK and Portugal with values between 0.2 and 0.25 . The lowest mobility is recorded in Luxembourg, Germany and Netherlands, which record values lower than 0.2. This ranking is in general confirmed by the ranking based on the immobility ratio and the average jump.

The evolution of short-term mobility over time differs across countries. Except Spain, Ireland, UK and Denmark, all other countries record a decrease in the degree of mobility from one year to the next, which is in general consistent with the evolution of the immobility ratio and average jump. Denmark and Netherlands are exceptions, recording opposite trends in mobility close and away from the diagonal. 
These mobility trends correspond to years 1994 to 2000. Therefore, linking with the evolution of inequality over 1994 and 2000 (Table 3), we conclude that in 2000 men were: better off both in terms of their relative wage and opportunity to escape low pay in the next period in Denmark, UK, Ireland, and Spain; better off in terms of their relative wage, but worst off in terms of their chance to escape low pay in Belgium, France, Austria and Finland; and worst off in terms of both in Netherlands, Luxembourg, Italy, Greece and Portugal.

In 2000-2001 a convergence in mobility rates is observed for four country clusters. Luxembourg, which records the lowest mobility, and Denmark, which record the highest mobility, have a singular evolution. Spain and Finland appear to converge towards a lower mobility than Denmark, followed by Ireland, which also has a singular evolution. The next cluster in terms of mobility is formed by UK, Italy and Belgium. The last two clusters are Austria and Netherlands, and Greece, Portugal, France and Germany. This ranking is in general confirmed by the ranking based on the immobility ratio and the average jump.

Figure 14 summarizes the relative change in short-term mobility for all countries. The highest decrease in mobility is recorded by Greece, with a reduction of almost $40 \%$, followed by Austria, with a reduction of more than 30\%, Belgium and France over 20\%, Italy and Portugal between 15\% and 20\%, and Luxembourg, Germany, Finland and Netherlands with a reduction lower than $10 \%$. Spain records the highest increase in short-term mobility with a rate of over $20 \%$, followed by Ireland, UK and Denmark, with a rate below $10 \%$.

The ranking, the magnitude and the direction of the relative change in short-term mobility based on Dickens index are, in general, similar with those based on the average jump. Figure 7 and Figure 14. A big discrepancy is observed in the direction of evolution for Denmark: based on average jump mobility decreased with almost 10\%, whereas based on Dickens index it increases with almost $2 \%$. Differences in the magnitude of the evolution are observed for Netherlands, Germany, Luxembourg and Finland, where the increase in mobility was higher as measured by the average jump than by the Dickens index.

The difference in the ranking, magnitude and the direction of evolution of short-term mobility might be explained by the limitations of using quintile transition matrices to look at mobility, particularly when looking at changes in mobility over time. If the earnings distribution has widened over time, then the size of the quintiles has also increased, so it might be that the movement across quintiles decreased. However, it might also be the case that mobility within quintiles has increased, which cannot be captured by the transition matrix approach. 
Consistent with the transition matrix approach and previous studies, long-term mobility is higher than short-term mobility and the trend is valid across countries. The relative increase in long term mobility relative to short-term mobility is summarized in Figure 15. The highest relative increase in mobility with the time span is recorded in Ireland with a value of almost $80 \%$, followed by UK, Netherlands, Germany, Denmark, Luxembourg and Portugal with values between $50 \%$ and $70 \%$. All other countries record values between $20 \%$ and $40 \%$. These findings are in line with those for the transition matrix approach. Some differences can be found in the ranking of the countries based on different mobility indices.

This evolution triggered a re-ranking of the countries with respect to their long term mobility. (Figure 16) Luxembourg appears to have the lowest earnings mobility also in the long run, followed by Spain, France and Germany which record similar values, Netherlands, and Portugal, UK, Italy and Austria, Greece, Finland, Belgium and Ireland, and the highest Denmark. This ranking coincides in general with the one from the transition matrix approach. Judging whether this mobility is high or low depends on the question being asked. Long term mobility is certainly high enough to make the point that people are not stuck at the bottom top of the earnings distribution. However, the mobility is too low to wash out the effect of the yearly inequality. Even when earnings are summed over the sample period, a substantial inequality remains, signalling the presence of a substantial inequality in the "permanent" component of earnings. Figure 17 shows the reduction in long-term inequality - measured by the Theil index for individual hourly earnings summed over the sample period - relative to cross-sectional inequality in the first wave - measured by Theil. These rates, however, overestimate the true values because cross-sectional inequality is based on all positive earnings, whereas longer-term inequality is based on a balanced panel. The rate of reduction ranges from 50\%-35\% for Denmark, Austria, Ireland, UK, Belgium, France, Luxembourg and Finland, to $30 \%-10 \%$ for Netherlands, Spain, Germany, Greece, Italy and Portugal, which provides a first clue that the first cluster of countries has a higher chance in reducing lifetime earnings differentials compared with the second one. This conclusion, however, needs to be explored further by estimating appropriate indicators that measure mobility as equalizer/disequalizer of longer term incomes, which represents a topic for future research. 


\section{LINKING MOBILITY AND INEQUALITY}

Next we aim to link the patterns in short and long-term mobility with yearly inequality. This requires a backward looking approach. In interpreting the figures one has to pay attention to the difference in samples in computing inequality and mobility. The inequality measures are based on all individuals with positive earnings. The mobility measures refer to balanced 2year panels, meaning individuals that recorded positive earnings in both years. We chose using an unbalanced panel for inequality to avoid underestimating the degree of dispersion. When interpreting the results, however, we have to bear in mind that the degree of inequality in period $t$ depends also on the inflows and outflows of the sample in period $t$, not only on the degree of mobility from one period.

\subsection{Short-Term Mobility and Yearly Inequality}

Inequality in time $\mathrm{t}$ depends on inequality in time $\mathrm{t}-1$, mobility between $\mathrm{t}$ and $\mathrm{t}-1$ and individuals entering and exiting the sample between period t-1 and t. Thus inequality in 1995 depends on inequality in 1994 and mobility between 1994 and 1995. Similarly, inequality in 2001 depends on inequality in 2000 and mobility between 2000 and 2001.

To shed some light on the potential link between short-term mobility and yearly inequality we look comparatively at the evolution of short term mobility from 1994/1995 to 2000/2001 and yearly inequality between 1995 and 2001. Figure 18 - left panel - ranks the countries with respect to their inequality in 1995 and mobility between 1994 and 1995. The same is done in the right panel for inequality in 2001 and mobility in 2000-2001

On average, it appears that the higher the inequality in year $t$, the lower the mobility between year t-1 and t. The ranking, however, has also some exceptions. For example, in 1995, Greece has among the highest mobility levels and the highest inequality. In 2001, Spain has among the highest mobility and among the highest inequality.

Looking at the relative change in inequality and mobility the picture is not clear-cut. Most countries recording a decrease in mobility, record also an increase in inequality. Exceptions are Austria and France, where both decrease. All countries recording an increase in mobility, record a decrease in inequality between the $2^{\text {nd }}$ wave and 2001. The ranking is ambiguous. The countries with the smallest (Netherlands) and the largest (Greece) reduction in mobility have the highest increase in inequality. Similarly, the countries with the lowest (UK) and the 
largest (Spain) increase in mobility do not have the largest reduction in inequality. Overall, it appears that short-term mobility has a reducing effect on yearly inequality.

\subsection{Long-Term Mobility and Yearly Inequality}

Similarly, extending the time frame, inequality in time $t$ depends on inequality in time t-s and mobility between $\mathrm{t}$ and $\mathrm{t}-\mathrm{s}$. Figure 20 ranks the 14 countries in terms of their long term mobility displaying at the same time the cross-sectional inequality in 2001 and the relative change in cross-sectional inequality between the $1^{\text {st }}$ wave and 2001 for each country.

On average it appears that a higher long-term mobility is associated with a lowed crosssectional inequality in 2001, but the ranking in the two measures is not consistent. The highest long-term mobility is present in Denmark, which record also the lowest inequality in 2001, but the highest inequality (Portugal) does not have the lowest mobility.

The link between long-term mobility and the relative change in inequality is ambiguous. Mobility rates are similar, but the relative change in inequality is very heterogeneous, with no visible pattern.

\section{CONCLUDING REMARKS}

In this paper we have explored wage mobility for males across 14 EU countries between 1994 and 2001 using ECHP.

Starting with the transition matrices among labour market states, we find considerable levels of short-term immobility in all countries, with high shares of individuals staying in the same earnings quintile from one period to the next. Individuals situated in the bottom of the distribution are more likely to enter unemployment and inactivity compared with the rest of the distribution. Moreover, those that manage to get a job in the next period are more likely to be in the bottom of the earnings distribution.

Mobility over the sample period is higher than one-period mobility, suggesting that the longer the period, the higher the opportunity to escape the initial state. The highest persistency in unemployment is found in Belgium, UK, Italy, Germany and Spain, and in inactivity in France, Belgium, Spain, Netherlands and Ireland.

Looking only at transition matrices among income quintiles, we found a high level of persistency from one period to the next in all countries. Moreover, individuals that change their income position from one period to the next do not move very far. Individuals situated 
at the top of the distribution are less mobile than people at the bottom, which in turn are less mobile than the middle of the distribution.

Over time, short-term mobility for the bottom quintile decreased in all countries, except Luxembourg, Spain and Finland. In 2000-2001 the highest persistency for low-earnings individuals is in Portugal, Germany, Austria, Belgium, Netherlands and Luxembourg where between $78 \%$ and $70 \%$ remained in the same income group, followed by Greece, France, Ireland, Denmark with probabilities between 69\% and 60\%, and UK, Finland, Italy and Spain with rates between $59 \%$ and $49 \%$.

Long-term mobility is higher than short-term mobility, but the persistency is still high: in Germany, Austria, Finland, Portugal and France, between $49 \%$ and $41 \%$ remained in bottom quintile in 2001, followed by Luxembourg, Netherlands, Spain, Belgium, Italy, Denmark, UK, Greece and Ireland, with values between $40 \%$ and 23\%. Overall, the lowest long-term mobility close and far away from the initial state was recorded in Luxembourg, France, Spain, Germany, Netherlands and Portugal, and the highest in Denmark and Ireland.

Most countries that recorded an increase in inequality between 1994 and 2001, recorded also an increase in short-term persistency over time, supported both by the increase in the share of individuals maintaining theirs state or moving to the closest state from one period to the next and by the decrease in mobility far away from the initial state. Netherlands is an exception, recording a decrease in the share of individuals maintaining their state or moving in the immediate income group and a decrease in mobility very far away from the initial from the initial state.

The decrease in inequality was accompanied by an increase in mobility close to the initial state and a decrease in mobility very far away from the initial state in Spain, Ireland and UK, and by the opposite in Belgium, France and Austria. In Denmark, the decrease in inequality was accompanied by an increase in mobility close the initial state and a decrease in mobility very far from the initial state, which might signal smaller transitory differentials compared with the other countries.

Mobility close to the diagonal appears to converge over time in five clusters: first, Luxembourg which records the highest IR in 2001; second, Germany, France and Greece; third, UK, Belgium, Netherlands, Portugal, Italy and Austria; forth, Ireland and Finland, and lastly, with the lowest immobility ratio, Denmark and Spain. Similarly, mobility away from 
the diagonal appears to converge over time in four clusters: first, Luxembourg - the lowest average jump in 2001; second, Germany, France, Austria, Netherlands, Belgium and Greece, Portugal; third, Italy, UK and Ireland; and lastly, Finland, Spain and Denmark, with the highest mobility away from the diagonal in 2001. Overall, Luxembourg appears to diverge from the other EU countries.

More heterogeneity is observed in long-term mobility rates. Luxembourg is the least mobile in the long run and Denmark and Ireland the most mobile.

To overcome the main drawbacks of the transition matrix approach, we looked at actual percentile rankings of workers within the wage distribution and computed a measure of mobility following Dickens (2000). This approach reconfirmed most of the findings above. For mobility at the bottom of the distribution, the results diverge for Luxembourg and Finland, where mobility appears to decrease over time, and in Denmark and Ireland, where mobility rises.

Based on the proposed index, all countries recording an increase in cross-sectional inequality recorded also a decrease in mobility. Among countries where inequality decreased, the trends in mobility increased in Denmark, Spain, Ireland and UK, and decreased in Belgium, France and Ireland.

What are the welfare implications of these trends in mobility? In Germany, Netherlands, Luxembourg, Finland, Italy, Greece and Portugal, individuals, both overall and at the bottom of the distribution, find it harder in 2001 to better their position in the earnings distribution compared with 1994 and this might be a factor behind the increase in earnings differentials. Moreover, the decrease in mobility rates might signal an increase in permanent earning differentials. Similar trends for mobility are observed in Belgium, France and Austria, with the exception that the decrease in mobility does not appear to have affected earnings differentials, which decreased in 2001 compared with the first wave.

In Belgium, Spain, Ireland and UK, individuals have an increased opportunity in 2001 to improve their earnings position compared with 1994, which might have contributed to reduce cross-sectional differentials over time. Only in UK, the individuals in the bottom of the distribution recorded a decrease in mobility, suggesting that they become better off in terms of their relative wage and worst off in terms of their opportunity to improve their earnings position. 
Mobility rates appear to converge towards 2001 in four country clusters. Luxembourg, with the lowest mobility in 2001, and Denmark, with the highest mobility, have a singular evolution. Spain and Finland appear to converge towards a lower mobility than Denmark, followed by Ireland, which also has a singular evolution. Next, UK, Italy and Belgium converge towards a lower level than Ireland. The last two clusters are Austria and Netherlands, and Greece, Portugal, France and Germany. This ranking is in general confirmed by the ranking based on the immobility ratio and the average jump.

The lowest opportunity of improving the earnings position in the long run is found in Luxembourg followed by the four clusters which record similar values: first, Spain, France and Germany; second, Netherlands, and Portugal; third, UK, Italy and Austria; forth Greece, Finland, Belgium and Ireland. Finally, men in Denmark have the highest opportunity of improving their income position in the long run. A topic for further research is to explore the implications of the lone term mobility rates for lifetime inequality. 

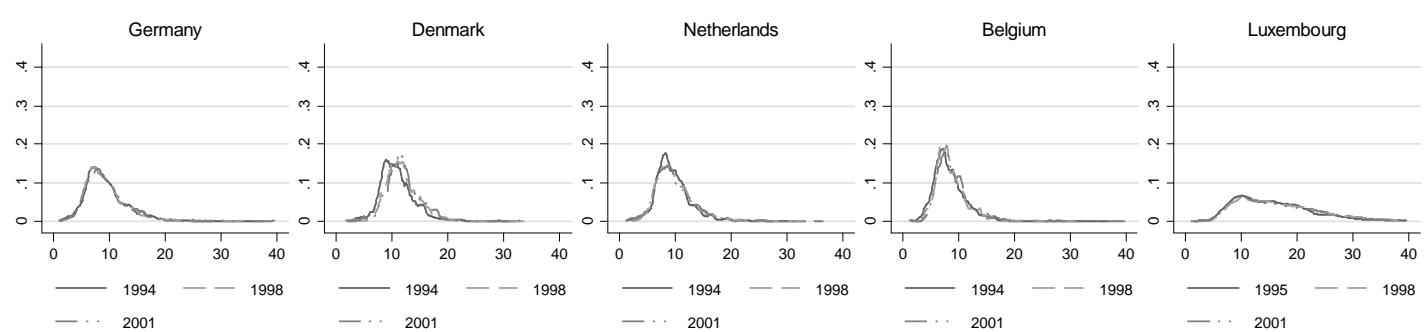

— - 2001

— - 2001
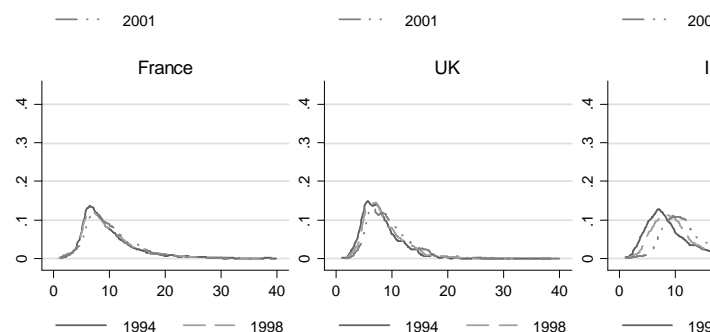

- - 2001

$\begin{array}{ll}- & 1995 \\ -\cdots & 2001\end{array}$
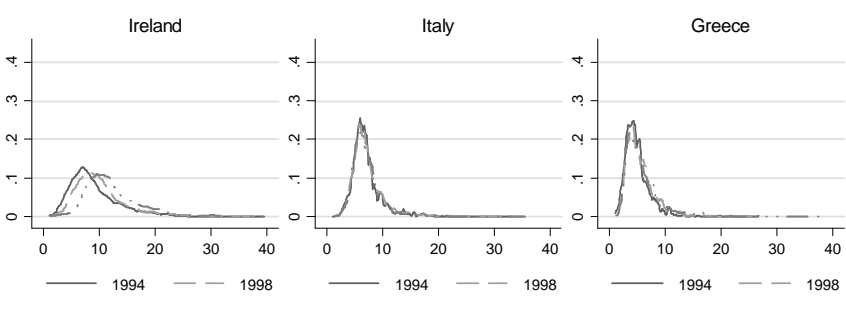

- ․ 2001

- . 2001

- ․ 2001

- . 2001

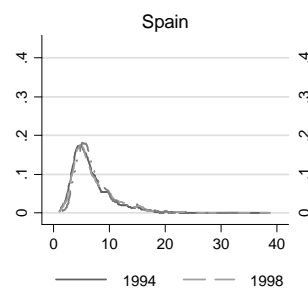

Portugal

Austria

Finland
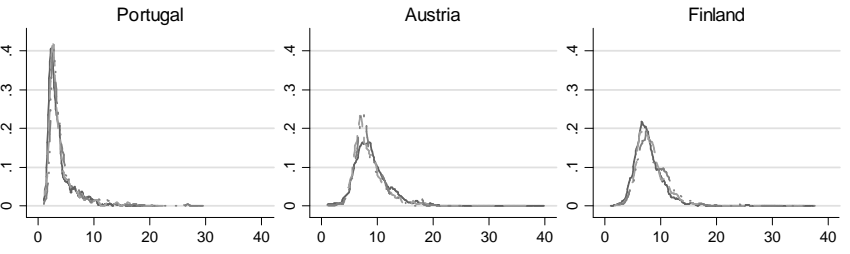

2001

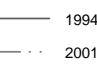

1995
2001

$\begin{array}{r}1996-1998 \\ \hline\end{array}$

2001

Figure 1. Epanechinov Kernel Density Estimates for Selected Years14 - EU 15

${ }^{14}$ The horizontal axis represents hourly earnings and the vertical axis the density. 

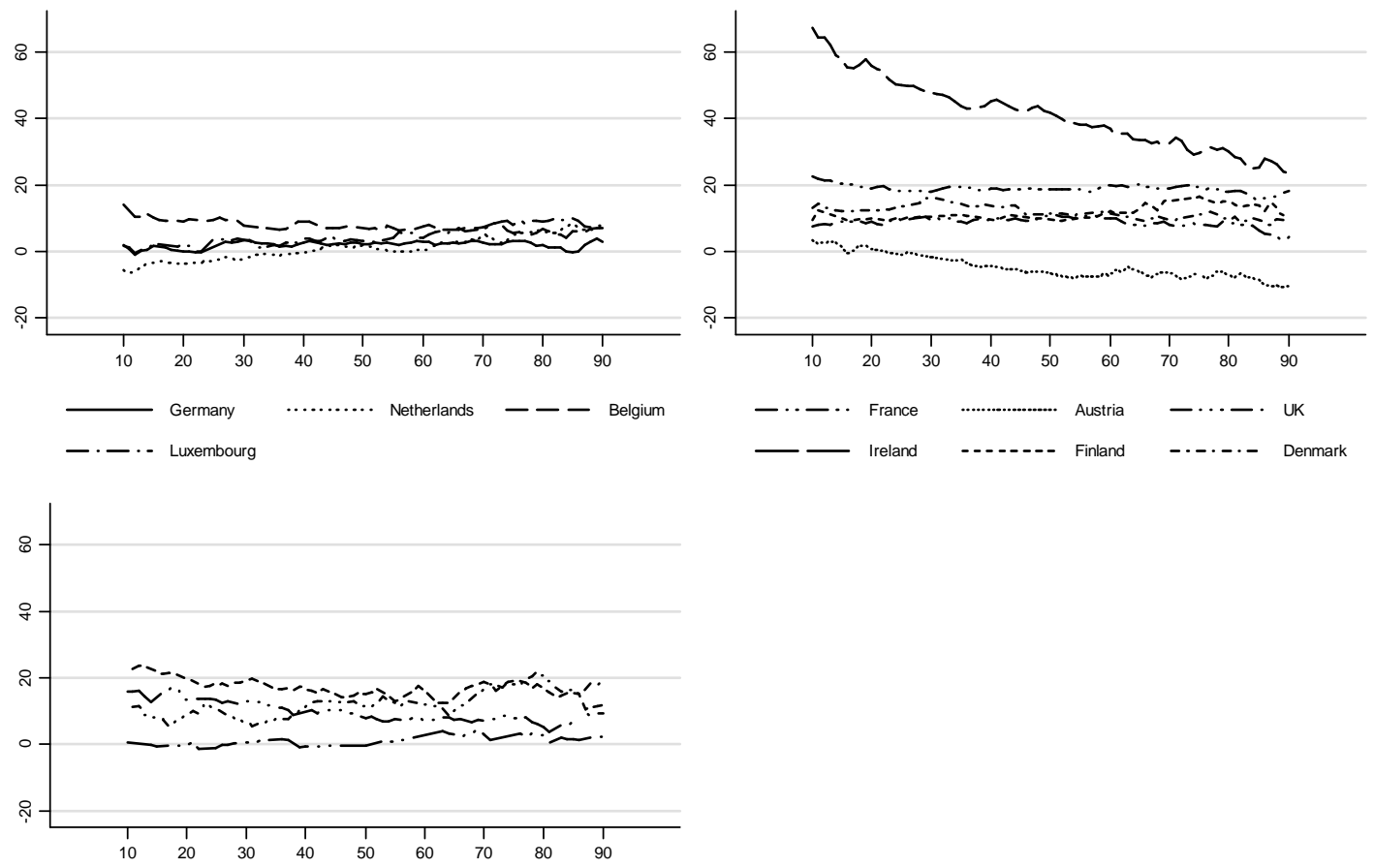

- - Italy

Portugal

Figure 2. Percentage Change in Mean Hourly Earnings by Percentiles Over The Sample Period
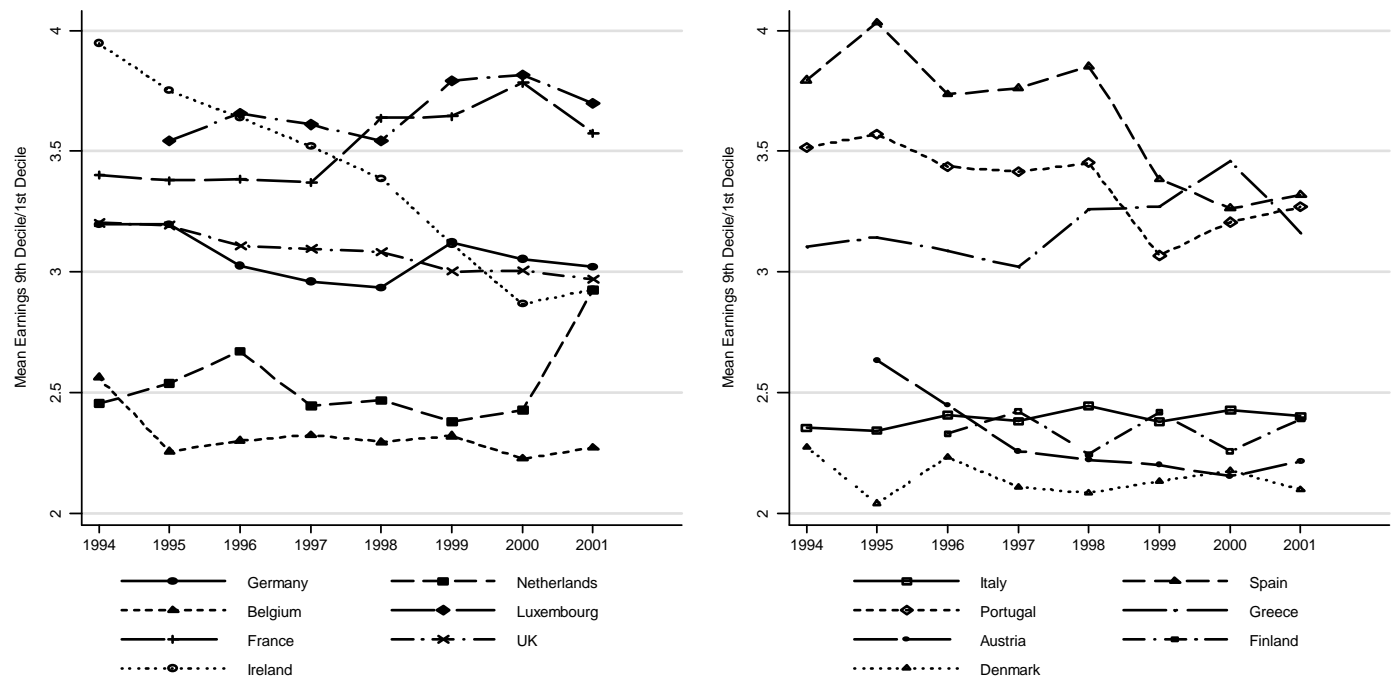

Figure 3. Ratio between Mean Earnings at the 9th Decile and the 1st Decile 


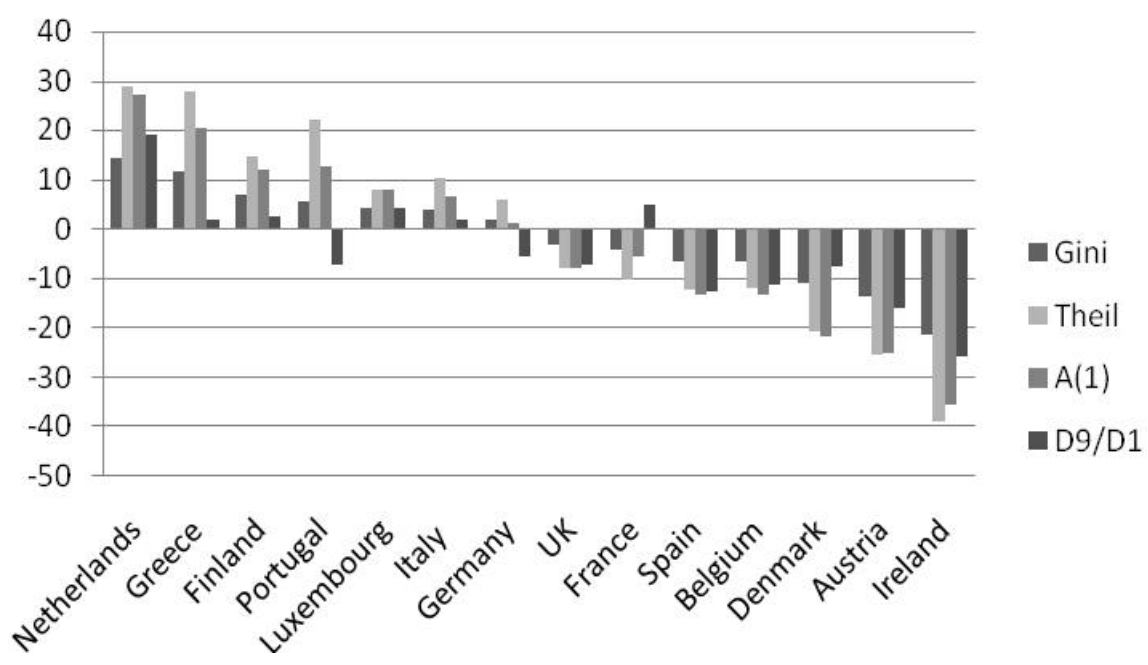

Figure 4. Relative Change in Inequality over Time - Gini, Theil, Atkinson(1), D9/D1 ${ }^{15}$
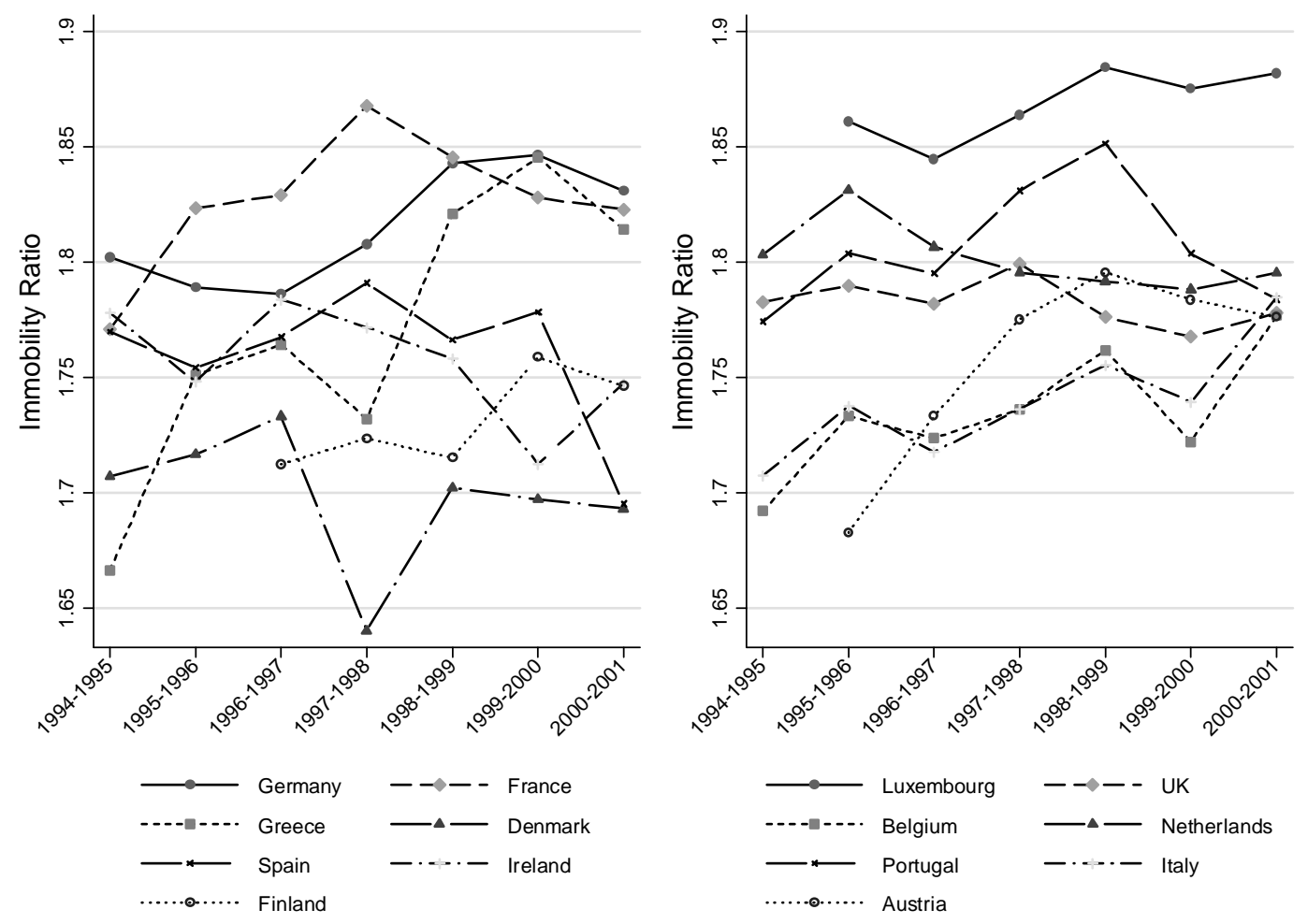

Figure 5. Immobility Ratio for One-Year Transitions between Earnings Quintiles over Time

\footnotetext{
${ }^{15}$ Countries are ranked based on Gini index.
} 

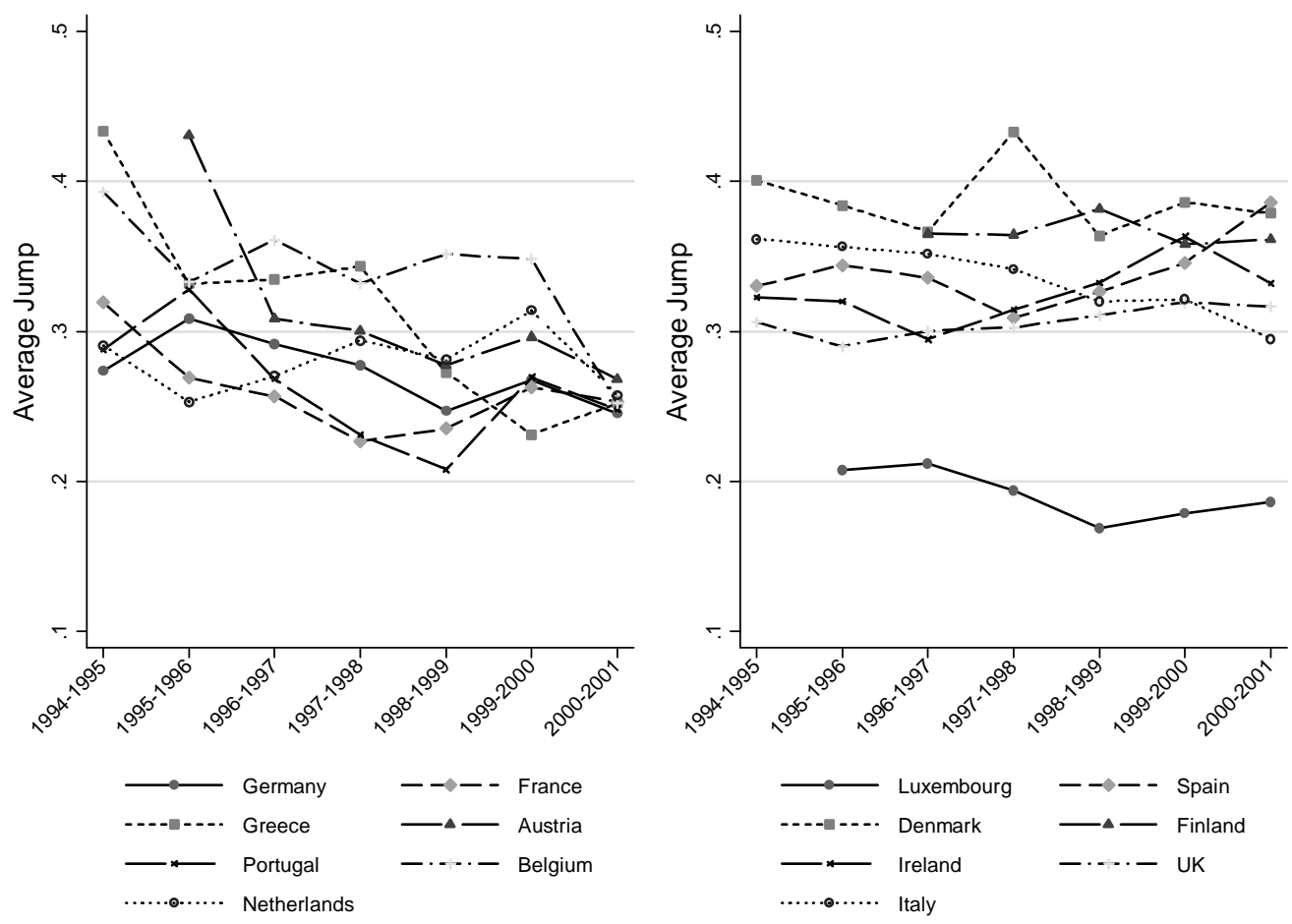

Figure 6. Average Jump for One-Year Transitions between Earnings Quintiles over Time
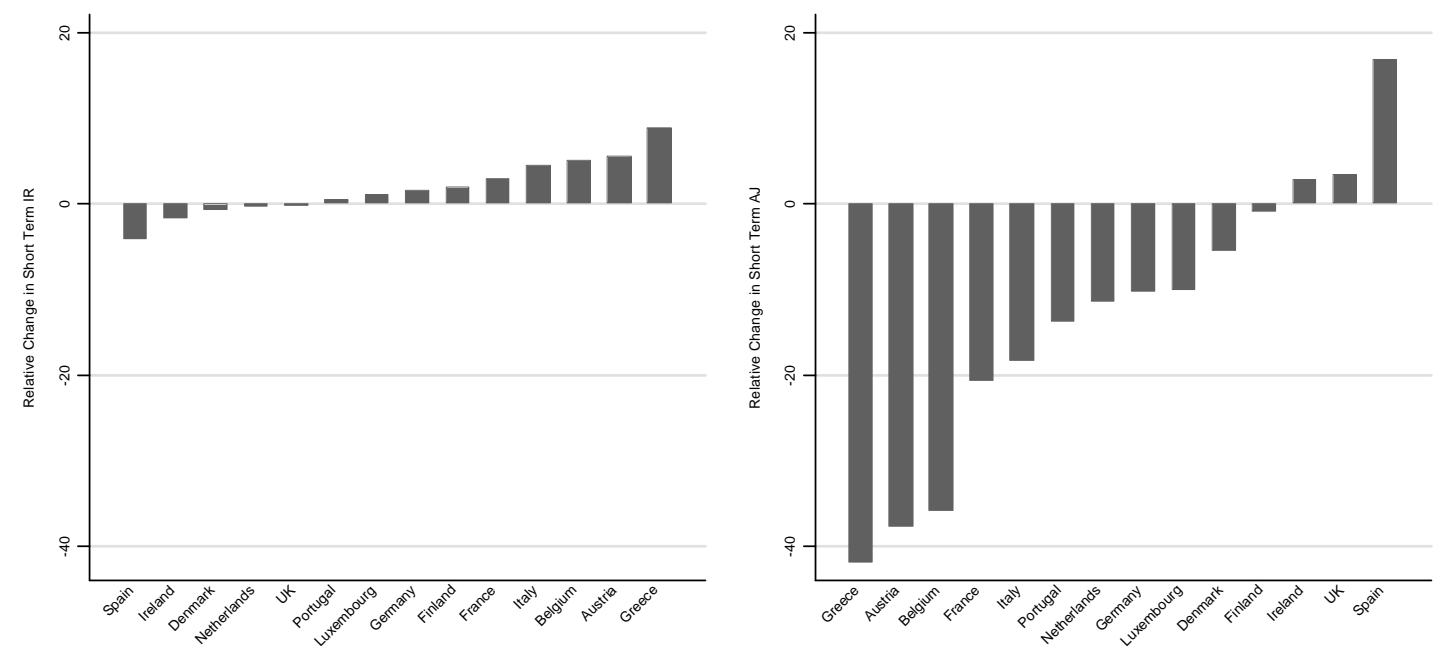

Figure 7. Relative Change over Time in Short-Term Immobility Ratio (IR) and Average Jump (AJ) 

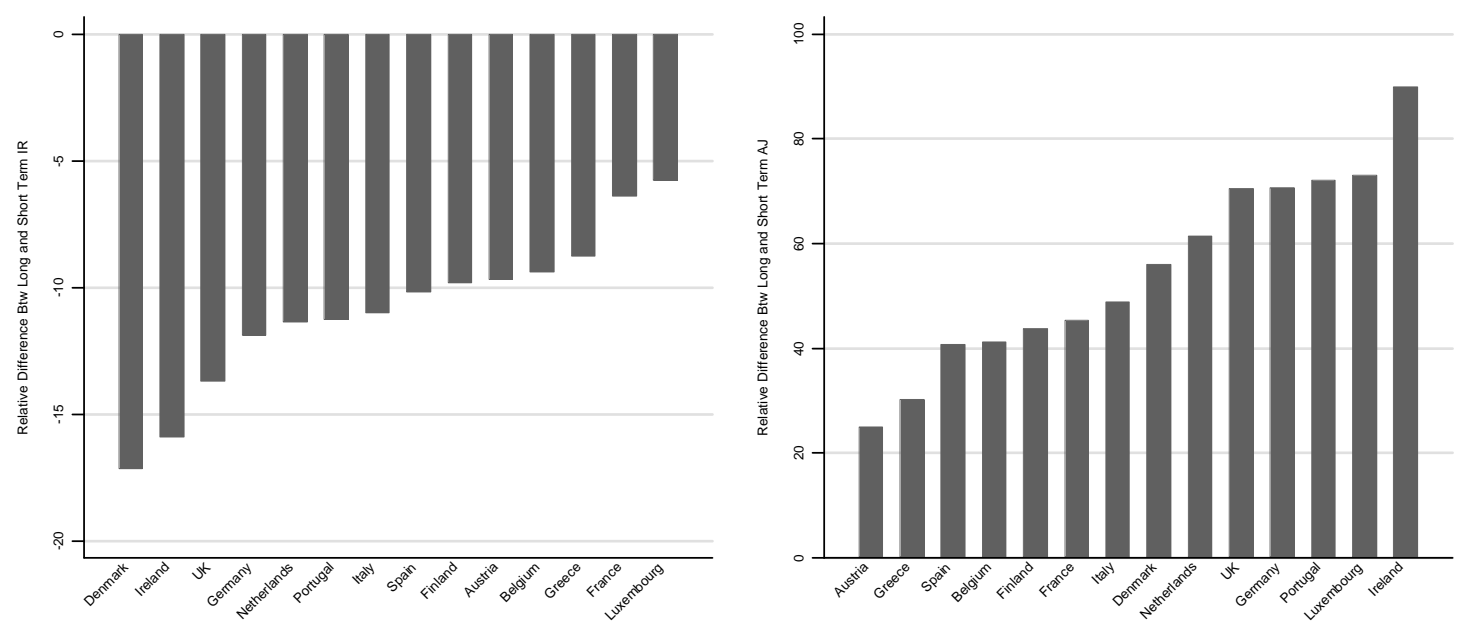

Figure 8. Relative Difference between Long and Short-term Immobility Ratio and Average Jump

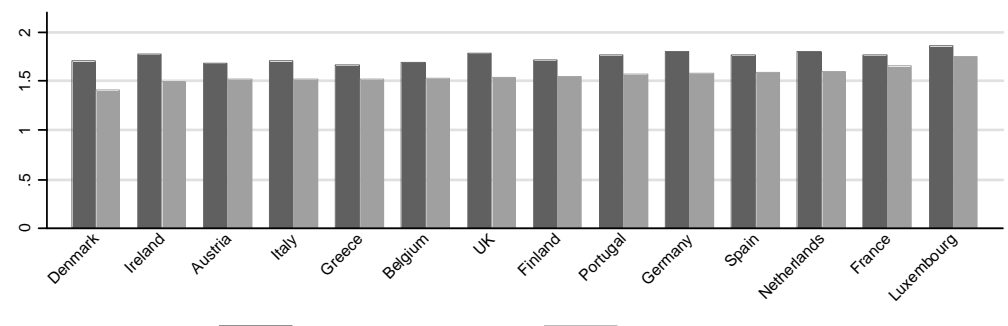

Short Term Immobility Ratio $\quad$ Long Term Immobility Ratio

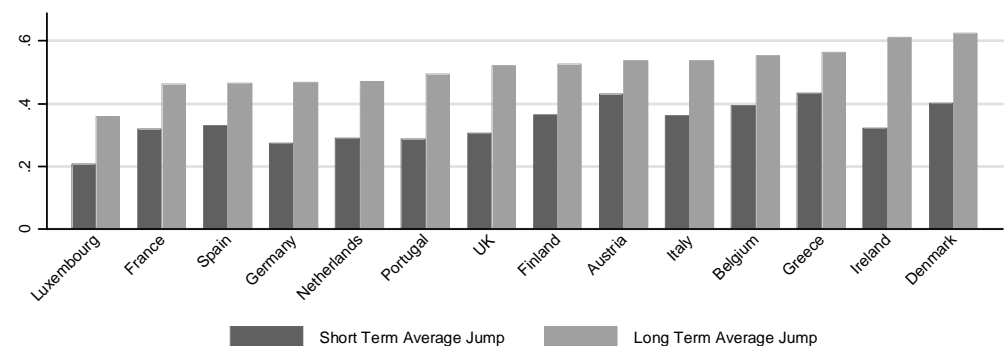

Figure 9. Short and Long Term Immobility Ratio and Average Jump 

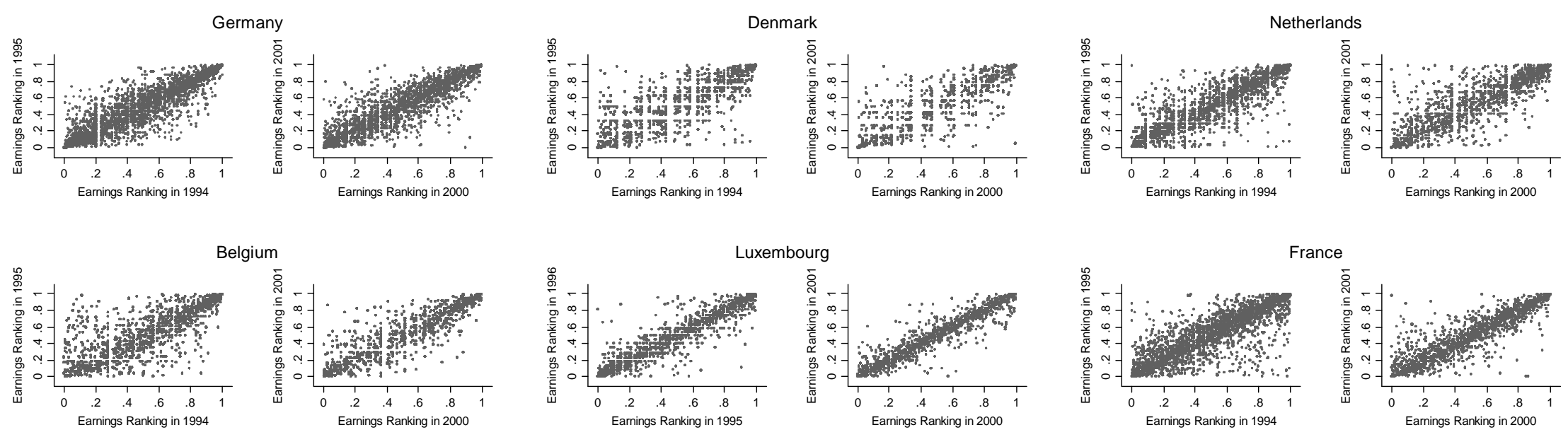

France
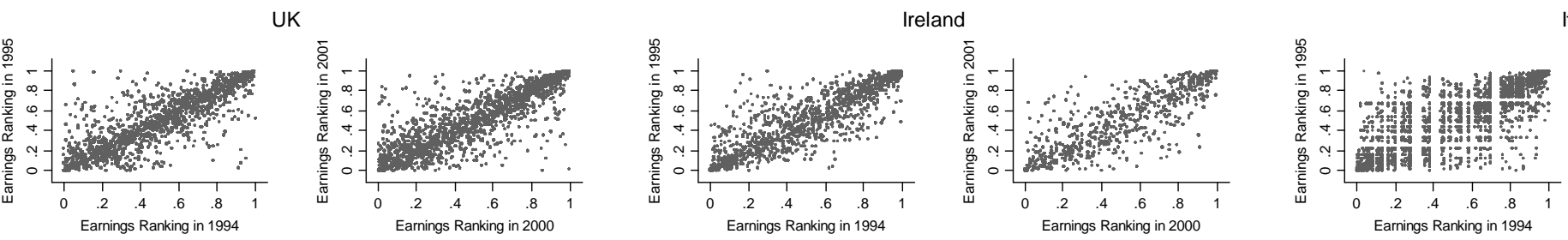

taly
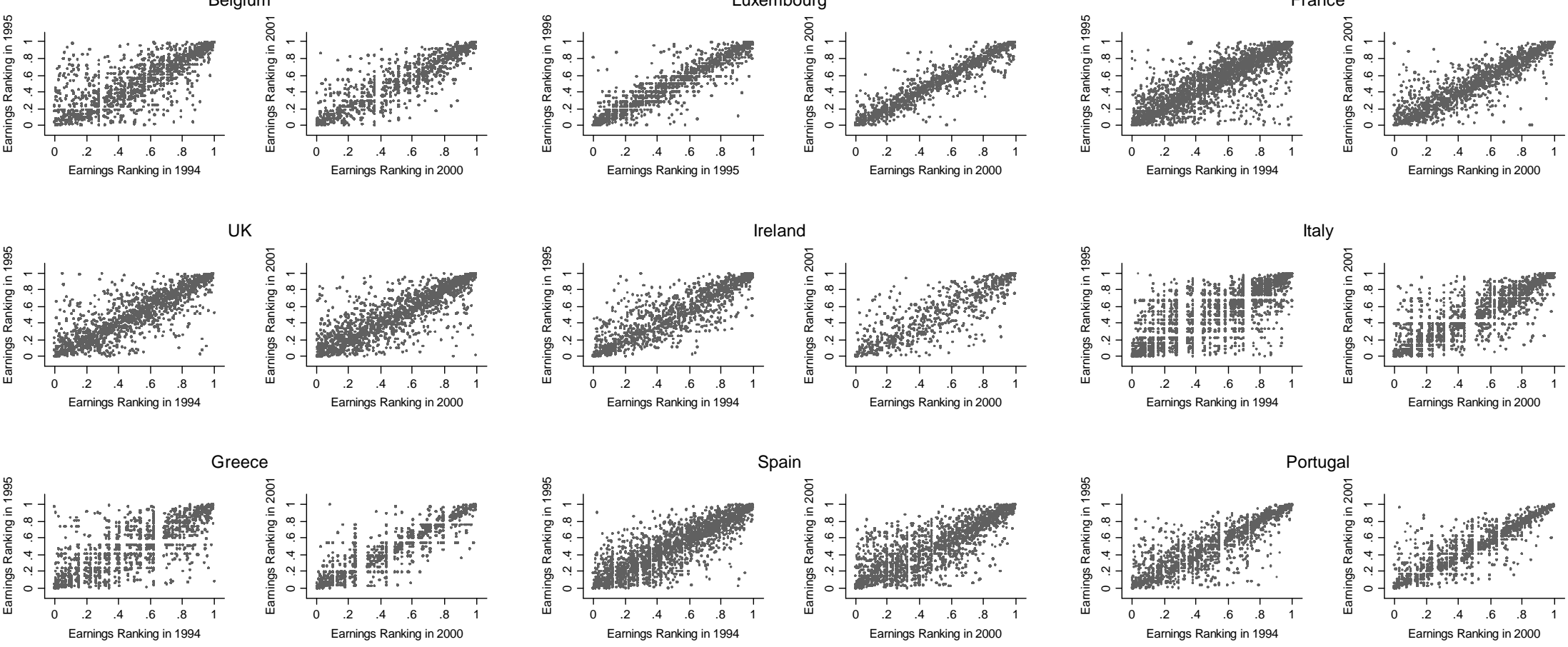

Portugal
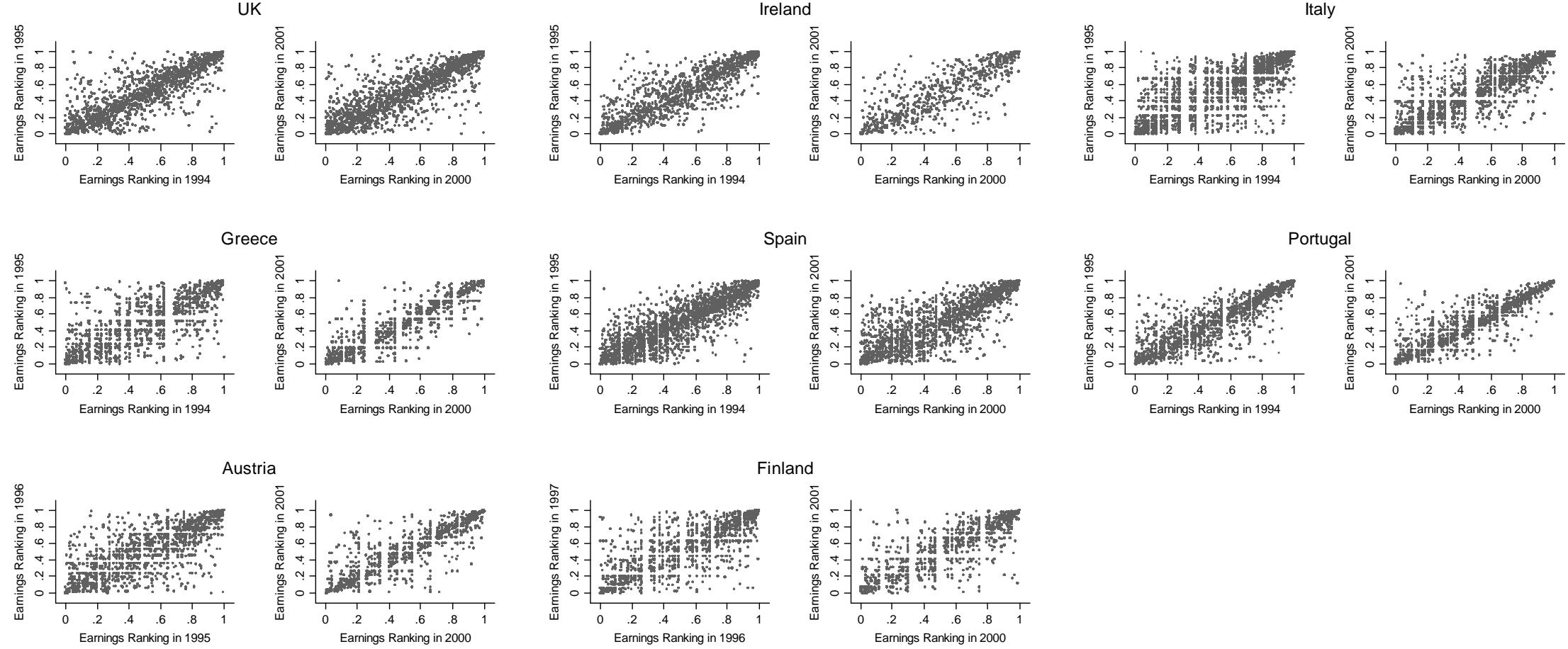

Figure 10. One-Year Earnings Mobility over Time 

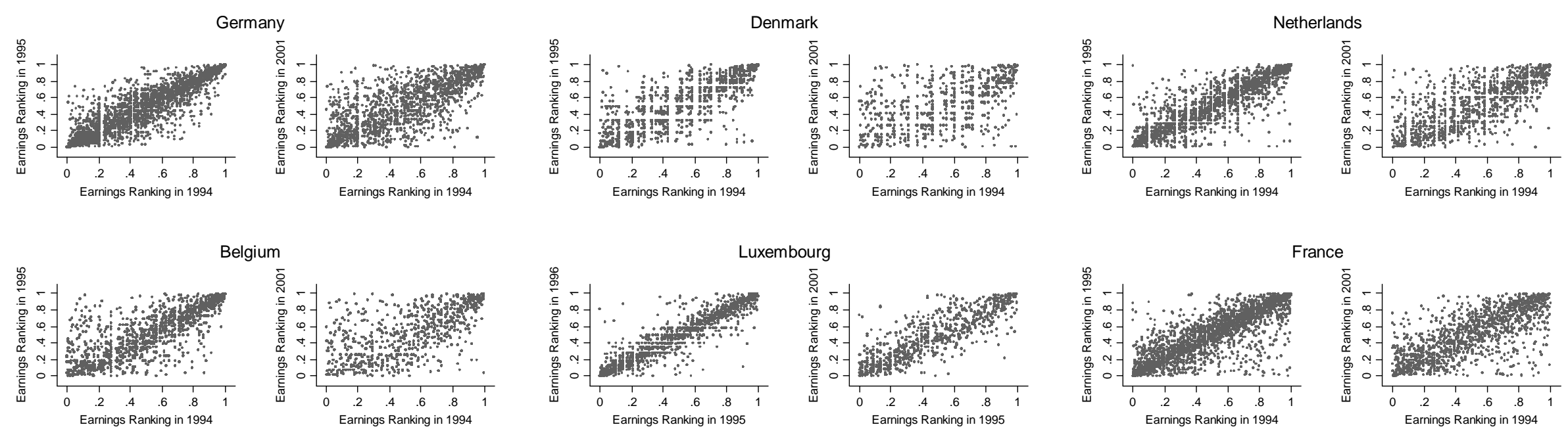

France

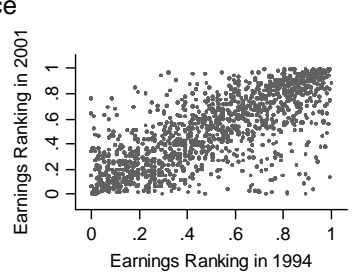

UK
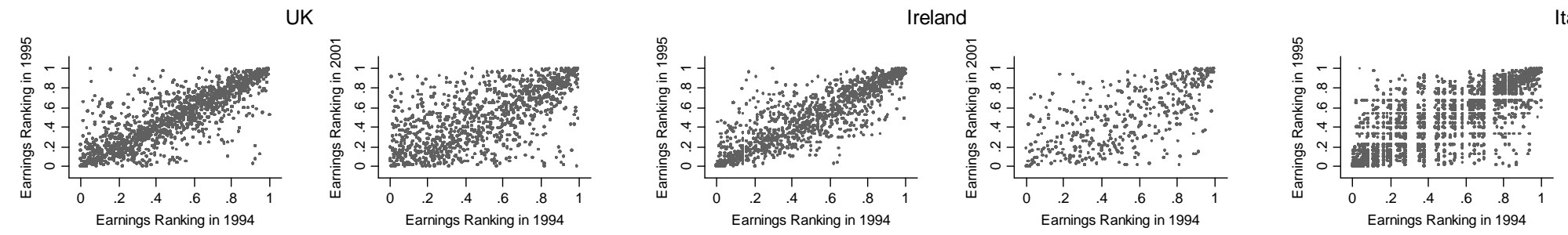

Italy
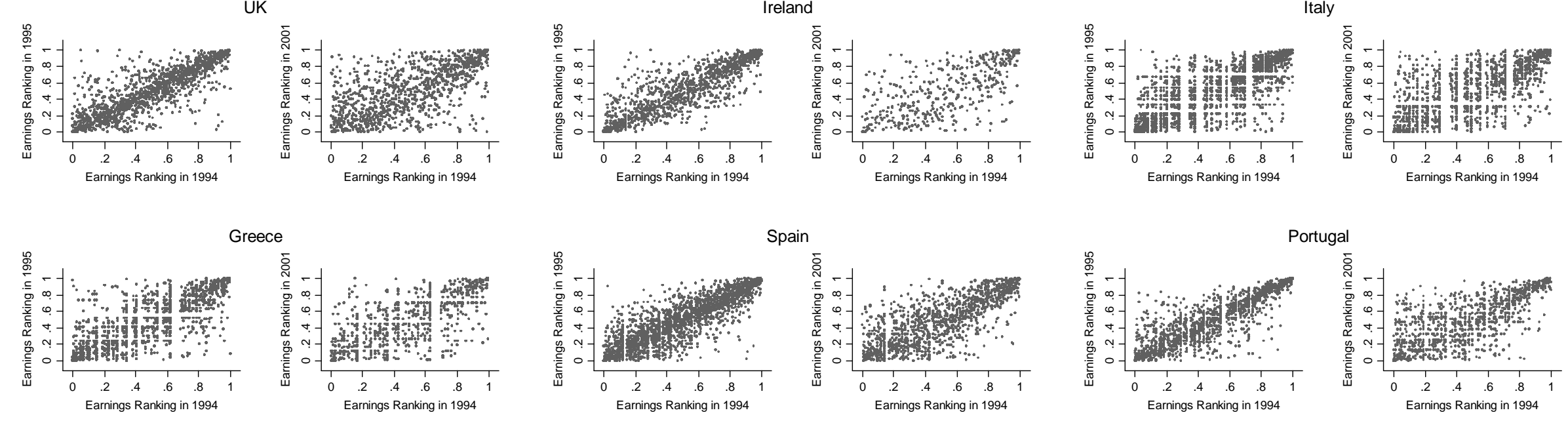

Greece
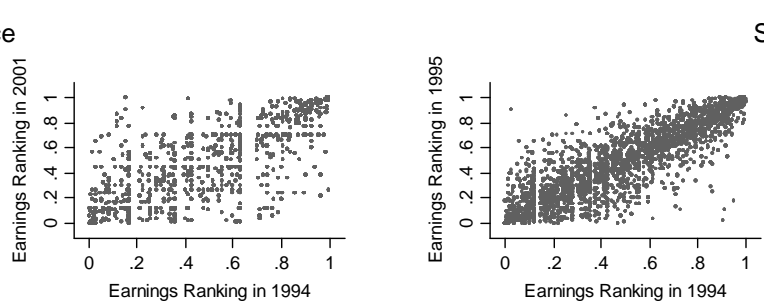

Spain
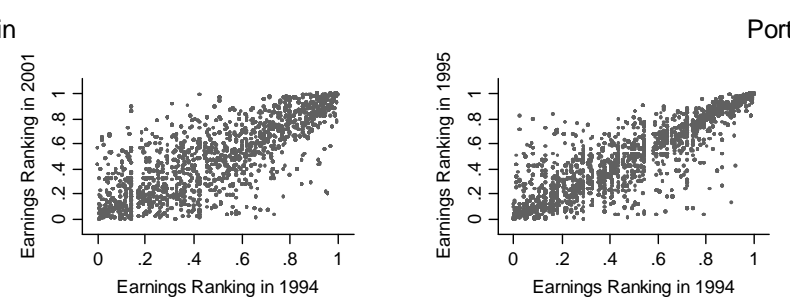

Portugal
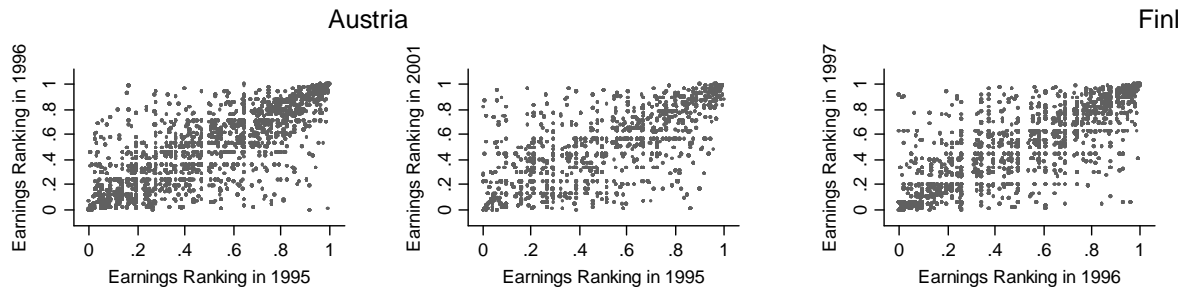

Finland
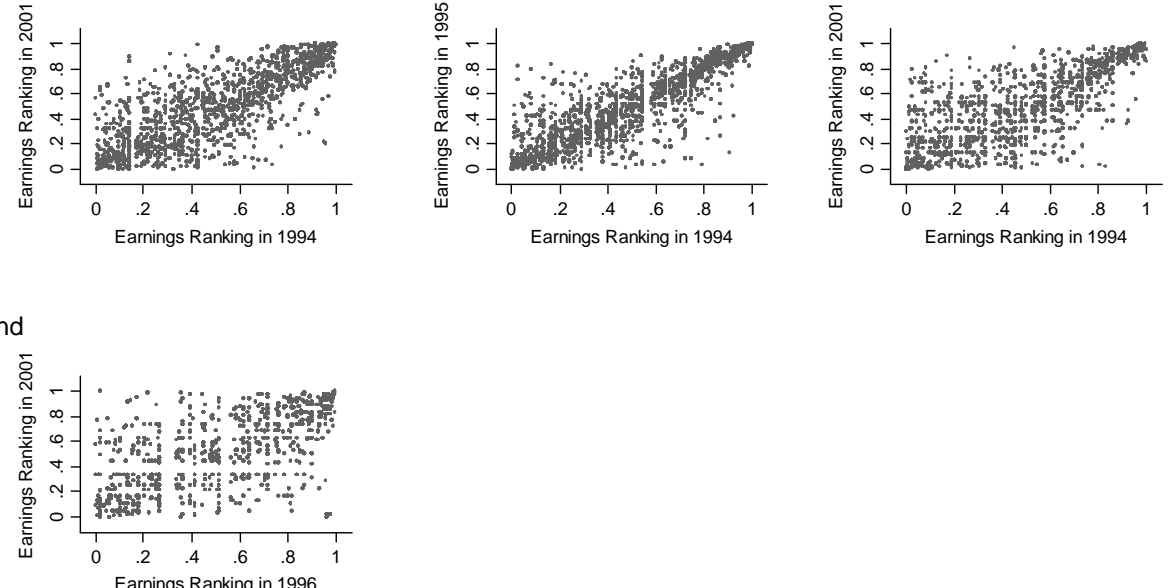

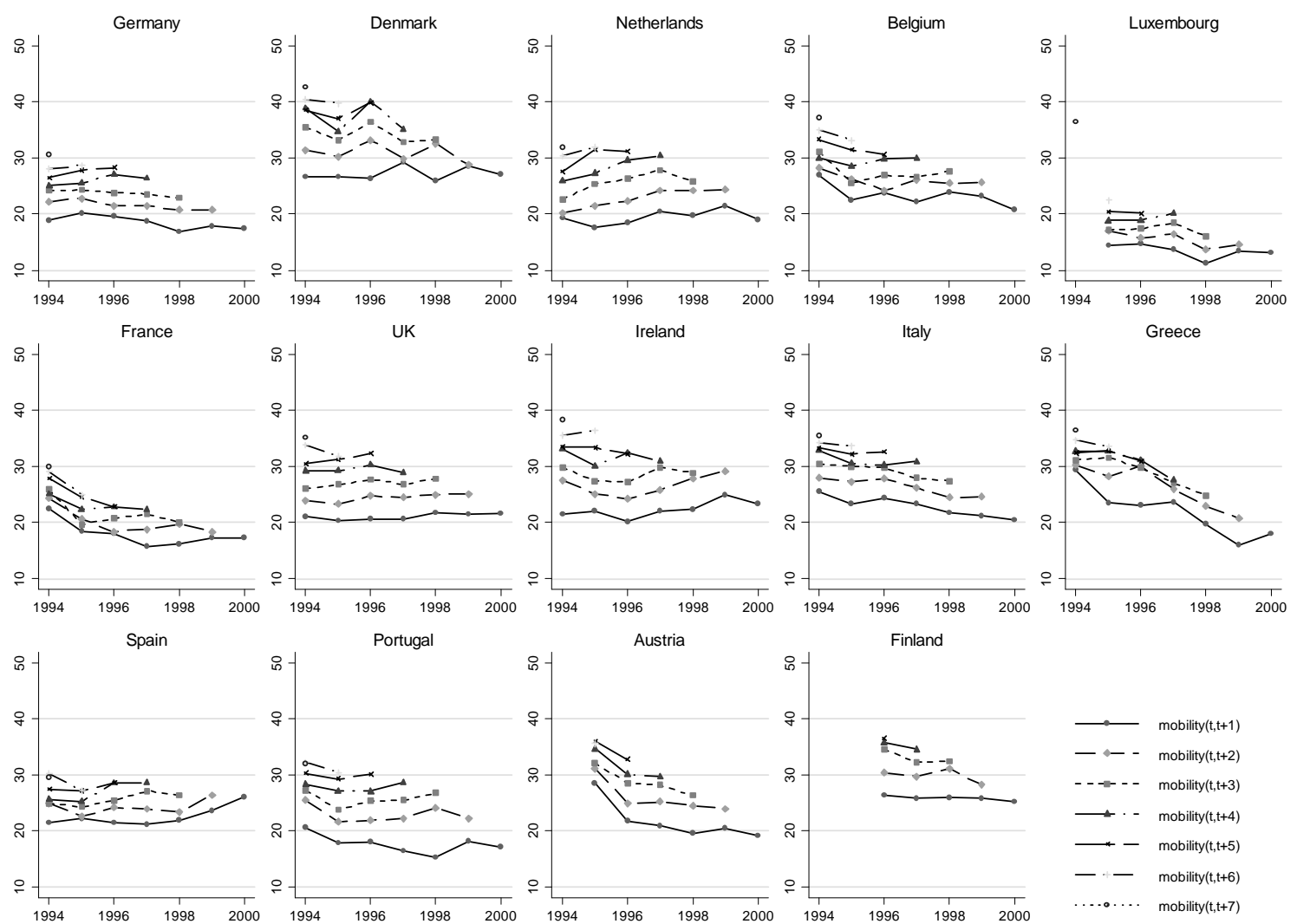

Figure 12. Dickens Mobility Index for Different Time Horizons the Sample Period (Index*100) 

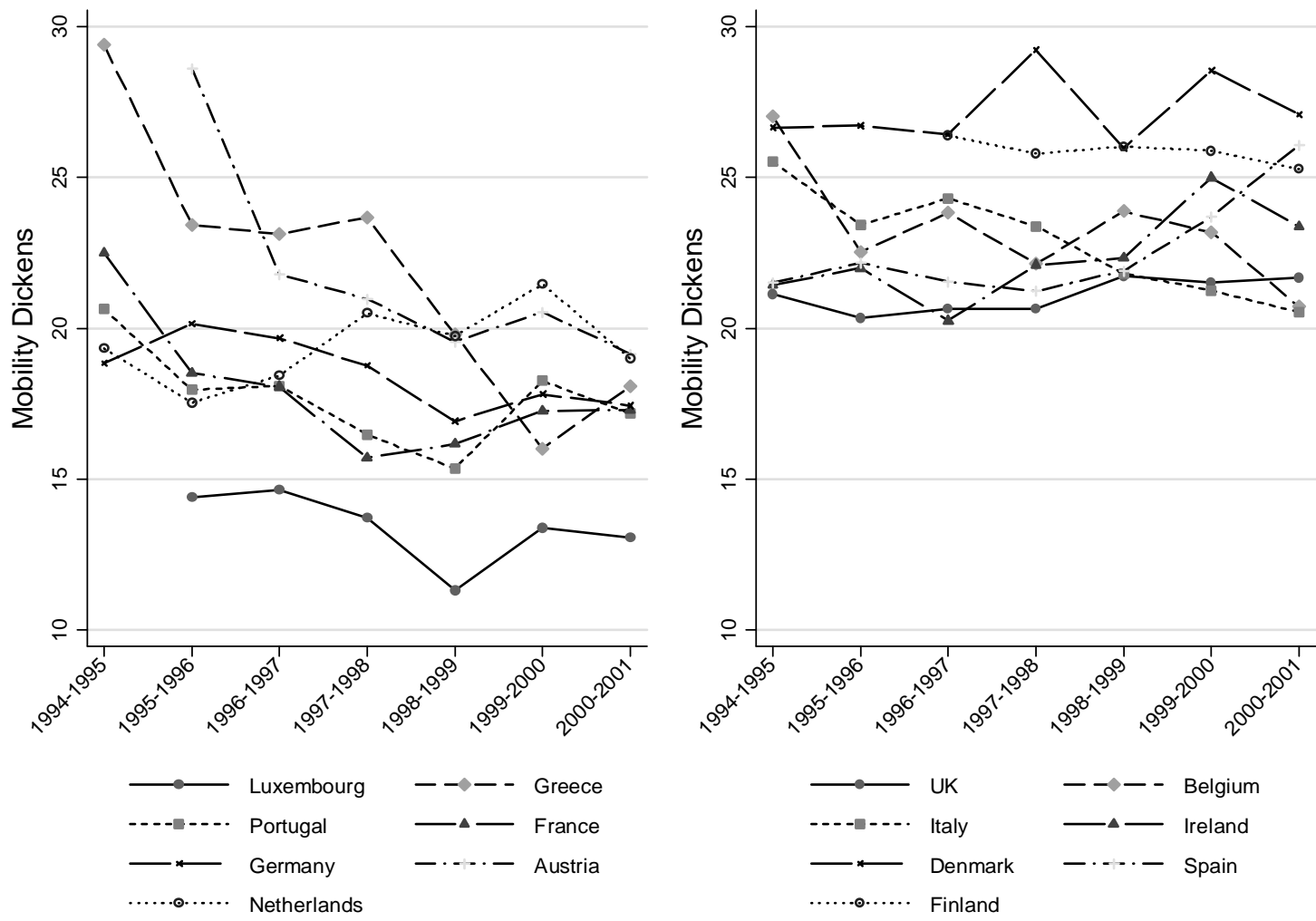

Figure 13. Dickens Short-Term Mobility over Time (Index*100)

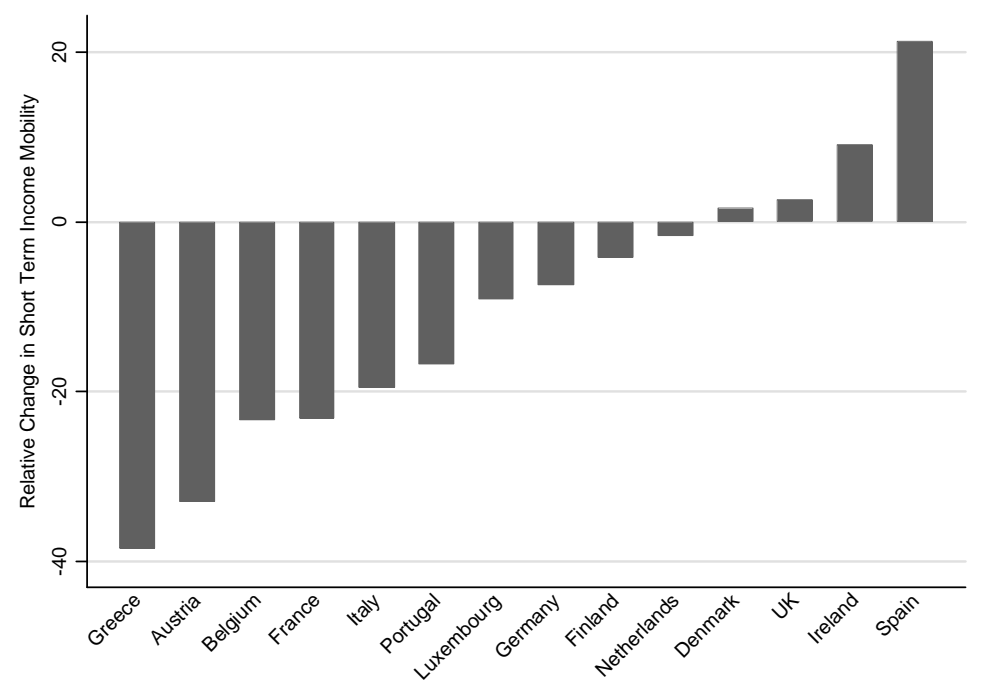

Figure 14. Relative Change in Short-term Mobility Measured by the Dickens Index 


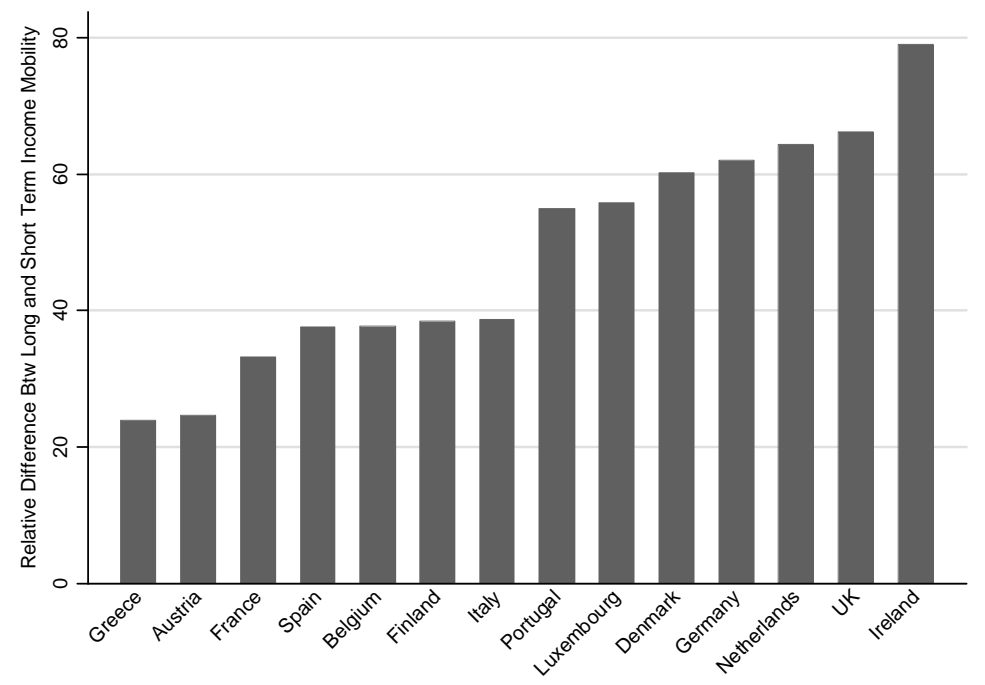

Figure 15. Relative Difference between Long and Short-term Mobility Measured by the Dickens Index

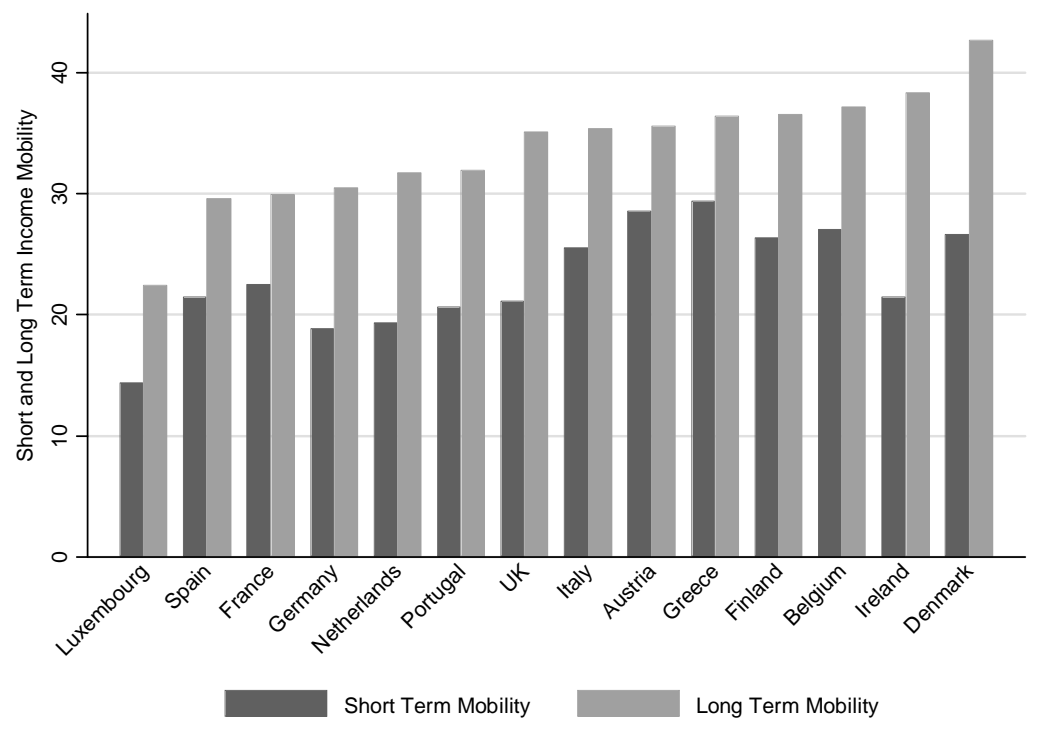

Figure 16. Short (1994/1995) and Long Term (1994/2001) Mobility Measured by the Dickens Index 


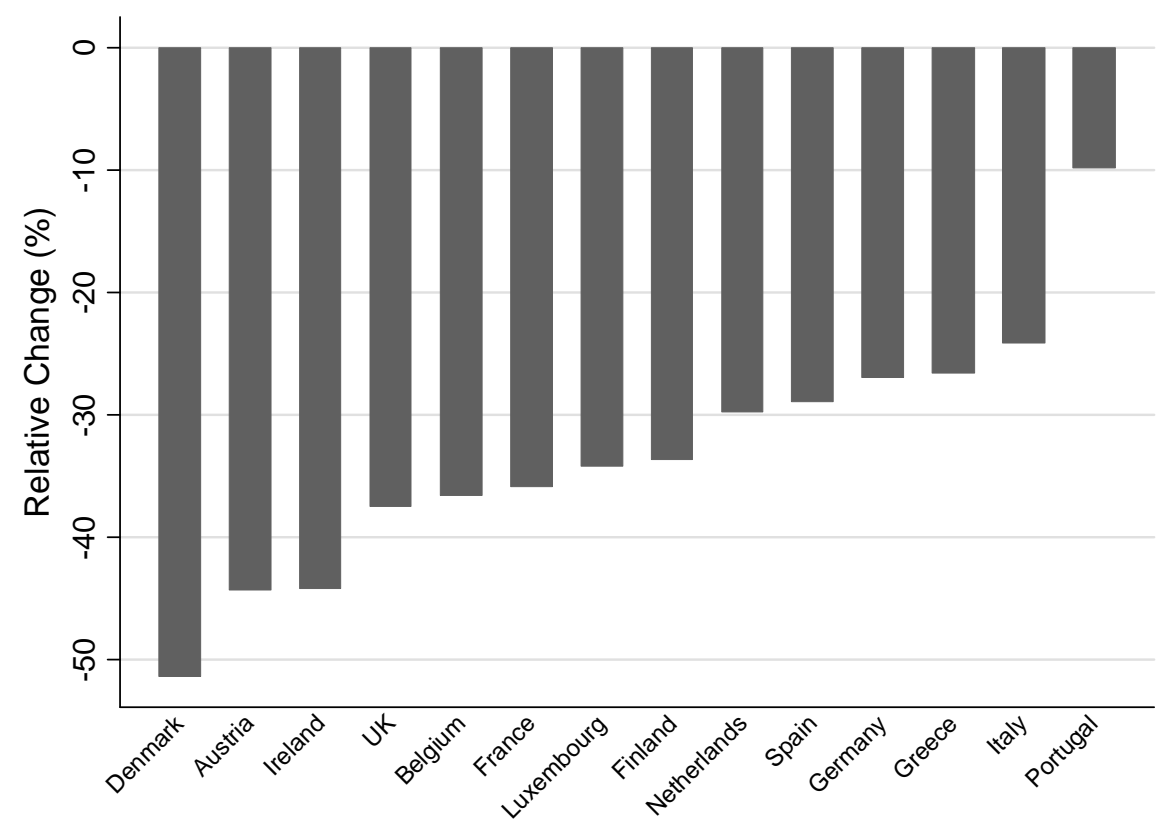

Figure 17. Relative Difference between Long-Term and Cross-sectional Earnings Inequality $\left(1^{\text {st }}\right.$ Wave)

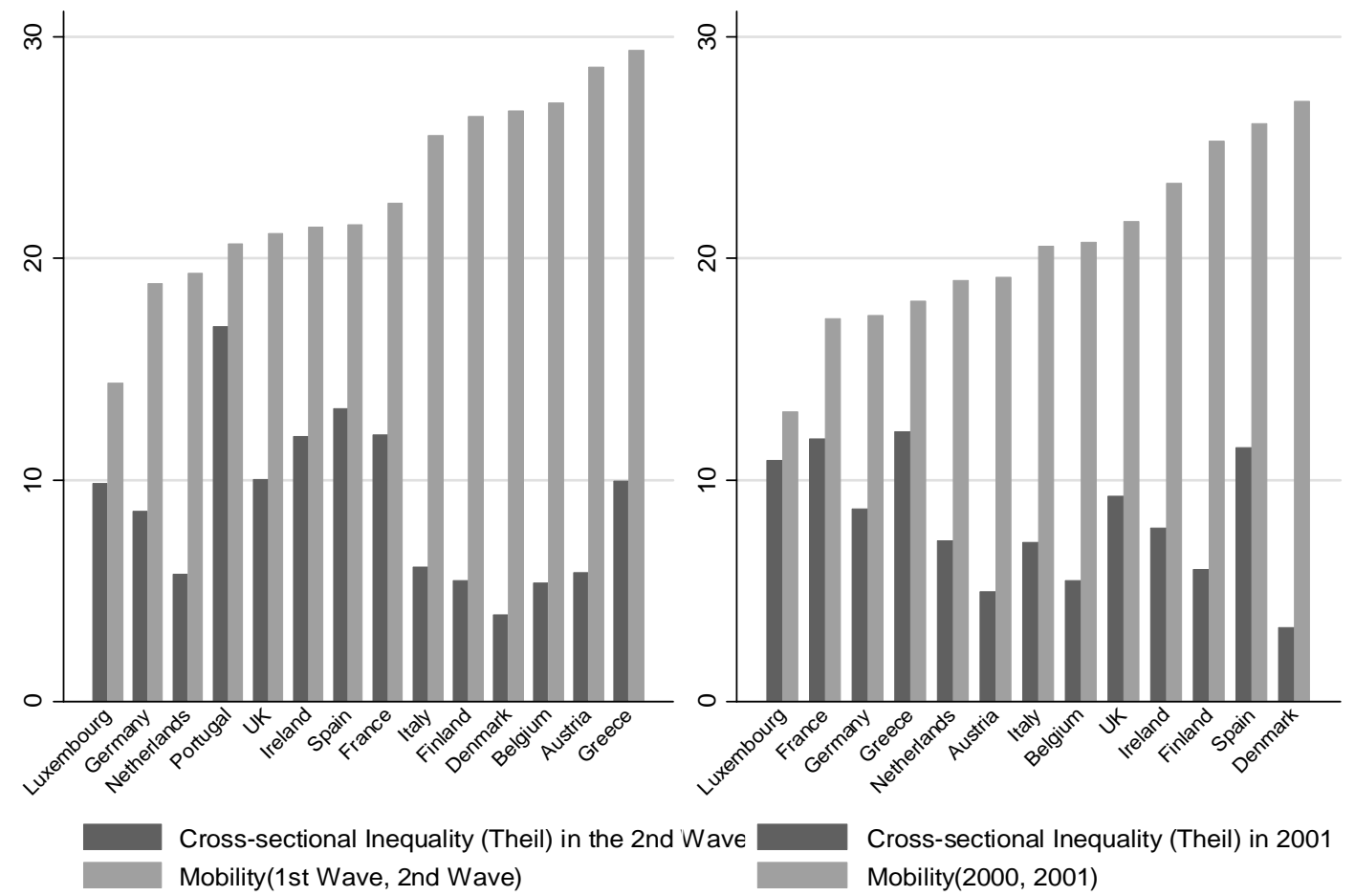

Figure 18. Link between Short-Term Mobility and Cross-Sectional Inequality: Mobility ( $1^{\text {st }}$ Wave, $2^{\text {nd }}$ Wave $)$-> Inequality $\left(2^{\text {nd }}\right.$ Wave $)$

Mobility (2000, 2001) -> Inequality (2001) 


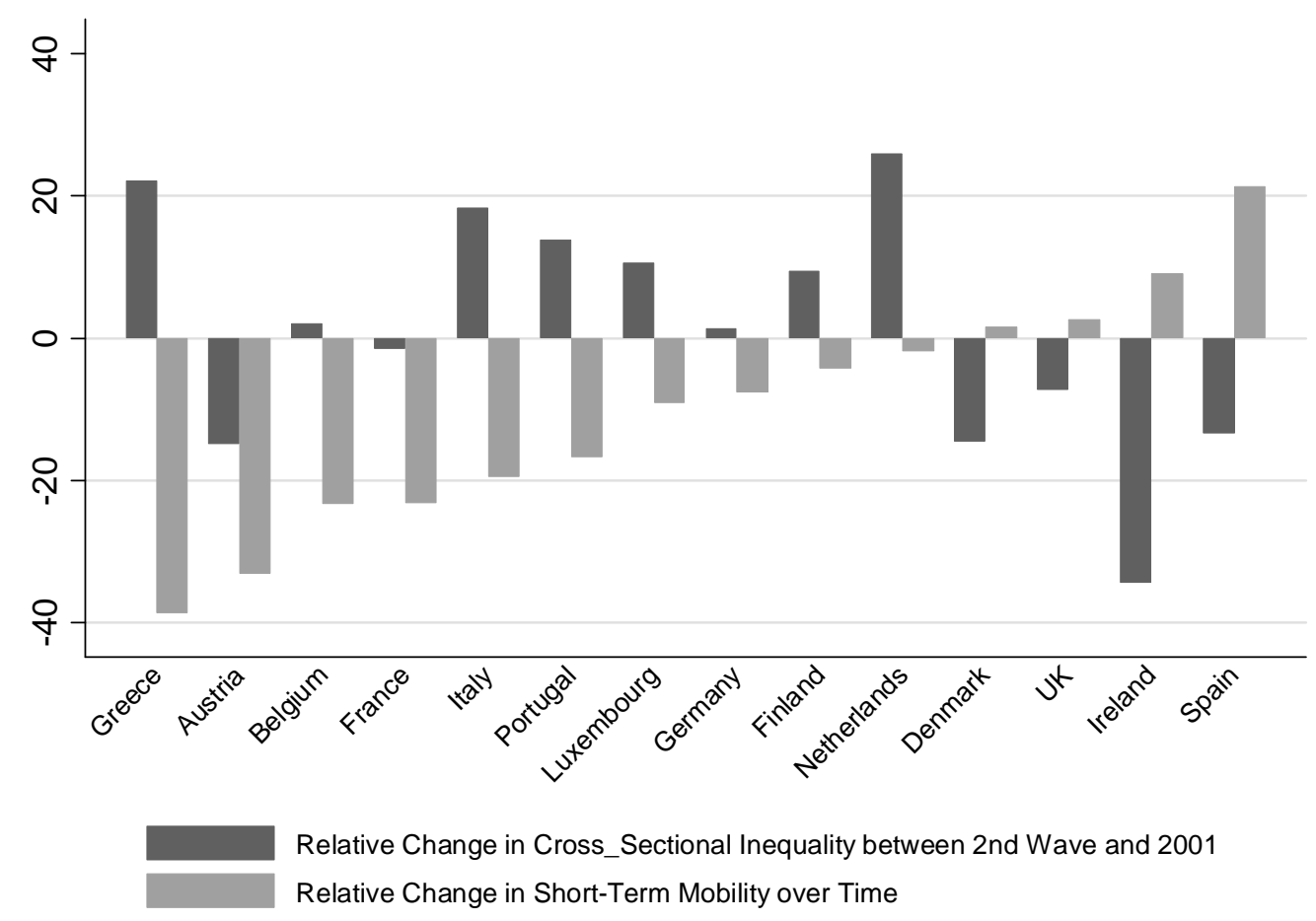

Figure 19. Relative Change in Cross-Sectional Inequality and Short-Term Mobility Over Time Note: Inequality - between the $2^{\text {nd }}$ and the last wave; Mobility between $1^{\text {st }}-2^{\text {nd }}$ wave and $2000-2001$
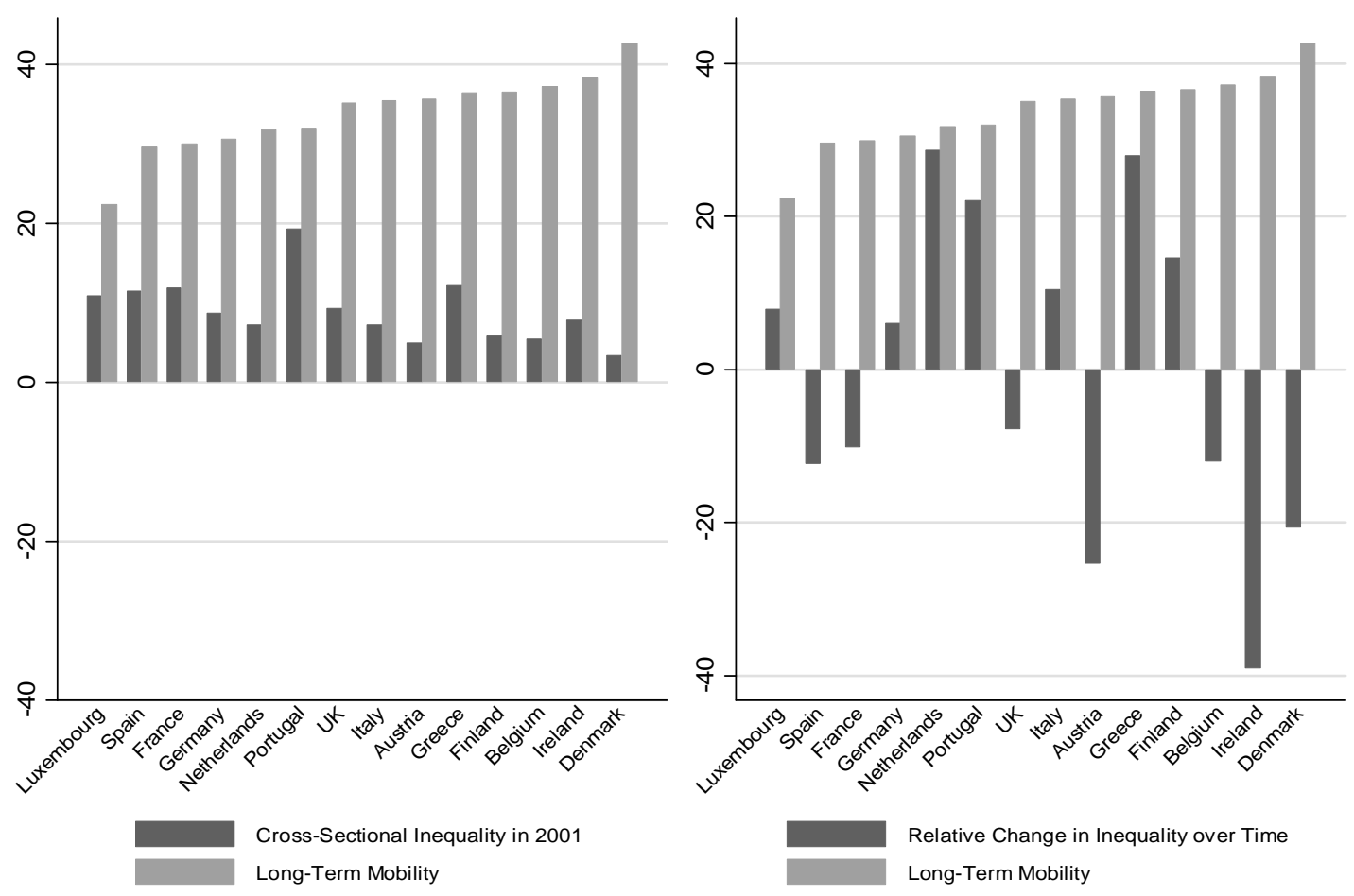

Figure 20. Long-Term Mobility and Cross-Sectional Inequality 
Table 1. Inflows and Outflows of Individuals in the Sample - Germany

\begin{tabular}{|c|c|c|c|c|c|c|c|c|}
\hline & 1994 & 1995 & 1996 & 1997 & 1998 & 1999 & 2000 & 2001 \\
\hline $\begin{array}{l}\text { Number of individuals with } \\
\text { positive earnings }\end{array}$ & 25018 & 26059 & 25806 & 24889 & 23290 & 22955 & 21909 & 20703 \\
\hline \multicolumn{9}{|c|}{$\begin{array}{c}\text { Absolute number and proportion of individuals who report positive earnings in current year conditional on being in the } \\
\text { sample in previous year }\end{array}$} \\
\hline & Frequencies & 23956 & 25224 & 24197 & 22814 & 22321 & 21290 & 20107 \\
\hline & $\%$ & 66.99 & 67.37 & 66.2 & 63.01 & 64.84 & 64.86 & 64.39 \\
\hline \multicolumn{9}{|c|}{$\begin{array}{c}\text { Absolute number and proportion of individuals who report no earnings in current year conditional on being in the sample in } \\
\text { the previous year }\end{array}$} \\
\hline Unemployed & Frequencies & 3448 & 3461 & 4119 & 3932 & 3055 & 2787 & 2766 \\
\hline Inactive & $\%$ & 9.64 & 9.24 & 11.27 & 10.86 & 8.87 & 8.49 & 8.86 \\
\hline \multirow{2}{*}{ Attrition } & Frequencies & 1885 & 2182 & 1892 & 3280 & 2951 & 2924 & 2830 \\
\hline & $\%$ & 5.27 & 5.83 & 5.18 & 9.06 & 8.57 & 8.91 & 9.06 \\
\hline \multirow{2}{*}{ Missing Wage } & Frequencies & 6470 & 6576 & 6345 & 6180 & 6100 & 5826 & 5524 \\
\hline & $\%$ & 18.09 & 17.56 & 17.36 & 17.07 & 17.72 & 17.75 & 17.69 \\
\hline \multirow[t]{2}{*}{ Total } & Frequencies & 35759 & 37443 & 36553 & 36206 & 34427 & 32827 & 31227 \\
\hline & $\%$ & 100 & 100 & 100 & 100 & 100 & 100 & 100 \\
\hline
\end{tabular}

Table 1. Inflows and Outflows of Individuals in the Sample - Denmark

\begin{tabular}{|c|c|c|c|c|c|c|c|c|}
\hline & 1994 & 1995 & 1996 & 1997 & 1998 & 1999 & 2000 & 2001 \\
\hline $\begin{array}{l}\text { Number of individuals with } \\
\text { positive earnings }\end{array}$ & 20899 & 20399 & 19190 & 19062 & 17321 & 16235 & 15678 & 15380 \\
\hline \multicolumn{9}{|c|}{$\begin{array}{l}\text { Absolute number and proportion of individuals who report positive earnings in current year conditional on being in the } \\
\text { sample in previous year }\end{array}$} \\
\hline & Frequencies & 19854 & 18527 & 18110 & 16442 & 15334 & 14865 & 14642 \\
\hline & $\%$ & 68.74 & 66.59 & 69.43 & 66.23 & 67.41 & 69.6 & 71.6 \\
\hline \multicolumn{9}{|c|}{$\begin{array}{c}\text { Absolute number and proportion of individuals who report no earnings in current year conditional on being in the sample in } \\
\text { the previous year }\end{array}$} \\
\hline Unemployed & Frequencies & 1535 & 1744 & 951 & 899 & 732 & 658 & 958 \\
\hline Inactive & $\%$ & 5.31 & 6.27 & 3.65 & 3.62 & 3.22 & 3.08 & 4.68 \\
\hline \multirow{2}{*}{ Attrition } & Frequencies & 2440 & 3096 & 2914 & 3603 & 2922 & 2133 & 1775 \\
\hline & $\%$ & 8.45 & 11.13 & 11.17 & 14.51 & 12.85 & 9.99 & 8.68 \\
\hline \multirow{2}{*}{ Missing Wage } & Frequencies & 5054 & 4454 & 4110 & 3881 & 3759 & 3703 & 3074 \\
\hline & $\%$ & 17.5 & 16.01 & 15.76 & 15.63 & 16.53 & 17.34 & 15.03 \\
\hline \multirow[t]{2}{*}{ Total } & Frequencies & 28883 & 27821 & 26085 & 24825 & 22747 & 21359 & 20449 \\
\hline & $\%$ & 100 & 100 & 100 & 100 & 100 & 100 & 100 \\
\hline
\end{tabular}

Table 1. Inflows and Outflows of Individuals in the Sample - Netherlands

\begin{tabular}{|c|c|c|c|c|c|c|c|c|}
\hline & 1994 & 1995 & 1996 & 1997 & 1998 & 1999 & 2000 & 2001 \\
\hline $\begin{array}{l}\text { Number of individuals with positive } \\
\text { earnings }\end{array}$ & 20221 & 22100 & 22892 & 22753 & 22863 & 23233 & 24065 & 24130 \\
\hline \multicolumn{9}{|c|}{$\begin{array}{l}\text { Absolute number and proportion of individuals who report positive earnings in current year conditional on being in the } \\
\text { sample in previous year }\end{array}$} \\
\hline & Frequencies & 20578 & 21328 & 21221 & 21055 & 20545 & 21026 & 21341 \\
\hline & $\%$ & 69.07 & 71.37 & 68.68 & 67.52 & 67.24 & 68.56 & 69.59 \\
\hline
\end{tabular}

Absolute number and proportion of individuals who report no earnings in current year conditional on being in the sample in

\begin{tabular}{ccccccccc}
\multicolumn{10}{c}{ the previous year } \\
\hline Unemployed & Frequencies & 2418 & 2356 & 2536 & 2120 & 1984 & 1840 & 1689 \\
Inactive & $\%$ & 8.12 & 7.88 & 8.21 & 6.8 & 6.49 & 6 & 5.51 \\
& Frequencies & 2941 & 1889 & 2591 & 3562 & 3984 & 4301 & 4891 \\
Attrition & $\%$ & 9.87 & 6.32 & 8.39 & 11.42 & 13.04 & 14.02 & 15.95 \\
& Frequencies & 3857 & 4310 & 4550 & 4448 & 4042 & 3502 & 2745 \\
Missing Wage & $\%$ & 12.95 & 14.42 & 14.73 & 14.26 & 13.23 & 11.42 & 8.95 \\
& Frequencies & 29794 & 29883 & 30898 & 31185 & 30555 & 30669 & 30666 \\
Total & & & & & & & & 39
\end{tabular}


$\%$

$\begin{array}{llll}100 & 100 & 100 & 100\end{array}$

$100 \quad 100$ 100

Table 1. Inflows and Outflows of Individuals in the Sample - Belgium

\begin{tabular}{|c|c|c|c|c|c|c|c|c|}
\hline & 1994 & 1995 & 1996 & 1997 & 1998 & 1999 & 2000 & 2001 \\
\hline $\begin{array}{l}\text { Number of individuals with } \\
\text { positive earnings }\end{array}$ & 35342 & 34367 & 33280 & 32378 & 31129 & 29414 & 28087 & 26538 \\
\hline \multicolumn{9}{|c|}{$\begin{array}{l}\text { Absolute number and proportion of individuals who report positive earnings in current year conditional on being in the } \\
\text { sample in previous year }\end{array}$} \\
\hline & Frequencies & 33277 & 32384 & 31564 & 30575 & 28731 & 27460 & 25790 \\
\hline & $\%$ & 63.43 & 63.65 & 64.38 & 63.88 & 64.28 & 65.15 & 64.38 \\
\hline \multicolumn{9}{|c|}{$\begin{array}{c}\text { Absolute number and proportion of individuals who report no earnings in current year conditional on being in the sample in } \\
\text { the previous year }\end{array}$} \\
\hline Unemployed & Frequencies & 3810 & 5127 & 4378 & 3601 & 3040 & 3090 & 2540 \\
\hline Inactive & $\%$ & 7.26 & 10.08 & 8.93 & 7.52 & 6.8 & 7.33 & 6.34 \\
\hline \multirow{2}{*}{ Attrition } & Frequencies & 4145 & 3798 & 3473 & 4803 & 4421 & 3851 & 4930 \\
\hline & $\%$ & 7.9 & 7.46 & 7.08 & 10.04 & 9.89 & 9.14 & 12.31 \\
\hline \multirow{2}{*}{ Missing Wage } & Frequencies & 11228 & 9573 & 9614 & 8882 & 8504 & 7748 & 6798 \\
\hline & $\%$ & 21.4 & 18.81 & 19.61 & 18.56 & 19.03 & 18.38 & 16.97 \\
\hline \multirow[t]{2}{*}{ Total } & Frequencies & 52460 & 50882 & 49029 & 47861 & 44696 & 42149 & 40058 \\
\hline & $\%$ & 100 & 100 & 100 & 100 & 100 & 100 & 100 \\
\hline
\end{tabular}

Table 1. Inflows and Outflows of Individuals in the Sample - Luxembourg

\begin{tabular}{ccccccccc}
\hline & 1994 & 1995 & 1996 & 1997 & 1998 & 1999 & 2000 & 2001 \\
\hline $\begin{array}{c}\text { Number of individuals with positive } \\
\text { earnings }\end{array}$ & & 15829 & 13695 & 14489 & 13403 & 14075 & 12667 & 12992 \\
\hline
\end{tabular}

Absolute number and proportion of individuals who report positive earnings in current year conditional on being in the sample in previous year

\begin{tabular}{|c|c|c|c|c|c|c|c|c|}
\hline & $\begin{array}{l}\text { Frequencies } \\
\%\end{array}$ & & $\begin{array}{l}13417 \\
64.75\end{array}$ & $\begin{array}{l}12498 \\
69.48\end{array}$ & $\begin{array}{l}13190 \\
69.33\end{array}$ & $\begin{array}{l}12257 \\
69.81\end{array}$ & $\begin{array}{l}12402 \\
68.71\end{array}$ & $\begin{array}{l}11457 \\
70.39\end{array}$ \\
\hline \multicolumn{9}{|c|}{$\begin{array}{c}\text { Absolute number and proportion of individuals who report no earnings in current year conditional on being in the sample in } \\
\text { the previous year }\end{array}$} \\
\hline Unemployed & Frequencies & & 1765 & 1559 & 1505 & 1408 & 1246 & 954 \\
\hline Inactive & $\%$ & & 8.52 & 8.67 & 7.91 & 8.02 & 6.9 & 5.86 \\
\hline \multirow{2}{*}{ Attrition } & Frequencies & & 3423 & 1663 & 2109 & 1913 & 2346 & 1940 \\
\hline & $\%$ & & 16.52 & 9.25 & 11.09 & 10.9 & 13 & 11.92 \\
\hline \multirow{2}{*}{ Missing Wage } & Frequencies & & 2116 & 2267 & 2220 & 1980 & 2057 & 1926 \\
\hline & $\%$ & & 10.21 & 12.6 & 11.67 & 11.28 & 11.4 & 11.83 \\
\hline \multirow[t]{2}{*}{ Total } & Frequencies & & 20721 & 17987 & 19024 & 17558 & 18051 & 16277 \\
\hline & $\%$ & 100 & 100 & 100 & 100 & 100 & 100 & 100 \\
\hline
\end{tabular}

Table 1. Inflows and Outflows of Individuals in the Sample - France

\begin{tabular}{|c|c|c|c|c|c|c|c|c|}
\hline & 1994 & 1995 & 1996 & 1997 & 1998 & 1999 & 2000 & 2001 \\
\hline $\begin{array}{l}\text { Number of individuals with positive } \\
\text { earnings }\end{array}$ & 20137 & 19270 & 19042 & 17906 & 14467 & 14012 & $\begin{array}{c}1376 \\
0\end{array}$ & $\begin{array}{c}1421 \\
2\end{array}$ \\
\hline \multicolumn{9}{|c|}{$\begin{array}{l}\text { Absolute number and proportion of individuals who report positive earnings in current year conditional on being in the } \\
\text { sample in previous year }\end{array}$} \\
\hline & Frequencies & 19143 & 18197 & 17243 & 14014 & 12209 & 12080 & 12468 \\
\hline & $\%$ & 62.47 & 64.76 & 62 & 52.08 & 54.24 & 55.54 & 60.8 \\
\hline
\end{tabular}

Absolute number and proportion of individuals who report no earnings in current year conditional on being in the sample in

\begin{tabular}{ccccccccc}
\multicolumn{10}{c}{ the previous year } \\
\hline Unemployed & Frequencies & 3259 & 3042 & 3426 & 3006 & 2607 & 2072 & 1995 \\
Inactive & $\%$ & 10.64 & 10.83 & 12.32 & 11.17 & 11.58 & 9.53 & 9.73 \\
& Frequencies & 3371 & 2213 & 2785 & 5584 & 3531 & 3786 & 2658 \\
Attrition & $\%$ & 11 & 7.88 & 10.01 & 20.75 & 15.69 & 17.41 & 12.96 \\
& Frequencies & 4871 & 4646 & 4358 & 4304 & 4162 & 3811 & 3385 \\
Missing Wage & $\%$ & 15.9 & 16.53 & 15.67 & 16 & 18.49 & 17.52 & 16.51 \\
& Frequencies & 30644 & 28098 & 27812 & 26908 & 22509 & 21749 & 20506
\end{tabular}




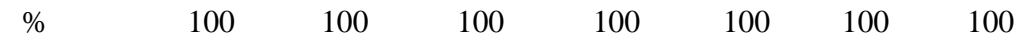

\begin{tabular}{cccccccccc}
\hline \multicolumn{8}{c}{ Table 1. Inflows and Outflows of Individuals in the Sample - UK } & & \\
\hline & 1994 & 1995 & 1996 & 1997 & 1998 & 1999 & 2000 & 2001 \\
\hline $\begin{array}{c}\text { Number of individuals with positive } \\
\text { earnings }\end{array}$ & 24949 & 25329 & 25495 & 26010 & 26145 & 25750 & 25674 & 25264 \\
\hline
\end{tabular}

Absolute number and proportion of individuals who report positive earnings in current year conditional on being in the sample in previous year

\begin{tabular}{|c|c|c|c|c|c|c|c|c|}
\hline & $\begin{array}{c}\text { Frequencies } \\
\%\end{array}$ & $\begin{array}{l}24511 \\
64.59\end{array}$ & $\begin{array}{l}24848 \\
66.31\end{array}$ & $\begin{array}{l}25303 \\
67.06\end{array}$ & $\begin{array}{l}25278 \\
67.04\end{array}$ & $\begin{array}{l}25006 \\
67.36\end{array}$ & $\begin{array}{r}24881 \\
68.33\end{array}$ & $\begin{array}{r}24467 \\
68.58\end{array}$ \\
\hline \multicolumn{9}{|c|}{$\begin{array}{l}\text { Absolute number and proportion of individuals who report no earnings in current year conditional on being in the sample in } \\
\text { the previous year }\end{array}$} \\
\hline Unemployed & Frequencies & 4712 & 5053 & 4663 & 4140 & 3941 & 3607 & 3595 \\
\hline Inactive & $\%$ & 12.42 & 13.48 & 12.36 & 10.98 & 10.62 & 9.91 & 10.08 \\
\hline \multirow{2}{*}{ Attrition } & Frequencies & 1836 & 966 & 1169 & 2073 & 1919 & 2153 & 2105 \\
\hline & $\%$ & 4.84 & 2.58 & 3.1 & 5.5 & 5.17 & 5.91 & 5.9 \\
\hline \multirow{2}{*}{ Missing Wage } & Frequencies & 6888 & 6605 & 6597 & 6213 & 6257 & 5774 & 5510 \\
\hline & $\%$ & 18.15 & 17.63 & 17.48 & 16.48 & 16.85 & 15.86 & 15.44 \\
\hline \multirow[t]{2}{*}{ Total } & Frequencies & 37947 & 37472 & 37732 & 37704 & 37123 & 36415 & 35677 \\
\hline & $\%$ & 100 & 100 & 100 & 100 & 100 & 100 & 100 \\
\hline
\end{tabular}

Table 1. Inflows and Outflows of Individuals in the Sample - Ireland

\begin{tabular}{ccccccccc}
\hline & 1994 & 1995 & 1996 & 1997 & 1998 & 1999 & 2000 & 2001 \\
\hline $\begin{array}{c}\text { Number of individuals with positive } \\
\text { earnings }\end{array}$ & 13937 & 13221 & 12590 & 12515 & 12435 & 12091 & 10745 & 9727 \\
\hline
\end{tabular}

Absolute number and proportion of individuals who report positive earnings in current year conditional on being in the sample in previous year

\begin{tabular}{|c|c|c|c|c|c|c|c|c|}
\hline & Frequencies & 12750 & 12217 & 12212 & 12020 & 11668 & 10236 & 9507 \\
\hline & $\%$ & 49.99 & 50.04 & 52.41 & 53.13 & 54.1 & 51.63 & 54.65 \\
\hline \multicolumn{9}{|c|}{$\begin{array}{c}\text { Absolute number and proportion of individuals who report no earnings in current year conditional on being in the sample in } \\
\text { the previous year }\end{array}$} \\
\hline Unemployed & Frequencies & 4930 & 4723 & 4254 & 3374 & 2905 & 2185 & 2307 \\
\hline Inactive & $\%$ & 19.33 & 19.35 & 18.26 & 14.91 & 13.47 & 11.02 & 13.26 \\
\hline \multirow{2}{*}{ Attrition } & Frequencies & 2167 & 2115 & 1600 & 1936 & 2516 & 3288 & 2362 \\
\hline & $\%$ & 8.5 & 8.66 & 6.87 & 8.56 & 11.66 & 16.59 & 13.58 \\
\hline \multirow{2}{*}{ Missing Wage } & Frequencies & 5656 & 5359 & 5235 & 5292 & 4480 & 4116 & 3220 \\
\hline & $\%$ & 22.18 & 21.95 & 22.47 & 23.39 & 20.77 & 20.76 & 18.51 \\
\hline \multirow[t]{2}{*}{ Total } & Frequencies & 25503 & 24414 & 23301 & 22622 & 21569 & 19825 & 17396 \\
\hline & $\%$ & 100 & 100 & 100 & 100 & 100 & 100 & 100 \\
\hline
\end{tabular}

Table 1. Inflows and Outflows of Individuals in the Sample - Italy

\begin{tabular}{|c|c|c|c|c|c|c|c|c|}
\hline & 1994 & 1995 & 1996 & 1997 & 1998 & 1999 & 2000 & 2001 \\
\hline $\begin{array}{l}\text { Number of individuals with positive } \\
\text { earnings }\end{array}$ & 32633 & 32236 & 32111 & 29661 & 28865 & 26993 & 26912 & 25170 \\
\hline \multicolumn{9}{|c|}{$\begin{array}{c}\text { Absolute number and proportion of individuals who report positive earnings in current year conditional on being in the } \\
\text { sample in previous year }\end{array}$} \\
\hline & Frequencies & 30946 & 31028 & 28717 & 27188 & 25717 & 25348 & 24139 \\
\hline & $\%$ & 51.58 & 51.19 & 47.18 & 47.34 & 46.87 & 48.73 & 48.86 \\
\hline
\end{tabular}

Absolute number and proportion of individuals who report no earnings in current year conditional on being in the sample in

\begin{tabular}{ccccccccc}
\multicolumn{10}{c}{ the previous year } \\
\hline Unemployed & Frequencies & 7900 & 7799 & 7670 & 6627 & 6890 & 5662 & 5027 \\
Inactive & $\%$ & 13.17 & 12.87 & 12.6 & 11.54 & 12.56 & 10.88 & 10.18 \\
& Frequencies & 3175 & 2947 & 5922 & 6030 & 5941 & 5399 & 5920 \\
Attrition & $\%$ & 5.29 & 4.86 & 9.73 & 10.5 & 10.83 & 10.38 & 11.98 \\
& Frequencies & 17978 & 18836 & 18559 & 17585 & 16325 & 15610 & 14315 \\
Missing Wage & $\%$ & 29.96 & 31.08 & 30.49 & 30.62 & 29.75 & 30.01 & 28.98 \\
& Frequencies & 59999 & 60610 & 60868 & 57430 & 54873 & 52019 & 49401 \\
Total & & & & & & &
\end{tabular}




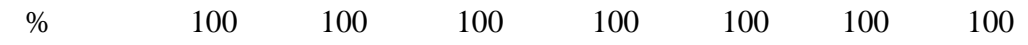

\begin{tabular}{|c|c|c|c|c|c|c|c|c|}
\hline \\
\hline \multicolumn{9}{|c|}{ Table 1. Inflows and Outflows of Individuals in the Sample - Greece } \\
\hline & 1994 & 1995 & 1996 & 1997 & 1998 & 1999 & 2000 & 2001 \\
\hline $\begin{array}{l}\text { Number of individuals with } \\
\text { positive earnings }\end{array}$ & 27974 & 27654 & 26150 & 24865 & 22675 & 22001 & 21335 & 21929 \\
\hline \multicolumn{9}{|c|}{$\begin{array}{c}\text { Absolute number and proportion of individuals who report positive earnings in current year conditional on being in the } \\
\text { sample in previous year }\end{array}$} \\
\hline & Frequencies & 26868 & 25946 & 24385 & 21815 & 20357 & 20443 & 21342 \\
\hline & $\%$ & 45.83 & 45.69 & 44.98 & 42.09 & 43.52 & 46.06 & 49.72 \\
\hline \multicolumn{9}{|c|}{$\begin{array}{c}\text { Absolute number and proportion of individuals who report no earnings in current year conditional on being in the sample in } \\
\text { the previous year }\end{array}$} \\
\hline Unemployed & Frequencies & 7537 & 6813 & 6419 & 4523 & 4489 & 4427 & 3858 \\
\hline Inactive & $\%$ & 12.86 & 12 & 11.84 & 8.73 & 9.6 & 9.97 & 8.99 \\
\hline \multirow{2}{*}{ Attrition } & Frequencies & 4417 & 4392 & 4347 & 7892 & 6222 & 4159 & 2363 \\
\hline & $\%$ & 7.53 & 7.73 & 8.02 & 15.23 & 13.3 & 9.37 & 5.5 \\
\hline \multirow{2}{*}{ Missing Wage } & Frequencies & 19802 & 19640 & 19068 & 17599 & 15707 & 15352 & 15365 \\
\hline & $\%$ & 33.78 & 34.58 & 35.17 & 33.96 & 33.58 & 34.59 & 35.79 \\
\hline \multirow[t]{2}{*}{ Total } & Frequencies & 58624 & 56791 & 54219 & 51829 & 46775 & 44381 & 42928 \\
\hline & $\%$ & 100 & 100 & 100 & 100 & 100 & 100 & 100 \\
\hline
\end{tabular}

Table 1. Inflows and Outflows of Individuals in the Sample - Spain

\begin{tabular}{ccccccccc}
\hline & 1994 & 1995 & 1996 & 1997 & 1998 & 1999 & 2000 & 2001 \\
\hline $\begin{array}{c}\text { Number of individuals with positive } \\
\text { earnings }\end{array}$ & 22559 & 21863 & 21296 & 20975 & 20371 & 20580 & 19898 & 20185 \\
\hline
\end{tabular}

Absolute number and proportion of individuals who report positive earnings in current year conditional on being in the

\begin{tabular}{ccccccccc}
\multicolumn{8}{c}{ sample in previous year } \\
\hline & Frequencies & 21460 & 20521 & 20329 & 19456 & 19679 & 19167 & 19352 \\
& $\%$ & 47.6 & 48.29 & 48.49 & 48.63 & 52.13 & 52.12 & 56.06 \\
\hline Absolute number and proportion of individuals who report no earnings in current year conditional on being in the sample in \\
\\
the previous year \\
Unemployed & Frequencies & 8419 & 8230 & 7353 & 5970 & 5083 & 4512 & 4761 \\
Inactive & $\%$ & 18.67 & 19.37 & 17.54 & 14.92 & 13.46 & 12.27 & 13.79 \\
Attrition & Frequencies & 4467 & 3000 & 4120 & 4327 & 3188 & 3922 & 3052 \\
& $\%$ & 9.91 & 7.06 & 9.83 & 10.81 & 8.44 & 10.66 & 8.84 \\
Missing Wage & Frequencies & 10741 & 10742 & 10121 & 10259 & 9802 & 9176 & 7357 \\
& $\%$ & 23.82 & 25.28 & 24.14 & 25.64 & 25.96 & 24.95 & 21.31 \\
Total & Frequencies & 45087 & 42493 & 41923 & 40012 & 37752 & 36777 & 34522 \\
& $\%$ & 100 & 100 & 100 & 100 & 100 & 100 & 100 \\
\hline
\end{tabular}

Table 1. Inflows and Outflows of Individuals in the Sample - Portugal

\begin{tabular}{|c|c|c|c|c|c|c|c|c|}
\hline & 1994 & 1995 & 1996 & 1997 & 1998 & 1999 & 2000 & 2001 \\
\hline $\begin{array}{l}\text { Number of individuals with positive } \\
\text { earnings }\end{array}$ & 14653 & 15450 & 15379 & 15087 & 14837 & 14569 & 14604 & 14550 \\
\hline \multicolumn{9}{|c|}{$\begin{array}{c}\text { Absolute number and proportion of individuals who report positive earnings in current year conditional on being in the } \\
\text { sample in previous year }\end{array}$} \\
\hline & Frequencies & 13892 & 14538 & 14321 & 13977 & 13921 & 13952 & 13942 \\
\hline & $\%$ & 57.84 & 57.5 & 57.32 & 56.98 & 59.12 & 60.83 & 62.16 \\
\hline
\end{tabular}

Absolute number and proportion of individuals who report no earnings in current year conditional on being in the sample in

\begin{tabular}{ccccccccc}
\multicolumn{10}{c}{ the previous year } \\
\hline Unemployed & Frequencies & 2187 & 2264 & 2396 & 2019 & 2067 & 1843 & 1702 \\
Inactive & $\%$ & 9.11 & 8.95 & 9.59 & 8.23 & 8.78 & 8.04 & 7.59 \\
& Frequencies & 1701 & 1908 & 1918 & 2346 & 1956 & 1617 & 1575 \\
Attrition & $\%$ & 7.08 & 7.55 & 7.68 & 9.56 & 8.31 & 7.05 & 7.02 \\
& Frequencies & 6236 & 6573 & 6350 & 6189 & 5602 & 5525 & 5211 \\
Missing Wage & $\%$ & 25.97 & 26 & 25.42 & 25.23 & 23.79 & 24.09 & 23.23 \\
& Frequencies & 24016 & 25283 & 24985 & 24531 & 23546 & 22937 & 22430 \\
Total & & & & & & & &
\end{tabular}


$\%$

100

100

100

100

100 100 100

Table 1. Inflows and Outflows of Individuals in the Sample - Austria

\begin{tabular}{|c|c|c|c|c|c|c|c|c|}
\hline & 1994 & 1995 & 1996 & 1997 & 1998 & 1999 & 2000 & 2001 \\
\hline $\begin{array}{l}\text { Number of individuals with } \\
\text { positive earnings }\end{array}$ & & 17944 & 17789 & 17199 & 16209 & 15162 & 13816 & 13056 \\
\hline
\end{tabular}

Absolute number and proportion of individuals who report positive earnings in current year conditional on being in the sample in previous year

\begin{tabular}{|c|c|c|c|c|c|c|c|}
\hline & $\begin{array}{c}\text { Frequencies } \\
\%\end{array}$ & $\begin{array}{c}16472 \\
67.96\end{array}$ & $\begin{array}{c}16384 \\
68.2\end{array}$ & $\begin{array}{l}15634 \\
67.49\end{array}$ & $\begin{array}{c}14551 \\
67.2\end{array}$ & $\begin{array}{l}13403 \\
66.51\end{array}$ & $\begin{array}{l}12601 \\
68.21\end{array}$ \\
\hline \multicolumn{8}{|c|}{$\begin{array}{c}\text { Absolute number and proportion of individuals who report no earnings in current year conditional on being in the sample in } \\
\text { the previous year }\end{array}$} \\
\hline Unemployed & Frequencies & 1209 & 1231 & 906 & 790 & 803 & 843 \\
\hline Inactive & $\%$ & 4.99 & 5.12 & 3.91 & 3.65 & 3.98 & 4.56 \\
\hline \multirow{2}{*}{ Attrition } & Frequencies & 2195 & 2080 & 2435 & 2470 & 2409 & 1794 \\
\hline & $\%$ & 9.06 & 8.66 & 10.51 & 11.41 & 11.95 & 9.71 \\
\hline \multirow{2}{*}{ Missing Wage } & Frequencies & 4361 & 4330 & 4189 & 3842 & 3538 & 3235 \\
\hline & $\%$ & 17.99 & 18.02 & 18.08 & 17.74 & 17.56 & 17.51 \\
\hline \multirow[t]{2}{*}{ Total } & Frequencies & 24237 & 24025 & 23164 & 21653 & 20153 & 18473 \\
\hline & $\%$ & 100 & 100 & 100 & 100 & 100 & 100 \\
\hline
\end{tabular}

Table 1. Inflows and Outflows of Individuals in the Sample - Finland

\begin{tabular}{|c|c|c|c|c|c|c|c|}
\hline & & 1996 & 1997 & 1998 & 1999 & 2000 & 2001 \\
\hline $\begin{array}{l}\text { Number of individuals with } \\
\text { positive earnings }\end{array}$ & & 15811 & 15845 & 15895 & 15546 & 13329 & 13057 \\
\hline \multicolumn{8}{|c|}{$\begin{array}{c}\text { Absolute number and proportion of individuals who report positive earnings in current year conditional on being in the } \\
\text { sample in previous year }\end{array}$} \\
\hline & Frequencies & & 15246 & 15345 & 14753 & 12756 & 12588 \\
\hline & $\%$ & & 55.95 & 57.2 & 59.29 & 53.83 & 64.16 \\
\hline \multicolumn{8}{|c|}{$\begin{array}{c}\text { Absolute number and proportion of individuals who report no earnings in current year conditional on being in the sample in } \\
\text { the previous year }\end{array}$} \\
\hline Unemployed & Frequencies & & 3446 & 2327 & 1657 & 1326 & 1267 \\
\hline Inactive & $\%$ & & 12.65 & 8.67 & 6.66 & 5.6 & 6.46 \\
\hline \multirow{2}{*}{ Attrition } & Frequencies & & 1933 & 3219 & 2658 & 5219 & 1708 \\
\hline & $\%$ & & 7.09 & 12 & 10.68 & 22.02 & 8.71 \\
\hline \multirow{2}{*}{ Missing Wage } & Frequencies & & 6623 & 5937 & 5814 & 4398 & 4057 \\
\hline & $\%$ & & 24.31 & 22.13 & 23.37 & 18.56 & 20.68 \\
\hline \multirow[t]{2}{*}{ Total } & Frequencies & & 27248 & 26828 & 24882 & 23699 & 19620 \\
\hline & $\%$ & & 100 & 100 & 100 & 100 & 100 \\
\hline
\end{tabular}


Table 2. Sample Statistics of Hourly Earnings

\begin{tabular}{|c|c|c|c|c|c|c|c|c|c|}
\hline & Year & 1994 & 1995 & 1996 & 1997 & 1998 & 1999 & 2000 & 2001 \\
\hline \multirow{3}{*}{ Germany } & Mean & 9.43 & 9.49 & 9.61 & 9.52 & 9.57 & 9.48 & 9.60 & 9.72 \\
\hline & Median & 8.65 & 8.68 & 8.78 & 8.84 & 8.70 & 8.65 & 8.75 & 8.82 \\
\hline & Standard Deviation & 4.00 & 4.17 & 4.09 & 4.01 & 4.39 & 4.32 & 4.39 & 4.37 \\
\hline \multirow{3}{*}{ Denmark } & Mean & 10.89 & 11.40 & 11.58 & 11.61 & 11.86 & 11.85 & 12.02 & 12.08 \\
\hline & Median & 10.36 & 10.76 & 10.96 & 11.14 & 11.46 & 11.36 & 11.77 & 11.50 \\
\hline & Standard Deviation & 3.23 & 3.31 & 3.52 & 3.54 & 3.13 & 3.31 & 3.43 & 3.20 \\
\hline \multirow{3}{*}{ Netherlands } & Mean & 9.69 & 9.56 & 9.59 & 9.70 & 10.02 & 9.88 & 10.04 & 9.91 \\
\hline & Median & 9.11 & 9.07 & 9.01 & 9.10 & 9.27 & 9.18 & 9.32 & 9.23 \\
\hline & Standard Deviation & 3.39 & 3.37 & 3.55 & 3.56 & 3.64 & 3.40 & 3.48 & 3.95 \\
\hline \multirow{3}{*}{ Belgium } & Mean & 8.48 & 8.82 & 8.71 & 8.75 & 8.81 & 8.83 & 8.92 & 9.10 \\
\hline & Median & 7.86 & 8.17 & 7.99 & 8.09 & 8.08 & 8.34 & 8.25 & 8.30 \\
\hline & Standard Deviation & 3.17 & 3.08 & 3.02 & 3.09 & 2.97 & 2.94 & 3.00 & 3.21 \\
\hline \multirow{3}{*}{ Luxembourg } & Mean & & 16.18 & 15.81 & 16.73 & 17.39 & 17.15 & 17.22 & 17.10 \\
\hline & Median & & 14.90 & 14.52 & 15.31 & 15.72 & 15.60 & 15.65 & 15.29 \\
\hline & Standard Deviation & & 7.50 & 7.19 & 7.77 & 8.21 & 8.38 & 8.37 & 8.22 \\
\hline \multirow{3}{*}{ France $^{16}$} & Mean & 10.23 & 9.92 & 9.87 & 10.05 & 10.33 & 10.60 & 10.55 & 10.87 \\
\hline & Median & 8.56 & 8.57 & 8.53 & 8.53 & 8.84 & 9.04 & 9.06 & 9.48 \\
\hline & Standard Deviation & 5.82 & 5.33 & 5.17 & 5.65 & 5.62 & 5.78 & 5.51 & 5.72 \\
\hline \multirow{3}{*}{ UK } & Mean & 8.16 & 8.11 & 8.22 & 8.34 & 8.68 & 9.01 & 9.21 & 9.68 \\
\hline & Median & 7.30 & 7.29 & 7.51 & 7.52 & 7.67 & 8.00 & 8.22 & 8.68 \\
\hline & Standard Deviation & 3.99 & 3.95 & 3.80 & 3.79 & 4.01 & 4.13 & 4.24 & 4.49 \\
\hline \multirow{3}{*}{ Ireland } & Mean & 9.30 & 9.54 & 9.76 & 10.02 & 10.43 & 10.84 & 11.69 & 12.44 \\
\hline & Median & 8.06 & 8.44 & 8.84 & 8.86 & 9.33 & 9.73 & 10.25 & 11.36 \\
\hline & Standard Deviation & 5.14 & 4.99 & 4.85 & 4.98 & 5.17 & 5.02 & 5.24 & 5.15 \\
\hline \multirow{3}{*}{ Italy } & Mean & 7.16 & 6.91 & 6.96 & 7.05 & 7.29 & 7.37 & 7.28 & 7.32 \\
\hline & Median & 6.65 & 6.32 & 6.43 & 6.48 & 6.69 & 6.76 & 6.59 & 6.67 \\
\hline & Standard Deviation & 2.77 & 2.59 & 2.67 & 2.68 & 3.01 & 3.00 & 2.99 & 3.04 \\
\hline \multirow{3}{*}{ Greece } & Mean & 4.95 & 5.03 & 5.23 & 5.59 & 5.63 & 5.85 & 5.70 & 5.77 \\
\hline & Median & 4.49 & 4.41 & 4.53 & 4.90 & 4.91 & 4.99 & 4.89 & 4.99 \\
\hline & Standard Deviation & 2.33 & 2.42 & 2.43 & 2.91 & 2.87 & 3.14 & 3.07 & 3.21 \\
\hline \multirow{3}{*}{ Spain } & Mean & 6.83 & 6.95 & 7.09 & 6.89 & 7.18 & 7.37 & 7.45 & 7.42 \\
\hline & Median & 5.86 & 5.82 & 5.92 & 5.72 & 6.04 & 6.15 & 6.29 & 6.33 \\
\hline & Standard Deviation & 3.81 & 3.86 & 4.00 & 3.92 & 4.06 & 4.15 & 4.07 & 3.87 \\
\hline \multirow{3}{*}{ Portugal } & Mean & 3.70 & 3.74 & 3.84 & 3.92 & 3.99 & 4.08 & 4.31 & 4.46 \\
\hline & Median & 2.92 & 2.82 & 2.98 & 3.03 & 3.05 & 3.08 & 3.29 & 3.34 \\
\hline & Standard Deviation & 2.34 & 2.45 & 2.54 & 2.65 & 2.81 & 2.82 & 3.16 & 3.33 \\
\hline \multirow{3}{*}{ Austria } & Mean & & 9.08 & 8.33 & 8.37 & 8.49 & 8.55 & 8.55 & 8.54 \\
\hline & Median & & 8.51 & 7.64 & 7.63 & 7.84 & 7.82 & 7.86 & 7.93 \\
\hline & Standard Deviation & & 3.52 & 3.00 & 3.07 & 2.95 & 2.89 & 2.84 & 2.82 \\
\hline \multirow{3}{*}{ Finland } & Mean & & & 7.89 & 8.01 & 8.41 & 8.45 & 8.66 & 8.86 \\
\hline & Median & & & 7.48 & 7.57 & 7.85 & 7.90 & 8.18 & 7.97 \\
\hline & Standard Deviation & & & 2.70 & 2.77 & 2.92 & 2.91 & 2.93 & 3.29 \\
\hline
\end{tabular}

\footnotetext{
${ }^{16}$ Gross Amounts
} 
Table 3. Earnings Inequality (Index*100)

\begin{tabular}{|c|c|c|c|c|c|c|c|c|c|}
\hline & & 1994 & 1995 & 1996 & 1997 & 1998 & 1999 & 2000 & 2001 \\
\hline \multirow{3}{*}{ Germany } & Gini & 22.15 & 22.34 & 22.04 & 21.89 & 22.58 & 22.81 & 22.75 & 22.54 \\
\hline & Theil & 8.22 & 8.61 & 8.23 & 8.06 & 8.85 & 8.96 & 8.92 & 8.72 \\
\hline & $\mathrm{A}(1)$ & 8.08 & 8.38 & 8.04 & 7.84 & 8.12 & 8.53 & 8.41 & 8.17 \\
\hline \multirow{3}{*}{ Denmark } & Gini & 15.76 & 15.26 & 15.52 & 15.21 & 14.24 & 14.68 & 14.94 & 14.05 \\
\hline & Theil & 4.22 & 3.92 & 4.23 & 4.15 & 3.37 & 3.73 & 3.83 & 3.35 \\
\hline & $\mathrm{A}(1)$ & 4.26 & 3.78 & 4.10 & 3.96 & 3.37 & 3.76 & 3.78 & 3.33 \\
\hline \multirow{3}{*}{ Netherlands } & Gini & 18.07 & 18.37 & 19.19 & 18.80 & 18.93 & 17.92 & 18.18 & 20.67 \\
\hline & Theil & 5.63 & 5.76 & 6.32 & 6.07 & 5.96 & 5.40 & 5.56 & 7.25 \\
\hline & $\mathrm{A}(1)$ & 5.56 & 5.77 & 6.33 & 5.90 & 5.65 & 5.18 & 5.44 & 7.08 \\
\hline \multirow{3}{*}{ Belgium } & Gini & 19.10 & 17.71 & 17.64 & 18.13 & 17.53 & 17.33 & 17.13 & 17.85 \\
\hline & Theil & 6.23 & 5.37 & 5.35 & 5.58 & 5.15 & 5.11 & 5.04 & 5.48 \\
\hline & $\mathrm{A}(1)$ & 5.92 & 4.95 & 5.04 & 5.24 & 4.85 & 4.92 & 4.69 & 5.14 \\
\hline \multirow{3}{*}{ Luxembourg } & Gini & & 25.23 & 24.74 & 25.41 & 25.62 & 26.58 & 26.50 & 26.32 \\
\hline & Theil & & 10.09 & 9.85 & 10.24 & 10.37 & 11.19 & 11.15 & 10.89 \\
\hline & $\mathrm{A}(1)$ & & 9.88 & 10.00 & 10.16 & 10.02 & 10.95 & 11.09 & 10.66 \\
\hline \multirow{3}{*}{ France } & Gini & 27.62 & 26.47 & 26.26 & 27.23 & 27.28 & 27.41 & 26.83 & 26.49 \\
\hline & Theil & 13.21 & 12.04 & 11.63 & 12.88 & 12.58 & 12.65 & 11.94 & 11.87 \\
\hline & $\mathrm{A}(1)$ & 11.64 & 10.88 & 10.58 & 11.41 & 11.54 & 11.59 & 11.17 & 10.98 \\
\hline \multirow{3}{*}{ UK } & Gini & 24.26 & 24.22 & 23.35 & 23.36 & 23.54 & 23.25 & 23.35 & 23.51 \\
\hline & Theil & 10.08 & 10.01 & 9.20 & 9.05 & 9.24 & 9.08 & 9.16 & 9.29 \\
\hline & $\mathrm{A}(1)$ & 9.25 & 9.19 & 8.57 & 8.46 & 8.55 & 8.32 & 8.46 & 8.51 \\
\hline \multirow{3}{*}{ Ireland } & Gini & 27.59 & 26.87 & 25.76 & 25.47 & 25.00 & 23.39 & 22.77 & 21.70 \\
\hline & Theil & 12.87 & 11.97 & 11.00 & 10.83 & 10.60 & 9.31 & 8.78 & 7.85 \\
\hline & $\mathrm{A}(1)$ & 11.84 & 11.21 & 10.50 & 10.14 & 9.85 & 8.66 & 8.15 & 7.64 \\
\hline \multirow{3}{*}{ Italy } & Gini & 19.16 & 18.47 & 19.02 & 18.93 & 19.85 & 19.72 & 19.78 & 19.90 \\
\hline & Theil & 6.51 & 6.08 & 6.42 & 6.29 & 7.13 & 7.01 & 7.08 & 7.19 \\
\hline & $\mathrm{A}(1)$ & 5.99 & 5.58 & 5.91 & 5.78 & 6.41 & 6.30 & 6.33 & 6.39 \\
\hline \multirow{3}{*}{ Greece } & Gini & 23.62 & 24.37 & 23.80 & 25.55 & 25.66 & 26.98 & 26.51 & 26.37 \\
\hline & Theil & 9.51 & 9.97 & 9.44 & 11.23 & 11.09 & 12.20 & 11.93 & 12.17 \\
\hline & $\mathrm{A}(1)$ & 8.77 & 9.13 & 8.70 & 9.97 & 9.99 & 10.97 & 10.68 & 10.55 \\
\hline \multirow{3}{*}{ Spain } & Gini & 27.87 & 28.27 & 28.19 & 28.71 & 28.37 & 26.99 & 26.36 & 26.07 \\
\hline & Theil & 13.08 & 13.22 & 13.36 & 13.67 & 13.47 & 12.69 & 12.09 & 11.47 \\
\hline & $\mathrm{A}(1)$ & 11.84 & 12.13 & 11.94 & 12.33 & 12.17 & 11.07 & 10.60 & 10.28 \\
\hline \multirow{3}{*}{ Portugal } & Gini & 30.05 & 31.14 & 30.66 & 30.85 & 31.13 & 30.11 & 31.32 & 31.72 \\
\hline & Theil & 15.79 & 16.93 & 16.76 & 17.27 & 18.01 & 17.21 & 18.86 & 19.27 \\
\hline & $\mathrm{A}(1)$ & 13.23 & 14.16 & 13.80 & 14.05 & 14.37 & 13.55 & 14.60 & 14.92 \\
\hline \multirow{3}{*}{ Austria } & Gini & & 19.49 & 18.34 & 18.34 & 17.39 & 17.07 & 16.72 & 16.85 \\
\hline & Theil & & 6.67 & 5.84 & 5.90 & 5.27 & 5.10 & 4.93 & 4.97 \\
\hline & $\mathrm{A}(1)$ & & 6.44 & 5.62 & 5.52 & 4.87 & 4.80 & 4.67 & 4.82 \\
\hline \multirow{3}{*}{ Finland } & Gini & & & 17.32 & 17.80 & 17.30 & 17.81 & 17.10 & 18.50 \\
\hline & Theil & & & 5.22 & 5.46 & 5.23 & 5.38 & 5.08 & 5.98 \\
\hline & $\mathrm{A}(1)$ & & & 4.94 & 5.29 & 4.83 & 5.19 & 4.76 & 5.53 \\
\hline
\end{tabular}


Table 4. Short-Term Transition Rates Among Labour Market States

\begin{tabular}{|c|c|c|c|c|c|c|c|c|c|}
\hline \multirow{18}{*}{ 离 } & State in 1995 & $\mathbf{1}^{\text {st }} \mathbf{Q}$ & $2^{\text {nd }} Q$ & $3^{\text {rd }} Q$ & $4^{\text {th }} Q$ & $5^{\text {th }} Q$ & Unempl. & Inactive & Missing* \\
\hline & $1^{\text {st }}$ Quintile & 56.21 & 17.05 & 4.73 & 0.86 & 0 & 6.81 & 1.58 & 12.76 \\
\hline & $2^{\text {nd }}$ Quintile & 13.66 & 47.58 & 17.52 & 6.19 & 0.84 & 6.31 & 0.76 & 7.13 \\
\hline & $3^{\text {rd }}$ Quintile & 3.6 & 17 & 42.71 & 20.28 & 3.14 & 2.2 & 0.56 & 10.44 \\
\hline & $4^{\text {th }}$ Quintile & 0.43 & 4.48 & 18.92 & 51.67 & 17.33 & 1.55 & 1.44 & 4.17 \\
\hline & $5^{\text {th }}$ Quintile & 0 & 0.46 & 2.36 & 11.86 & 77.28 & 0.93 & 0.97 & 6.14 \\
\hline & Unemployed & 19.35 & 10.13 & 4.95 & 1.2 & 0.08 & 39.72 & 1.95 & 22.62 \\
\hline & Inactive & 3.5 & 4.56 & 2.12 & 0.53 & 2.01 & 20.25 & 27.47 & 39.55 \\
\hline & Missing Wage* & 6.29 & 3.93 & 2.78 & 1.58 & 1.89 & 5.55 & 4.32 & 73.67 \\
\hline & State in 2001 & $1^{\text {st }} Q$ & $2^{\text {nd }} Q$ & $3^{\text {rd }} \mathbf{Q}$ & $4^{\text {th }} Q$ & $5^{\text {th }} Q$ & Unempl. & Inactive & Missing* \\
\hline & $1^{\text {st }}$ Quintile & 54.96 & 12.34 & 2.99 & 0.52 & 0.16 & 9.31 & 1.98 & 17.73 \\
\hline & $2^{\text {nd }}$ Quintile & 14.92 & 48.06 & 17.06 & 3.65 & 0.34 & 3.97 & 0.64 & 11.36 \\
\hline & $3^{\text {rd }}$ Quintile & 3.3 & 20 & 47.65 & 18.01 & 1 & 1.55 & 0.89 & 7.91 \\
\hline & $4^{\text {th }}$ Quintile & 0.53 & 2.31 & 13.86 & 58.68 & 12.4 & 0.48 & 0.53 & 11.23 \\
\hline & $5^{\text {th }}$ Quintile & 0.53 & 2.31 & 2.63 & 13.49 & 71.68 & 0.5 & 0.57 & 8.27 \\
\hline & Unemployed & 14.83 & 2.71 & 5.93 & 1.1 & 0.08 & 46.44 & 2.37 & 26.53 \\
\hline & Inactive & 8.46 & 0 & 2.57 & 1.65 & 1.47 & 8.09 & 45.77 & 31.99 \\
\hline & Missing & 2.51 & 2.03 & 1.35 & 0.72 & 1.09 & 2.11 & 0.89 & 89.3 \\
\hline \multirow{17}{*}{ 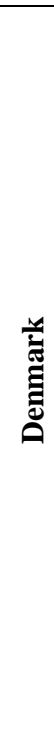 } & State in 1995 & $\mathbf{1}^{\text {st }} \mathbf{Q}$ & $2^{\text {nd }} Q$ & $3^{\text {rd }} \mathbf{Q}$ & $4^{\text {th }} Q$ & $5^{\text {th }} Q$ & Unempl. & Inactive & Missing* \\
\hline & $1^{\text {st }}$ Quintile & 41.28 & 19.41 & 9.96 & 1.7 & 1.98 & 4.61 & 0 & 21.06 \\
\hline & $2^{\text {nd }}$ Quintile & 21.45 & 40.87 & 14.52 & 7.36 & 1.07 & 3.69 & 0.79 & 10.26 \\
\hline & $3^{\text {rd }}$ Quintile & 6.28 & 30 & 28.78 & 17.72 & 6.16 & 2.02 & 0 & 8.66 \\
\hline & $4^{\text {th }}$ Quintile & 0.78 & 6.91 & 22.95 & 43.62 & 14.92 & 1.07 & 0 & 9.74 \\
\hline & $5^{\text {th }}$ Quintile & 2.25 & 1.06 & 1.69 & 25.86 & 61.83 & 0.48 & 0 & 6.83 \\
\hline & Unemployed & 12.86 & 15.85 & 6.16 & 3.25 & 2.87 & 34.02 & 0.25 & 24.75 \\
\hline & Inactive & 4.55 & 0 & 0 & 0 & 0 & 26.14 & 0 & 69.32 \\
\hline & Missing Wage* & 8.82 & 1.39 & 0.29 & 0.94 & 4.4 & 1.86 & 1.19 & 81.1 \\
\hline & State in 2001 & $1^{\text {st }} Q$ & $2^{\text {nd }} Q$ & $3^{\text {rd }} \mathbf{Q}$ & $4^{\text {th }} Q$ & $5^{\text {th }} Q$ & Unempl. & Inactive & Missing* \\
\hline & $1^{\text {st }}$ Quintile & 48.61 & 16.15 & 12.74 & 1.74 & 0.7 & 2.09 & 3.63 & 14.35 \\
\hline & $2^{\text {nd }}$ Quintile & 24.64 & 35.88 & 18.56 & 3 & 4.81 & 4.93 & 0 & 8.18 \\
\hline & $3^{\text {rd }}$ Quintile & 5.88 & 21 & 45.01 & 14.56 & 3.05 & 0.14 & 0 & 10.83 \\
\hline & $4^{\text {th }}$ Quintile & 4.39 & 8.29 & 21.01 & 39.61 & 17.96 & 2.43 & 0 & 6.31 \\
\hline & $5^{\text {th }}$ Quintile & 0.57 & 0.67 & 5.59 & 13.02 & 66.9 & 1.95 & 0.38 & 10.92 \\
\hline & Unemployed & 7.9 & 3.71 & 2.9 & 3.71 & 0 & 41.77 & 0 & 40 \\
\hline & Inactive & 41.46 & 0 & 0 & 0 & 0 & 7.32 & 51.22 & 0 \\
\hline 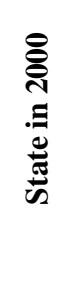 & Missing & 3.11 & 1.81 & 2.24 & 1.09 & 0.76 & 0.9 & 0.05 & 90.03 \\
\hline \multirow{18}{*}{ 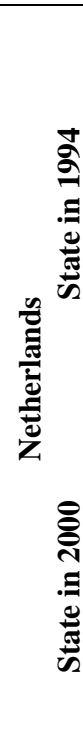 } & State in 1995 & $\mathbf{1}^{\text {st }} \mathbf{Q}$ & $2^{\text {nd }} Q$ & $3^{\text {rd }} Q$ & $4^{\text {th }} Q$ & $5^{\text {th }} Q$ & Unempl. & Inactive & Missing* \\
\hline & $1^{\text {st }}$ Quintile & 47.57 & 22.85 & 4.74 & 1.65 & 0.07 & 2.25 & 1.3 & 19.57 \\
\hline & $2^{\text {nd }}$ Quintile & 11.35 & 44.68 & 24.03 & 5.72 & 1.45 & 0.66 & 0.71 & 11.41 \\
\hline & $3^{\text {rd }}$ Quintile & 2.96 & 14 & 45.96 & 22.65 & 3.07 & 0.4 & 1.03 & 9.62 \\
\hline & $4^{\text {th }}$ Quintile & 0.51 & 2.67 & 13.11 & 52.7 & 18.97 & 2.21 & 0.78 & 9.04 \\
\hline & $5^{\text {th }}$ Quintile & 0.91 & 0.51 & 2.35 & 13.61 & 73.84 & 1.85 & 0.46 & 6.48 \\
\hline & Unemployed & 15.02 & 5.69 & 6.81 & 2.47 & 3 & 42.92 & 8.05 & 16.04 \\
\hline & Inactive & 8.1 & 1.49 & 2.79 & 3.45 & 1.12 & 22.44 & 47.49 & 13.13 \\
\hline & Missing Wage* & 13.79 & 6.97 & 4.49 & 5.99 & 4.77 & 2.85 & 0.8 & 60.34 \\
\hline & State in 2001 & $\mathbf{1}^{\text {st }} \mathbf{Q}$ & $2^{\text {nd }} Q$ & $3^{\text {rd }} \mathbf{Q}$ & $4^{\text {th }} Q$ & $5^{\text {th }} Q$ & Unempl. & Inactive & Missing* \\
\hline & $1^{\text {st }}$ Quintile & 53.88 & 15.15 & 3.56 & 2.7 & 0.45 & 0.29 & 0.31 & 23.66 \\
\hline & $2^{\text {nd }}$ Quintile & 7.82 & 49.78 & 18.96 & 6.14 & 1.31 & 0.57 & 0.17 & 15.25 \\
\hline & $3^{\text {rd }}$ Quintile & 4.74 & 7 & 52.65 & 16.22 & 4.42 & 0.89 & 0.32 & 13.42 \\
\hline & $4^{\text {th }}$ Quintile & 0.85 & 1.15 & 15.05 & 52.18 & 12.51 & 1.06 & 0.61 & 16.59 \\
\hline & $5^{\text {th }}$ Quintile & 0 & 0.71 & 1.19 & 15.11 & 65.95 & 0.27 & 0 & 16.78 \\
\hline & Unemployed & 7.2 & 1.83 & 0.54 & 0 & 2.47 & 46.13 & 18.6 & 23.23 \\
\hline & Inactive & 4.96 & 1.6 & 0.8 & 0 & 1.77 & 4.96 & 59.75 & 26.15 \\
\hline & Missing & 3.78 & 1.92 & 0.82 & 1.34 & 1.06 & 0.38 & 0.45 & 90.24 \\
\hline
\end{tabular}


Table 4, (Continued)

\begin{tabular}{|c|c|c|c|c|c|c|c|c|c|}
\hline \multirow{18}{*}{ 国 } & State in 1995 & $\mathbf{1}^{\text {st }} \mathbf{Q}$ & $2^{\text {nd }} Q$ & $3^{\text {ra }} Q$ & $4^{\text {th }} Q$ & $5^{\text {th }} Q$ & Unempl. & Inactive & Missing* \\
\hline & $1^{\text {st }}$ Quintile & 44.95 & 16.63 & 10.1 & 6.77 & 4.15 & 4.39 & 0.25 & 12.76 \\
\hline & $2^{\text {nd }}$ Quintile & 24.75 & 37.63 & 16.29 & 6.7 & 1.36 & 0.83 & 0 & 12.45 \\
\hline & $3^{\text {rd }}$ Quintile & 5.29 & 25 & 43.1 & 11.4 & 4 & 0.53 & 0.53 & 10.18 \\
\hline & $4^{\text {th }}$ Quintile & 3.35 & 5.11 & 21.81 & 45.16 & 15.11 & 0.89 & 0 & 8.57 \\
\hline & $5^{\text {th }}$ Quintile & 0.64 & 1.51 & 2.78 & 16.61 & 68.27 & 1.84 & 0.24 & 8.13 \\
\hline & Unemployed & 13.03 & 11.53 & 0 & 0.76 & 1.24 & 54.21 & 1.22 & 18 \\
\hline & Inactive & 0 & 0.81 & 0 & 0 & 0 & 13.67 & 64.89 & 20.63 \\
\hline & Missing Wage* & 6.09 & 2.75 & 1.97 & 0.66 & 0.66 & 2.67 & 0.72 & 84.49 \\
\hline & State in 2001 & 1st $Q$ & 2nd Q & 3rd Q & 4th $Q$ & 5th $Q$ & Unempl. & Inactive & Missing* \\
\hline & $1^{\text {st }}$ Quintile & 62.45 & 15.38 & 7.37 & 0.34 & 0.3 & 0.44 & 0 & 13.72 \\
\hline & $2^{\text {nd }}$ Quintile & 10.49 & 45.04 & 19.82 & 5.54 & 1.73 & 1.71 & 0 & 15.68 \\
\hline & $3^{\text {rd }}$ Quintile & 5.34 & 17 & 36.25 & 22.99 & 2.37 & 0.97 & 0 & 15.19 \\
\hline & $4^{\text {th }}$ Quintile & 0.89 & 5.95 & 20.93 & 50.18 & 13.53 & 0.55 & 0 & 7.95 \\
\hline & $5^{\text {th }}$ Quintile & 0 & 1.3 & 1.6 & 16.38 & 70.82 & 0.45 & 0 & 9.45 \\
\hline & Unemployed & 16.9 & 0 & 2.74 & 0 & 0 & 58.62 & 0.99 & 20.75 \\
\hline & Inactive & 0 & 3.42 & 0 & 0 & 0 & 0 & 62.86 & 33.72 \\
\hline & Missing & 1.37 & 1.13 & 1.62 & 0.7 & 0.46 & 0.78 & 0.64 & 93.3 \\
\hline \multirow{17}{*}{ 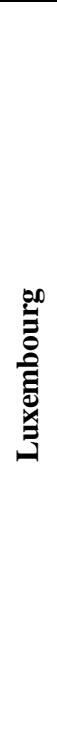 } & State in 1996 & 1st Q & 2nd Q & 3rd Q & 4th Q & 5th Q & Unempl. & Inactive & Missing* \\
\hline & $1^{\text {st }}$ Quintile & 57.09 & 14.93 & 1.06 & 0.65 & 0.81 & 3.09 & 0.34 & 22.03 \\
\hline & $2^{\text {nd }}$ Quintile & 12.92 & 54.54 & 14.01 & 0.19 & 0.22 & 1.18 & 0 & 16.92 \\
\hline & $3^{\text {rd }}$ Quintile & 2.36 & 12.16 & 57.08 & 8.76 & 3.39 & 0.58 & 0.36 & 15.31 \\
\hline & $4^{\text {th }}$ Quintile & 0.2 & 0.56 & 17.68 & 51.76 & 10.24 & 0.16 & 0 & 19.39 \\
\hline & $5^{\text {th }}$ Quintile & 0.25 & 0 & 3.45 & 14.19 & 65.8 & 0 & 0 & 16.31 \\
\hline & Unemployed & 5.3 & 1.32 & 0.55 & 1.54 & 0 & 59.62 & 2.98 & 28.68 \\
\hline & Inactive & 15 & 0 & 0 & 0 & 0 & 8 & 24 & 53 \\
\hline & Missing Wage* & 8.08 & 2.83 & 1.62 & 1.83 & 4.54 & 11.37 & 1.8 & 67.94 \\
\hline & State in 2001 & 1st Q & 2nd Q & 3rd Q & 4th $Q$ & 5th $Q$ & Unempl. & Inactive & Missing* \\
\hline & $1^{\text {st }}$ Quintile & 58.16 & 22.08 & 1.44 & 0.51 & 0 & 1.17 & 0 & 16.64 \\
\hline & $2^{\text {nd }}$ Quintile & 9.98 & 58.63 & 16.61 & 1.52 & 0.56 & 0.16 & 0 & 12.54 \\
\hline & $3^{\text {rd }}$ Quintile & 2.53 & 5.53 & 60.67 & 18.54 & 0.75 & 0 & 0 & 11.98 \\
\hline & $4^{\text {th }}$ Quintile & 0.28 & 1.26 & 9.48 & 63.97 & 17.43 & 0 & 0 & 7.59 \\
\hline & $5^{\text {th }}$ Quintile & 0 & 0.2 & 0.28 & 10.4 & 74.12 & 0 & 0 & 15.01 \\
\hline & Unemployed & 13.93 & 5.57 & 3.54 & 0 & 0 & 55.5 & 3.61 & 17.85 \\
\hline & Inactive & 0 & 0 & 0 & 0 & 0 & 9.76 & 66.67 & 23.58 \\
\hline & Missing & 0.72 & 0.7 & 0.35 & 0.1 & 0.75 & 0.29 & 0.22 & 96.87 \\
\hline \multirow{18}{*}{ 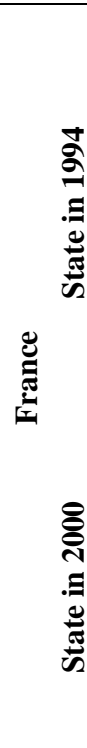 } & State in 1995 & 1st Q & 2nd Q & 3rd Q & 4th $Q$ & 5th Q & Unempl. & Inactive & Missing* \\
\hline & $1^{\text {st }}$ Quintile & 50.21 & 19.57 & 5.51 & 0.92 & 0.55 & 5.26 & 1.36 & 16.62 \\
\hline & $2^{\text {nd }}$ Quintile & 12.37 & 45.38 & 20.14 & 3.2 & 0.76 & 2.79 & 1.39 & 13.98 \\
\hline & $3^{\text {rd }}$ Quintile & 4.28 & 15 & 45.24 & 21.12 & 2.67 & 0.55 & 0.28 & 10.58 \\
\hline & $4^{\text {th }}$ Quintile & 2.29 & 4.5 & 14.03 & 48.05 & 19.62 & 0.97 & 0.4 & 10.15 \\
\hline & $5^{\text {th }}$ Quintile & 2.81 & 2.36 & 3.8 & 14.76 & 64.82 & 0.15 & 0.37 & 10.93 \\
\hline & Unemployed & 14.52 & 4.34 & 3.68 & 3.73 & 4.44 & 35.24 & 3.94 & 30.11 \\
\hline & Inactive & 0 & 0.93 & 3.59 & 0 & 0.93 & 2.66 & 76.1 & 15.8 \\
\hline & Missing Wage* & 5.16 & 2.62 & 1.82 & 2.96 & 1.95 & 7.24 & 2.55 & 75.71 \\
\hline & State in 2001 & 1st Q & 2nd Q & 3rd Q & 4th $Q$ & 5 th $Q$ & Unempl. & Inactive & Missing* \\
\hline & 1st Quintile & 48.37 & 16.06 & 5.75 & 1.99 & 0.54 & 6.84 & 1.09 & 19.36 \\
\hline & 2nd Quintile & 16.79 & 46.58 & 16.86 & 3.13 & 0.29 & 2.88 & 0.44 & 13.04 \\
\hline & 3rd Quintile & 2.14 & 15 & 49.2 & 16.06 & 0.91 & 1.34 & 0.55 & 14.83 \\
\hline & 4th Quintile & 0.58 & 3.24 & 12.43 & 56.16 & 14.94 & 0.95 & 0.25 & 11.45 \\
\hline & 5th Quintile & 0.44 & 0.18 & 1.53 & 11.03 & 71.68 & 0.18 & 0.18 & 14.78 \\
\hline & Unemployed & 16.43 & 8.43 & 2.81 & 1.06 & 0.69 & 49.78 & 1.75 & 19.05 \\
\hline & Inactive & 8.81 & 0 & 1.04 & 0 & 0 & 3.88 & 73.58 & 12.69 \\
\hline & Missing & 3.07 & 2.12 & 2.28 & 2.17 & 2.01 & 2.1 & 0.5 & 85.75 \\
\hline
\end{tabular}


Table 4 (Continued)

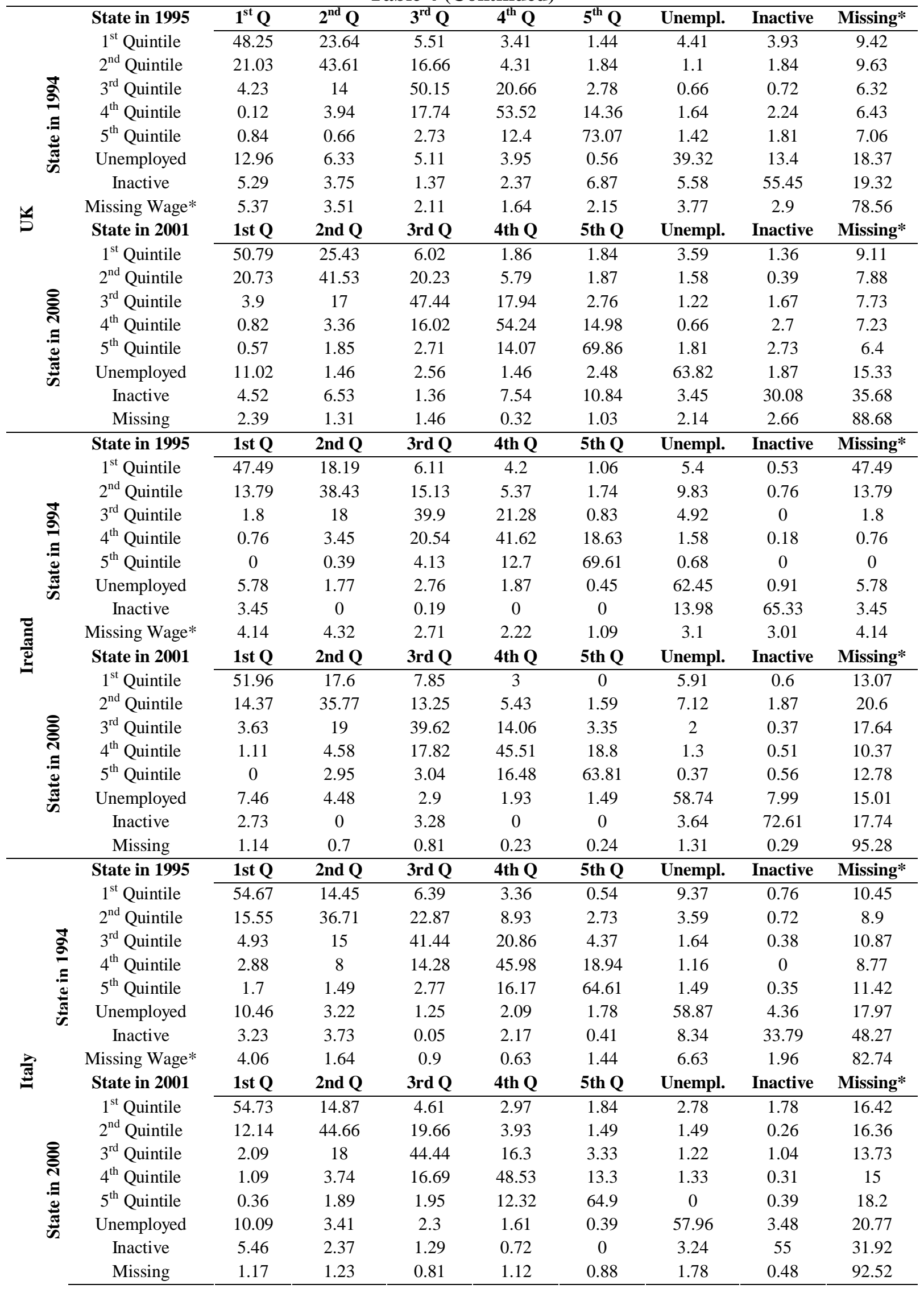


Table 4 (Continued)

\begin{tabular}{|c|c|c|c|c|c|c|c|c|c|}
\hline \multirow{18}{*}{ 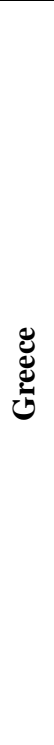 } & State in 1995 & 1st Q & 2nd $Q$ & 3rd Q & 4th Q & 5th Q & Unempl. & Inactive & Missing* \\
\hline & 1st Quintile & 39.99 & 20.39 & 9.28 & 2.09 & 1.84 & 7.28 & 0.91 & 18.23 \\
\hline & 2nd Quintile & 16.5 & 28.77 & 25.81 & 4.87 & 4.05 & 6.05 & 0.13 & 13.82 \\
\hline & 3rd Quintile & 4.81 & 17 & 35.22 & 19.86 & 5.99 & 1.56 & 0.39 & 14.95 \\
\hline & 4th Quintile & 2.94 & 6.44 & 20.1 & 36.09 & 18.06 & 2.13 & 0 & 14.24 \\
\hline & 5th Quintile & 0.7 & 3.13 & 7.73 & 18.06 & 56.56 & 0.46 & 0.25 & 13.11 \\
\hline & Unemployed & 15.29 & 6.95 & 5.53 & 1.4 & 1.74 & 36.37 & 9.35 & 23.38 \\
\hline & Inactive & 6.74 & 2.58 & 0.52 & 0 & 0.63 & 19.07 & 44.73 & 25.73 \\
\hline & Missing Wage* & 3.68 & 3.03 & 1.79 & 0.92 & 1.5 & 7.48 & 4.83 & 76.77 \\
\hline & State in 2001 & 1st Q & 2nd $Q$ & 3rd Q & 4th $Q$ & 5th Q & Unempl. & Inactive & Missing* \\
\hline & 1st Quintile & 57.69 & 19.5 & 4.41 & 1.08 & 0.37 & 6.24 & 1.19 & 9.51 \\
\hline & 2nd Quintile & 10.75 & 52.41 & 20.83 & 6.52 & 0.82 & 2.18 & 0 & 6.49 \\
\hline & 3rd Quintile & 4.26 & 14 & 55.8 & 13.9 & 2.45 & 1.59 & 0 & 7.76 \\
\hline & 4th Quintile & 0 & 2.19 & 17.84 & 52.7 & 19.34 & 1.32 & 0.23 & 6.38 \\
\hline & 5th Quintile & 0 & 0.5 & 2.58 & 10.8 & 76.59 & 1.57 & 0.95 & 7 \\
\hline & Unemployed & 16.89 & 8.83 & 7.46 & 5.7 & 0 & 39.23 & 9.5 & 12.39 \\
\hline & Inactive & 8.28 & 4.42 & 0.75 & 0 & 1.05 & 5.37 & 53.51 & 26.61 \\
\hline & Missing & 0.98 & 1.03 & 0.6 & 0.36 & 0.38 & 0.79 & 1.05 & 94.8 \\
\hline \multirow{18}{*}{ 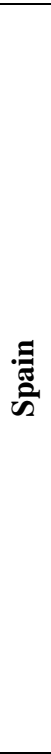 } & State in 1995 & 1st Q & 2nd $Q$ & 3rd Q & 4th $Q$ & 5th Q & Unempl. & Inactive & Missing* \\
\hline & 1st Quintile & 38.99 & 21.45 & 9.27 & 1.57 & 0.18 & 10.95 & 2.06 & 15.55 \\
\hline & 2nd Quintile & 14.17 & 31.82 & 22.21 & 5.62 & 0.78 & 7.95 & 0.71 & 16.74 \\
\hline & 3rd Quintile & 4.64 & 13 & 33.48 & 20.93 & 2.92 & 8.16 & 0.52 & 16.66 \\
\hline & 4th Quintile & 0.37 & 2.65 & 11.34 & 49.61 & 21.04 & 2.03 & 1.64 & 11.32 \\
\hline & 5th Quintile & 0.4 & 0.24 & 1.22 & 14.67 & 69.13 & 1.94 & 0.33 & 12.06 \\
\hline & Unemployed & 13.21 & 8.97 & 7.79 & 2.17 & 0.52 & 46 & 3.27 & 18.06 \\
\hline & Inactive & 6.08 & 3.77 & 2.03 & 0.6 & 0.21 & 19.96 & 40.77 & 26.59 \\
\hline & Missing Wage* & 3.92 & 3.63 & 1.91 & 0.55 & 0.95 & 7.02 & 4.85 & 77.18 \\
\hline & State in 2001 & 1st Q & 2nd $Q$ & 3rd Q & 4th $Q$ & 5th Q & Unempl. & Inactive & Missing* \\
\hline & 1st Quintile & 38.28 & 23.31 & 8.71 & 6.47 & 0.38 & 11.92 & 0.78 & 10.16 \\
\hline & 2nd Quintile & 21.29 & 34.57 & 18.5 & 10.27 & 0.28 & 6.04 & 0.68 & 8.38 \\
\hline & 3rd Quintile & 7.61 & 17 & 38.97 & 14.88 & 3.67 & 3.94 & 0.32 & 13.4 \\
\hline & 4th Quintile & 3.5 & 4.99 & 18.15 & 40.77 & 16.36 & 2.5 & 1.19 & 12.53 \\
\hline & 5th Quintile & 0 & 1.29 & 1.11 & 15.31 & 69.04 & 0.68 & 0.38 & 12.2 \\
\hline & Unemployed & 14.22 & 10.02 & 7.66 & 3.72 & 0.77 & 39.71 & 7.62 & 16.28 \\
\hline & Inactive & 2.14 & 0.35 & 0.25 & 0.15 & 0.35 & 10.74 & 68.39 & 17.64 \\
\hline & Missing & 2.15 & 1.57 & 0.99 & 1.51 & 1.56 & 1.48 & 1.4 & 89.34 \\
\hline \multirow{18}{*}{ 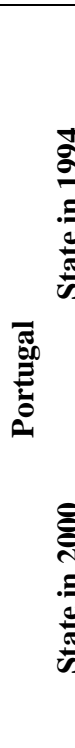 } & State in 1995 & 1st Q & 2nd Q & 3rd Q & 4th Q & 5th Q & Unempl. & Inactive & Missing* \\
\hline & 1st Quintile & 51.15 & 23.41 & 8.84 & 2.5 & 0.17 & 4.76 & 0.2 & 8.97 \\
\hline & 2nd Quintile & 16.63 & 43.8 & 22.63 & 4.26 & 0 & 2.62 & 0.07 & 9.99 \\
\hline & 3rd Quintile & 5.1 & 12 & 45.81 & 19.03 & 1.86 & 4.21 & 3.72 & 8.14 \\
\hline & 4th Quintile & 2 & 6.32 & 12.94 & 53.79 & 9.81 & 3.23 & 0.75 & 11.17 \\
\hline & 5th Quintile & 0.03 & 0.21 & 1.72 & 8.8 & 71.88 & 3.85 & 0 & 13.51 \\
\hline & Unemployed & 18.83 & 7.45 & 9.93 & 1.79 & 0 & 36 & 6.41 & 19.59 \\
\hline & Inactive & 4.84 & 2.67 & 0.2 & 4.15 & 1.28 & 5.53 & 50.35 & 31 \\
\hline & Missing Wage* & 4.42 & 2.31 & 2.22 & 2.08 & 2.95 & 2.2 & 2.4 & 81.41 \\
\hline & State in 2001 & 1st Q & 2nd $Q$ & 3rd Q & 4th Q & 5th Q & Unempl. & Inactive & Missing* \\
\hline & 1st Quintile & 68.37 & 10.58 & 4.28 & 2.31 & 1.71 & 2.9 & 1.32 & 8.53 \\
\hline & 2nd Quintile & 13.53 & 50.22 & 21.93 & 3.24 & 0.09 & 3.78 & 0.16 & 7.05 \\
\hline & 3rd Quintile & 4.82 & 10 & 52.41 & 15.01 & 6.42 & 2.72 & 0.18 & 8.66 \\
\hline & 4th Quintile & 0.07 & 6.08 & 17.34 & 58.25 & 6.85 & 1.91 & 0.85 & 8.65 \\
\hline & 5th Quintile & 0 & 0.48 & 2.43 & 10.25 & 76.13 & 0.51 & 0.07 & 10.12 \\
\hline & Unemployed & 10.98 & 7.94 & 15.07 & 1.05 & 2.1 & 34.7 & 4.44 & 23.71 \\
\hline & Inactive & 4.05 & 0 & 0 & 0 & 0.85 & 0.28 & 73.47 & 21.35 \\
\hline & Missing & 1.42 & 0.53 & 0.96 & 1.31 & 1.46 & 0.83 & 0.71 & 92.78 \\
\hline
\end{tabular}


Table 4 (Continued)

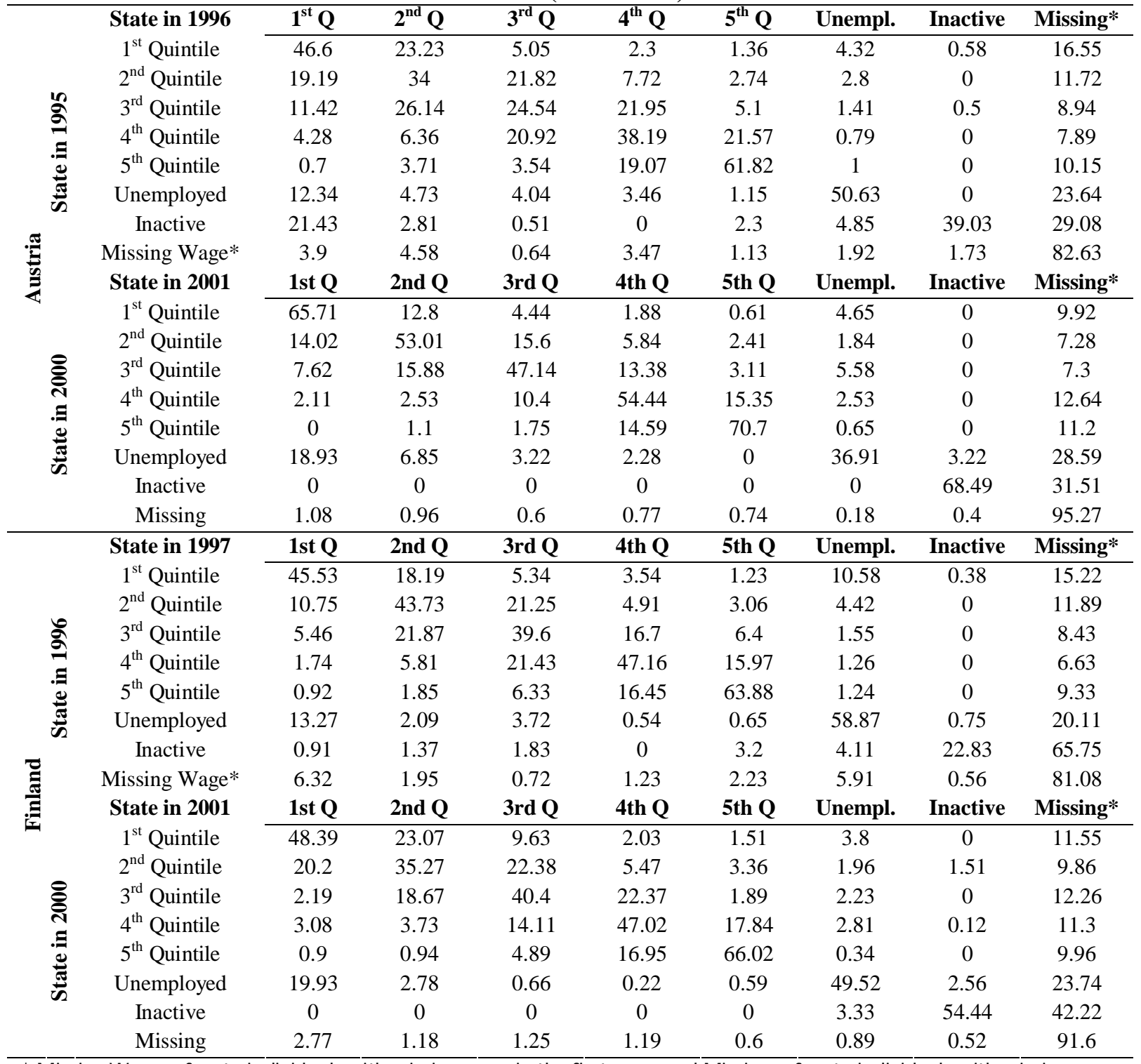

* M issing Wage refers to individuals with missing wage in the first wave and $\bar{M}$ issing refers to individuals with missing wage, self-employed, retired, not in formal employment and those that dropped from the survey in the previous year 
Table 5. Long-Term Transition Rates Among Labour Market States

\begin{tabular}{|c|c|c|c|c|c|c|c|c|c|c|}
\hline \multirow{8}{*}{ 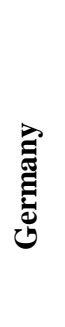 } & \multirow{9}{*}{ 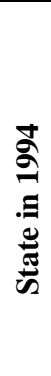 } & State in 2001 & $1^{\text {st }} Q$ & $2^{\text {nd }} Q$ & $\mathbf{3}^{\text {rd }} \mathbf{Q}$ & $4^{\text {th }} Q$ & $5^{\text {th }} Q$ & Unempl. & Inactive & Missing* \\
\hline & & $1^{\text {st }}$ Quintile & 24.7 & 13.38 & 8.87 & 2.4 & 0.88 & 10.62 & 1.84 & 37.32 \\
\hline & & $2^{\text {nd }}$ Quintile & 10.35 & 21.27 & 13.02 & 12.84 & 2.98 & 4.69 & 0.14 & 34.7 \\
\hline & & $3^{\text {rd }}$ Quintile & 5.97 & 11.48 & 17.89 & 17.2 & 4.6 & 4.95 & 1.17 & 36.74 \\
\hline & & $4^{\text {th }}$ Quintile & 1.32 & 5.8 & 11.66 & 25.46 & 16.74 & 2.19 & 1.38 & 35.45 \\
\hline & & $5^{\text {th }}$ Quintile & 0.52 & 0.91 & 2.6 & 10.65 & 44.21 & 0.48 & 0.4 & 40.22 \\
\hline & & Unemployed & 16.84 & 6.38 & 5.36 & 6.53 & 3.34 & 14.37 & 1.84 & 45.35 \\
\hline & & Inactive & 7.95 & 1.91 & 7.85 & 0.21 & 2.55 & 3.82 & 8.7 & 67.02 \\
\hline \multirow{10}{*}{ 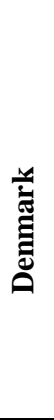 } & & Missing Wage* & 8.66 & 5.78 & 7.98 & 6.26 & 3.29 & 3.13 & 2.42 & 62.48 \\
\hline & \multirow{9}{*}{ 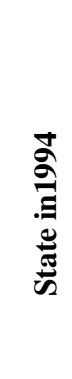 } & State in 2001 & 1st Q & 2nd $Q$ & 3rd Q & 4th $Q$ & 5th Q & Unempl. & Inactive & Missing* \\
\hline & & 1st Quintile & 16.67 & 9.31 & 14.33 & 5.83 & 2.48 & 4.89 & 2.24 & 44.25 \\
\hline & & 2nd Quintile & 24.11 & 17.35 & 12.64 & 2.17 & 7.36 & 0.14 & 0 & 36.23 \\
\hline & & 3rd Quintile & 6.56 & 11.35 & 18.59 & 7.29 & 8.58 & 1.08 & 0.36 & 46.19 \\
\hline & & 4th Quintile & 2.85 & 12.07 & 12.07 & 16.37 & 12.66 & 1.45 & 0 & 42.53 \\
\hline & & 5th Quintile & 2.29 & 2.22 & 3.6 & 14.22 & 30.78 & 1.52 & 0 & 45.36 \\
\hline & & Unemployed & 5.94 & 10.58 & 2.99 & 4.38 & 8.47 & 7.21 & 0.67 & 59.74 \\
\hline & & Inactive & 21.59 & 0 & 0 & 0 & 0 & 0 & 0 & 78.41 \\
\hline & & Missing & 6.21 & 4.56 & 8.31 & 5.05 & 3.82 & 3.19 & 0.16 & 68.7 \\
\hline \multirow{9}{*}{ 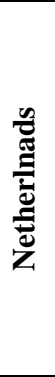 } & \multirow{9}{*}{ 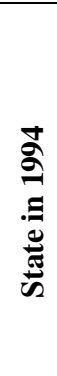 } & State in 2001 & 1st Q & 2nd Q & 3rd Q & 4th Q & 5th Q & Unempl. & Inactive & Missing* \\
\hline & & $1^{\text {st }}$ Quintile & 18.3 & 12.93 & 8.78 & 6.36 & 1.63 & 0.88 & 1.11 & 50.01 \\
\hline & & $2^{\text {nd }}$ Quintile & 6.14 & 19.42 & 15.38 & 8.01 & 1.74 & 1.08 & 1.5 & 46.73 \\
\hline & & $3^{\text {rd }}$ Quintile & 1.19 & 9.3 & 19.44 & 16.57 & 9.04 & 0.56 & 0.45 & 43.45 \\
\hline & & $4^{\text {th }}$ Quintile & 0.24 & 2.48 & 9.98 & 23.29 & 12.55 & 0.81 & 1.19 & 49.46 \\
\hline & & $5^{\text {th }}$ Quintile & 0.33 & 0.46 & 2.86 & 10.32 & 43.37 & 0.08 & 0.53 & 42.05 \\
\hline & & Unemployed & 9.87 & 9.39 & 2.15 & 3.59 & 2.15 & 9.6 & 7.3 & 55.95 \\
\hline & & Inactive & 3.54 & 0 & 1.4 & 0.84 & 5.49 & 9.31 & 26.82 & 52.61 \\
\hline & & Missing Wage* & 9.07 & 7 & 8.73 & 9.56 & 4.76 & 0.55 & 1.08 & 59.24 \\
\hline \multirow{9}{*}{ 国 } & \multirow{9}{*}{ 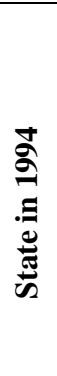 } & State in 2001 & 1st Q & 2nd $Q$ & 3rd Q & 4th Q & 5th Q & Unempl. & Inactive & Missing* \\
\hline & & $1^{\text {st }}$ Quintile & 19.91 & 13.81 & 10.73 & 7.76 & 3.8 & 2.53 & 0.72 & 40.74 \\
\hline & & $2^{\text {nd }}$ Quintile & 15.53 & 16.71 & 11.06 & 8.06 & 4.29 & 2.76 & 0.9 & 40.7 \\
\hline & & $3^{\text {rd }}$ Quintile & 7.53 & 17.91 & 15.34 & 12.69 & 5.46 & 0.7 & 0.62 & 39.76 \\
\hline & & $4^{\text {th }}$ Quintile & 2.14 & 2.8 & 13.85 & 23.12 & 13.15 & 0.68 & 0 & 44.26 \\
\hline & & $5^{\text {th }}$ Quintile & 0.8 & 2.16 & 1.79 & 12.41 & 39.45 & 0.97 & 0.68 & 41.74 \\
\hline & & Unemployed & 4.13 & 7.04 & 8.34 & 1.53 & 0.48 & 22.39 & 0.99 & 55.12 \\
\hline & & Inactive & 0.81 & 0 & 2.9 & 0 & 0 & 0 & 28.78 & 67.51 \\
\hline & & Missing & 6.79 & 4.18 & 6.34 & 5.72 & 1.94 & 1.93 & 1.53 & 71.56 \\
\hline \multirow{9}{*}{ 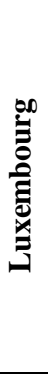 } & \multirow{9}{*}{ 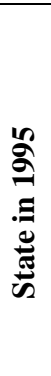 } & State in 2001 & 1st Q & 2nd $Q$ & 3rd Q & 4th Q & 5th Q & Unempl. & Inactive & Missing* \\
\hline & & $1^{\text {st }}$ Quintile & 17.82 & 19.54 & 5.58 & 1 & 0.87 & 0.5 & 0.81 & 53.88 \\
\hline & & $2^{\text {nd }}$ Quintile & 4.64 & 23.77 & 16.99 & 4.93 & 0 & 0 & 0 & 49.68 \\
\hline & & $3^{\text {rd }}$ Quintile & 1.06 & 4.12 & 25.04 & 18.88 & 6.24 & 0 & 0 & 44.65 \\
\hline & & $4^{\text {th }}$ Quintile & 0 & 0.92 & 6.29 & 28.65 & 18.6 & 0 & 0 & 45.54 \\
\hline & & $5^{\text {th }}$ Quintile & 0 & 0.25 & 1.36 & 9.85 & 42.91 & 0 & 0 & 45.63 \\
\hline & & Unemployed & 2.98 & 3.47 & 11.42 & 7 & 2.26 & 4.58 & 1.99 & 66.3 \\
\hline & & Inactive & 0 & 20 & 0 & 0 & 0 & 0 & 9 & 71 \\
\hline & & Missing Wage* & 5.9 & 4.26 & 1.71 & 0.53 & 3.51 & 2.14 & 2.49 & 79.47 \\
\hline \multirow{9}{*}{ 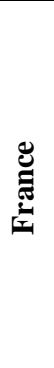 } & \multirow{9}{*}{ 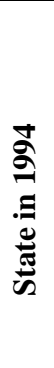 } & State in 2001 & 1st Q & 2nd $Q$ & 3rd Q & 4th Q & 5th Q & Unempl. & Inactive & Missing* \\
\hline & & $1^{\text {st }}$ Quintile & 19.2 & 18.63 & 6.8 & 1.61 & 0.57 & 4.07 & 1.71 & 47.41 \\
\hline & & $2^{\text {nd }}$ Quintile & 8.33 & 14.69 & 16.79 & 5.79 & 1.32 & 4.55 & 1.05 & 47.48 \\
\hline & & $3^{\text {rd }}$ Quintile & 1.59 & 6.45 & 18.62 & 20.01 & 4.89 & 1.79 & 0.68 & 45.97 \\
\hline & & $4^{\text {th }}$ Quintile & 2.36 & 3.21 & 7.68 & 20.62 & 18.73 & 1.12 & 0.72 & 45.56 \\
\hline & & $5^{\text {th }}$ Quintile & 0.99 & 1.32 & 4.22 & 10.29 & 38.46 & 0.75 & 0.42 & 43.55 \\
\hline & & Unemployed & 10.84 & 6.27 & 3.55 & 3.66 & 2.67 & 8.96 & 3.12 & 60.93 \\
\hline & & Inactive & 1.86 & 1.06 & 0 & 4.25 & 0.66 & 1.33 & 29.88 & 60.96 \\
\hline & & Missing & 4.69 & 5.81 & 4.03 & 4.52 & 2.12 & 4.23 & 1.61 & 73 \\
\hline
\end{tabular}


Table 5 (Continued)

\begin{tabular}{|c|c|c|c|c|c|c|c|c|c|c|}
\hline \multirow{9}{*}{ 光 } & \multirow{9}{*}{ 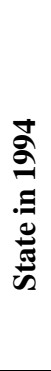 } & State in 2001 & $\mathbf{1}^{\text {st }} \mathbf{Q}$ & $2^{\text {nd }} Q$ & $3^{\text {ra }} Q$ & $4^{\text {th }} Q$ & $5^{\text {th }} Q$ & Unempl. & Inactive & Missing* \\
\hline & & $1^{\text {st }}$ Quintile & 20.32 & 19.25 & 15.53 & 6.11 & 2.99 & 5.31 & 3.11 & 27.39 \\
\hline & & $2^{\text {nd }}$ Quintile & 13.82 & 22.88 & 15.82 & 10.43 & 3.37 & 0.48 & 1.4 & 31.8 \\
\hline & & $3^{\text {rd }}$ Quintile & 6.95 & 11.35 & 24.86 & 17.05 & 10.17 & 1.35 & 0 & 28.27 \\
\hline & & $4^{\text {th }}$ Quintile & 2.38 & 4.81 & 11.71 & 29.82 & 22.79 & 0.84 & 3.14 & 24.51 \\
\hline & & $5^{\text {th }}$ Quintile & 1.63 & 0.42 & 2.15 & 12.96 & 45.2 & 1.87 & 2.29 & 33.49 \\
\hline & & Unemployed & 11.92 & 7.52 & 7.67 & 6.3 & 3.18 & 16.2 & 5.32 & 41.9 \\
\hline & & Inactive & 6.74 & 5.62 & 4.33 & 3.54 & 4.04 & 24.9 & 7.41 & 43.42 \\
\hline & & Missing Wage* & 5.64 & 5.65 & 7.37 & 5.61 & 4.2 & 3.26 & 3.81 & 64.45 \\
\hline \multirow{9}{*}{ 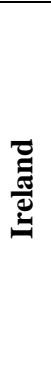 } & \multirow{9}{*}{ 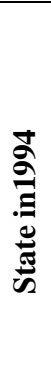 } & State in 2001 & 1st Q & 2nd $Q$ & 3rd Q & 4th Q & 5th Q & Unempl. & Inactive & Missing* \\
\hline & & $1^{\text {st }}$ Quintile & 10.49 & 11.65 & 8.72 & 8.33 & 5.97 & 2.05 & 0 & 52.79 \\
\hline & & $2^{\text {nd }}$ Quintile & 9 & 6.2 & 10.05 & 7.22 & 1.63 & 2.1 & 2.9 & 60.89 \\
\hline & & $3^{\text {rd }}$ Quintile & 1.94 & 9.74 & 13.55 & 9.06 & 8.12 & 0 & 0.54 & 57.05 \\
\hline & & $4^{\text {th }}$ Quintile & 0.76 & 0.76 & 8.42 & 11.8 & 18.09 & 1.15 & 0.32 & 58.71 \\
\hline & & $5^{\text {th }}$ Quintile & 0.65 & 0.83 & 1.18 & 7 & 29.17 & 0.72 & 0 & 60.46 \\
\hline & & Unemployed & 5.7 & 6.28 & 7 & 1.91 & 0.35 & 13.89 & 5.72 & 59.14 \\
\hline & & Inactive & 6.52 & 0 & 1.12 & 0 & 0 & 9.04 & 23.86 & 59.46 \\
\hline & & Missing & 2.57 & 2.71 & 1.89 & 4.85 & 0.85 & 0.76 & 3.89 & 82.48 \\
\hline \multirow{9}{*}{$\stackrel{\vec{\sigma}}{\underline{\Xi}}$} & \multirow{9}{*}{ 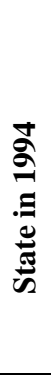 } & State in 2001 & 1st Q & 2nd Q & 3rd Q & 4th Q & 5th Q & Unempl. & Inactive & Missing* \\
\hline & & $1^{\text {st }}$ Quintile & 17.46 & 16.67 & 9.27 & 5.29 & 2.29 & 3.9 & 0.61 & 44.5 \\
\hline & & $2^{\text {nd }}$ Quintile & 4.97 & 14.49 & 16.73 & 10.58 & 3.66 & 2.23 & 0.49 & 46.85 \\
\hline & & $3^{\text {rd }}$ Quintile & 3 & 7.93 & 16.19 & 14.2 & 7.53 & 1.29 & 1.67 & 48.19 \\
\hline & & $4^{\text {th }}$ Quintile & 1.01 & 5.38 & 8.97 & 21.99 & 16.94 & 0.37 & 1.27 & 44.07 \\
\hline & & $5^{\text {th }}$ Quintile & 0.17 & 1.79 & 3.23 & 9.01 & 34.99 & 0.29 & 0.58 & 49.93 \\
\hline & & Unemployed & 13.24 & 7.71 & 4.45 & 3.44 & 2.09 & 16.22 & 2.84 & 50 \\
\hline & & Inactive & 3.87 & 1.98 & 3.04 & 1.71 & 1.34 & 6.69 & 11.3 & 70.08 \\
\hline & & Missing Wage* & 4.15 & 2.61 & 3.03 & 3.17 & 2.16 & 3.93 & 1.67 & 79.29 \\
\hline \multirow{9}{*}{ 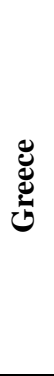 } & \multirow{9}{*}{ 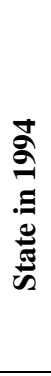 } & State in 2001 & 1st Q & 2nd $Q$ & 3rd Q & 4th Q & 5th Q & Unempl. & Inactive & Missing* \\
\hline & & $1^{\text {st }}$ Quintile & 15.45 & 13.37 & 11.53 & 5.46 & 3.26 & 2.21 & 0.7 & 48.02 \\
\hline & & $2^{\text {nd }}$ Quintile & 7.72 & 10.31 & 15.43 & 10.12 & 2.98 & 1.41 & 0.26 & 51.79 \\
\hline & & $3^{\text {rd }}$ Quintile & 1.42 & 4.84 & 17.51 & 18.75 & 4.45 & 0.23 & 0.66 & 52.13 \\
\hline & & $4^{\text {th }}$ Quintile & 3.16 & 2.9 & 11.96 & 19.13 & 12.53 & 0.68 & 0 & 49.63 \\
\hline & & $5^{\text {th }}$ Quintile & 0 & 2.7 & 3 & 12.27 & 34.75 & 0 & 0.57 & 46.71 \\
\hline & & Unemployed & 8.11 & 12.07 & 6.86 & 3.69 & 1.57 & 8.09 & 3.16 & 56.44 \\
\hline & & Inactive & 6.62 & 6.3 & 3.01 & 4.44 & 0.59 & 1.59 & 16.18 & 61.26 \\
\hline & & Missing & 3.3 & 4.17 & 3.56 & 1.11 & 2.28 & 2.75 & 2.27 & 80.57 \\
\hline \multirow{9}{*}{ 旋 } & \multirow{9}{*}{ 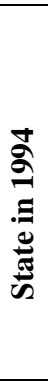 } & State in 2001 & 1st Q & 2nd $Q$ & 3rd Q & 4th Q & 5th Q & Unempl. & Inactive & Missing* \\
\hline & & $1^{\text {st }}$ Quintile & 18.47 & 14.53 & 9.31 & 5.33 & 1.33 & 3.98 & 2.01 & 45.05 \\
\hline & & $2^{\text {nd }}$ Quintile & 5.49 & 15.59 & 12.21 & 6.62 & 2.18 & 2.53 & 1.04 & 54.34 \\
\hline & & $3^{\text {rd }}$ Quintile & 6.01 & 6.16 & 17.34 & 15.75 & 5.62 & 2.83 & 1.61 & 44.67 \\
\hline & & $4^{\text {th }}$ Quintile & 1.51 & 1.39 & 5.89 & 23.28 & 19.72 & 2.33 & 3.33 & 42.56 \\
\hline & & $5^{\text {th }}$ Quintile & 0 & 1.25 & 1.29 & 3.56 & 44.87 & 0.51 & 2.49 & 46.03 \\
\hline & & Unemployed & 10.5 & 8.75 & 8.53 & 7.49 & 0.91 & 12.46 & 2.96 & 48.39 \\
\hline & & Inactive & 3.85 & 4.55 & 4.91 & 2 & 0.78 & 6.91 & 24.74 & 52.26 \\
\hline & & Missing Wage* & 4.87 & 4.48 & 3.64 & 4.86 & 4.3 & 2.62 & 2.52 & 72.7 \\
\hline \multirow{9}{*}{ 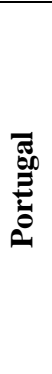 } & \multirow{9}{*}{ 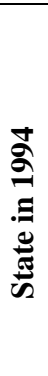 } & State in 2001 & 1st Q & 2nd $Q$ & 3rd Q & 4th Q & 5th Q & Unempl. & Inactive & Missing* \\
\hline & & $1^{\text {st }}$ Quintile & 25.3 & 18.35 & 9.01 & 7.83 & 0.67 & 3.1 & 0.64 & 35.09 \\
\hline & & $2^{\text {nd }}$ Quintile & 11.42 & 16.67 & 18.81 & 9.58 & 1.36 & 1.47 & 1.74 & 38.96 \\
\hline & & $3^{\text {rd }}$ Quintile & 6.27 & 13.65 & 16.61 & 15.99 & 6.34 & 2.79 & 2.38 & 35.95 \\
\hline & & $4^{\text {th }}$ Quintile & 3.43 & 3.94 & 8.49 & 22.34 & 14.43 & 1.05 & 0.48 & 45.84 \\
\hline & & $5^{\text {th }}$ Quintile & 0.07 & 0.07 & 3.85 & 7.18 & 40.43 & 1.31 & 0.14 & 46.96 \\
\hline & & Unemployed & 9.66 & 14.07 & 8.34 & 3.1 & 3.45 & 4.69 & 9.66 & 47.03 \\
\hline & & Inactive & 11.06 & 1.68 & 3.06 & 1.78 & 1.09 & 2.96 & 28.43 & 49.95 \\
\hline & & Missing & 3.2 & 2.67 & 4.49 & 4.34 & 7.07 & 1.49 & 1.27 & 75.48 \\
\hline
\end{tabular}


Table 5 (Continued)

\begin{tabular}{|c|c|c|c|c|c|c|c|c|c|c|}
\hline \multirow{9}{*}{ 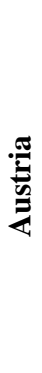 } & \multirow{9}{*}{ 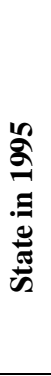 } & State in 2001 & $\mathbf{1}^{\text {st }} \mathbf{Q}$ & $2^{\text {nd }} Q$ & $3^{\text {rd }} \mathbf{Q}$ & $4^{\text {th }} Q$ & $5^{\text {th }} Q$ & Unempl. & Inactive & Missing* \\
\hline & & $1^{\text {st }}$ Quintile & 23.54 & 16.86 & 7.6 & 3.13 & 1.94 & 2.25 & 0.39 & 44.3 \\
\hline & & $2^{\text {nd }}$ Quintile & 10.63 & 14.49 & 17.77 & 11.53 & 2.8 & 3.11 & 0 & 39.68 \\
\hline & & $3^{\text {rd }}$ Quintile & 8.85 & 12.93 & 11.45 & 14.4 & 5.82 & 4.3 & 0.41 & 41.84 \\
\hline & & $4^{\text {th }}$ Quintile & 0.62 & 5.86 & 7.46 & 24.87 & 13.32 & 1.24 & 0.59 & 46.04 \\
\hline & & $5^{\text {th }}$ Quintile & 1.51 & 3.15 & 3.85 & 8.84 & 35.19 & 1.14 & 0 & 46.32 \\
\hline & & Unemployed & 10.27 & 1.15 & 3.58 & 1.73 & 2.08 & 19.03 & 0 & 62.17 \\
\hline & & Inactive & 14.29 & 0 & 2.81 & 6.63 & 2.3 & 0.51 & 9.18 & 64.29 \\
\hline & & Missing Wage* & 4.91 & 3.65 & 3.63 & 1.3 & 3.4 & 0.17 & 0.14 & 82.81 \\
\hline \multirow{9}{*}{$\underset{\Xi}{\stackrel{\Xi}{\Xi}}$} & \multirow{9}{*}{ 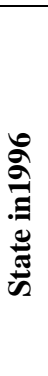 } & State in 2001 & 1st Q & 2nd $Q$ & 3rd Q & 4th Q & 5 th Q & Unempl. & Inactive & Missing* \\
\hline & & $1^{\text {st }}$ Quintile & 20.59 & 11.87 & 7.01 & 6.76 & 2.68 & 2.12 & 0.6 & 48.37 \\
\hline & & $2^{\text {nd }}$ Quintile & 7.29 & 19.15 & 19.27 & 10.53 & 1.95 & 0.56 & 0.28 & 40.98 \\
\hline & & $3^{\text {rd }}$ Quintile & 5.07 & 10.82 & 21.71 & 14.7 & 8.04 & 2 & 0 & 37.66 \\
\hline & & $4^{\text {th }}$ Quintile & 0.69 & 4.32 & 10.95 & 20.96 & 17.83 & 1.64 & 0 & 43.59 \\
\hline & & $5^{\text {th }}$ Quintile & 1.72 & 0.95 & 3.88 & 10.79 & 35.23 & 0.67 & 0.29 & 46.47 \\
\hline & & Unemployed & 14.51 & 9.58 & 5.16 & 3.49 & 1.45 & 12.88 & 0.83 & 52.1 \\
\hline & & Inactive & 0 & 0 & 4.57 & 2.74 & 0 & 6.39 & 0 & 86.3 \\
\hline & & Missing & 5.66 & 4.51 & 4.35 & 5.08 & 4.25 & 3.17 & 1.81 & 71.16 \\
\hline
\end{tabular}

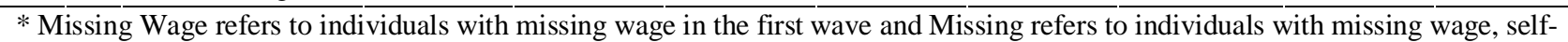
employed, retired, not in formal employment and those that dropped from the survey in the previous year. 
Table 6. Short-Term Transition Rates Among Income Quintiles

\begin{tabular}{|c|c|c|c|c|c|c|}
\hline \multirow{14}{*}{ 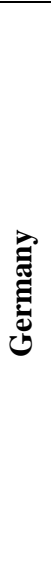 } & \multicolumn{6}{|c|}{ State in 1995} \\
\hline & State in 1994 & 1st Quintile & 2nd Quintile & 3rd Quintile & 4th Quintile & 5th Quintile \\
\hline & 1st Quintile & 71.28 & 21.63 & 6 & 1.09 & 0 \\
\hline & 2nd Quintile & 15.93 & 55.46 & 20.42 & 7.22 & 0.98 \\
\hline & 3rd Quintile & 4.15 & 19.68 & 49.2 & 23.36 & 3.62 \\
\hline & 4th Quintile & 0.47 & 4.82 & 20.38 & 55.66 & 18.67 \\
\hline & 5th Quintile & 0 & 0.5 & 2.56 & 12.9 & 84.03 \\
\hline & \multicolumn{6}{|c|}{ State in 2001} \\
\hline & State in 2000 & 1st Quintile & 2nd Quintile & 3rd Quintile & 4th Quintile & 5th Quintile \\
\hline & 1st Quintile & 77.43 & 17.39 & 4.21 & 0.74 & 0.23 \\
\hline & 2nd Quintile & 17.75 & 57.19 & 20.3 & 4.34 & 0.41 \\
\hline & 3rd Quintile & 3.68 & 21.97 & 53.15 & 20.09 & 1.12 \\
\hline & 4th Quintile & 0.6 & 2.63 & 15.79 & 66.86 & 14.13 \\
\hline & 5th Quintile & 0.58 & 2.55 & 2.91 & 14.89 & 79.08 \\
\hline \multirow{14}{*}{ 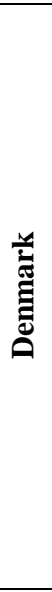 } & \multicolumn{6}{|c|}{ State in 1995} \\
\hline & State in 1994 & 1st Quintile & 2nd Quintile & 3rd Quintile & 4th Quintile & 5th Quintile \\
\hline & 1st Quintile & 55.54 & 26.12 & 13.4 & 2.28 & 2.67 \\
\hline & 2nd Quintile & 25.15 & 47.93 & 17.03 & 8.63 & 1.26 \\
\hline & 3rd Quintile & 7.03 & 34.02 & 32.22 & 19.84 & 6.89 \\
\hline & 4th Quintile & 0.88 & 7.75 & 25.73 & 48.91 & 16.73 \\
\hline & 5th Quintile & 2.42 & 1.15 & 1.82 & 27.9 & 66.71 \\
\hline & \multicolumn{6}{|c|}{ State in 2001} \\
\hline & State in 2000 & 1st Quintile & 2nd Quintile & 3rd Quintile & 4th Quintile & 5th Quintile \\
\hline & 1st Quintile & 60.81 & 20.21 & 15.94 & 2.17 & 0.87 \\
\hline & 2nd Quintile & 28.36 & 41.29 & 21.36 & 3.45 & 5.54 \\
\hline & 3rd Quintile & 6.61 & 23.05 & 50.56 & 16.36 & 3.42 \\
\hline & 4th Quintile & 4.81 & 9.09 & 23.02 & 43.4 & 19.68 \\
\hline & 5th Quintile & 0.66 & 0.77 & 6.44 & 15.01 & 77.12 \\
\hline \multirow{14}{*}{ 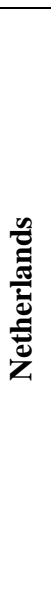 } & \multicolumn{6}{|c|}{ State in 1995} \\
\hline & State in 1994 & 1st Quintile & 2nd Quintile & 3rd Quintile & 4th Quintile & 5th Quintile \\
\hline & 1st Quintile & 61.88 & 29.72 & 6.16 & 2.14 & 0.09 \\
\hline & 2nd Quintile & 13.02 & 51.22 & 27.54 & 6.55 & 1.66 \\
\hline & 3rd Quintile & 3.33 & 16.08 & 51.68 & 25.46 & 3.45 \\
\hline & 4th Quintile & 0.58 & 3.04 & 14.91 & 59.91 & 21.56 \\
\hline & 5th Quintile & 1 & 0.55 & 2.58 & 14.92 & 80.94 \\
\hline & \multicolumn{6}{|c|}{ State in 2001} \\
\hline & State in 2000 & 1st Quintile & 2nd Quintile & 3rd Quintile & 4th Quintile & 5th Quintile \\
\hline & 1st Quintile & 71.13 & 20.01 & 4.7 & 3.56 & 0.6 \\
\hline & 2nd Quintile & 9.31 & 59.25 & 22.57 & 7.3 & 1.56 \\
\hline & 3rd Quintile & 5.55 & 8.59 & 61.68 & 19 & 5.18 \\
\hline & 4th Quintile & 1.04 & 1.41 & 18.41 & 63.84 & 15.3 \\
\hline & 5th Quintile & 0 & 0.85 & 1.43 & 18.22 & 79.5 \\
\hline \multirow{13}{*}{ 声 } & \multicolumn{6}{|c|}{ State in 1995} \\
\hline & State in 1994 & 1st Quintile & 2nd Quintile & 3rd Quintile & 4th Quintile & 5th Quintile \\
\hline & 1st Quintile & 54.42 & 20.13 & 12.22 & 8.2 & 5.03 \\
\hline & 2nd Quintile & 28.54 & 43.39 & 18.78 & 7.72 & 1.57 \\
\hline & 3rd Quintile & 5.96 & 28.14 & 48.55 & 12.84 & 4.51 \\
\hline & 4th Quintile & 3.7 & 5.64 & 24.09 & 49.88 & 16.68 \\
\hline & 5th Quintile & 0.71 & 1.68 & 3.09 & 18.49 & 76.02 \\
\hline & \multicolumn{6}{|c|}{ State in 2001} \\
\hline & State in 2000 & 1st Quintile & 2nd Quintile & 3rd Quintile & 4th Quintile & 5th Quintile \\
\hline & 1st Quintile & 72.75 & 17.92 & 8.59 & 0.39 & 0.35 \\
\hline & 2nd Quintile & 12.7 & 54.52 & 23.99 & 6.7 & 2.09 \\
\hline & 3rd Quintile & 6.37 & 20.15 & 43.23 & 27.42 & 2.82 \\
\hline & 4th Quintile & 0.98 & 6.51 & 22.88 & 54.85 & 14.79 \\
\hline
\end{tabular}




\begin{tabular}{|c|c|c|c|c|c|c|}
\hline & 5th Quintile & 0 & 1.44 & 1.78 & 18.18 & 78.6 \\
\hline \multirow{14}{*}{ 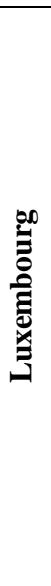 } & \multicolumn{6}{|c|}{ State in 1996} \\
\hline & State in 1995 & 1st Quintile & 2nd Quintile & 3rd Quintile & 4th Quintile & 5th Quintile \\
\hline & 1st Quintile & 76.59 & 20.03 & 1.42 & 0.88 & 1.09 \\
\hline & 2nd Quintile & 15.78 & 66.6 & 17.11 & 0.23 & 0.27 \\
\hline & 3rd Quintile & 2.82 & 14.51 & 68.15 & 10.46 & 4.05 \\
\hline & 4th Quintile & 0.25 & 0.7 & 21.98 & 64.35 & 12.73 \\
\hline & 5th Quintile & 0.3 & 0 & 4.12 & 16.95 & 78.62 \\
\hline & & & State & 2001 & & \\
\hline & State in 2000 & 1st Quintile & 2nd Quintile & 3rd Quintile & 4th Quintile & 5th Quintile \\
\hline & 1st Quintile & 70.77 & 26.87 & 1.75 & 0.61 & 0 \\
\hline & 2nd Quintile & 11.44 & 67.15 & 19.03 & 1.74 & 0.64 \\
\hline & 3rd Quintile & 2.87 & 6.29 & 68.93 & 21.06 & 0.85 \\
\hline & 4th Quintile & 0.3 & 1.36 & 10.26 & 69.22 & 18.86 \\
\hline & 5th Quintile & 0 & 0.23 & 0.33 & 12.24 & 87.2 \\
\hline \multirow{14}{*}{ 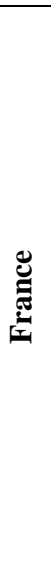 } & \multicolumn{6}{|c|}{ State in 1995} \\
\hline & State in 1994 & 1st Quintile & 2nd Quintile & 3rd Quintile & 4th Quintile & 5th Quintile \\
\hline & 1st Quintile & 65.42 & 25.5 & 7.18 & 1.2 & 0.71 \\
\hline & 2nd Quintile & 15.11 & 55.45 & 24.6 & 3.91 & 0.93 \\
\hline & 3rd Quintile & 4.84 & 17.24 & 51.07 & 23.84 & 3.02 \\
\hline & 4th Quintile & 2.59 & 5.09 & 15.85 & 54.3 & 22.18 \\
\hline & 5th Quintile & 3.17 & 2.67 & 4.29 & 16.67 & 73.2 \\
\hline & \multicolumn{6}{|c|}{ State in 2001} \\
\hline & State in 2000 & 1st Quintile & 2nd Quintile & 3rd Quintile & 4th Quintile & 5th Quintile \\
\hline & 1st Quintile & 66.52 & 22.09 & 7.91 & 2.74 & 0.75 \\
\hline & 2nd Quintile & 20.07 & 55.68 & 20.16 & 3.74 & 0.35 \\
\hline & 3rd Quintile & 2.57 & 17.98 & 59.08 & 19.28 & 1.09 \\
\hline & 4th Quintile & 0.67 & 3.7 & 14.23 & 64.29 & 17.1 \\
\hline & 5th Quintile & 0.51 & 0.21 & 1.8 & 13 & 84.47 \\
\hline \multirow{14}{*}{ 光 } & \multicolumn{6}{|c|}{ State in 1995} \\
\hline & State in 1994 & 1st Quintile & 2nd Quintile & 3rd Quintile & 4th Quintile & 5th Quintile \\
\hline & 1st Quintile & 58.66 & 28.75 & 6.7 & 4.14 & 1.75 \\
\hline & 2nd Quintile & 24.05 & 49.87 & 19.05 & 4.93 & 2.1 \\
\hline & 3rd Quintile & 4.58 & 15.68 & 54.34 & 22.38 & 3.01 \\
\hline & 4th Quintile & 0.13 & 4.4 & 19.78 & 59.68 & 16.01 \\
\hline & 5th Quintile & 0.94 & 0.74 & 3.04 & 13.82 & 81.46 \\
\hline & \multicolumn{6}{|c|}{ State in 2001} \\
\hline & State in 2000 & 1st Quintile & 2nd Quintile & 3rd Quintile & 4th Quintile & 5th Quintile \\
\hline & 1st Quintile & 59.09 & 29.59 & 7 & 2.17 & 2.15 \\
\hline & 2nd Quintile & 23 & 46.06 & 22.44 & 6.43 & 2.08 \\
\hline & 3rd Quintile & 4.37 & 19.4 & 53.07 & 20.07 & 3.08 \\
\hline & 4th Quintile & 0.92 & 3.76 & 17.91 & 60.66 & 16.75 \\
\hline & 5th Quintile & 0.64 & 2.08 & 3.04 & 15.79 & 78.44 \\
\hline \multirow{14}{*}{ 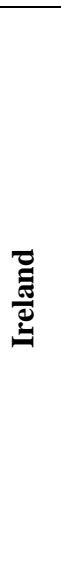 } & \multicolumn{6}{|c|}{ State in 1995} \\
\hline & State in 1994 & 1st Quintile & 2nd Quintile & 3rd Quintile & 4th Quintile & 5th Quintile \\
\hline & 1st Quintile & 61.64 & 23.6 & 7.93 & 5.45 & 1.37 \\
\hline & 2nd Quintile & 18.52 & 51.61 & 20.32 & 7.21 & 2.34 \\
\hline & 3rd Quintile & 2.2 & 21.77 & 48.92 & 26.09 & 1.01 \\
\hline & 4th Quintile & 0.89 & 4.06 & 24.16 & 48.96 & 21.92 \\
\hline & 5th Quintile & 0 & 0.45 & 4.75 & 14.63 & 80.17 \\
\hline & \multicolumn{6}{|c|}{ State in 2001} \\
\hline & State in 2000 & 1st Quintile & 2nd Quintile & 3rd Quintile & 4th Quintile & 5th Quintile \\
\hline & 1st Quintile & 64.62 & 21.88 & 9.76 & 3.73 & 0 \\
\hline & 2nd Quintile & 20.41 & 50.8 & 18.82 & 7.71 & 2.26 \\
\hline & 3rd Quintile & 4.54 & 24.16 & 49.53 & 17.58 & 4.19 \\
\hline & 4th Quintile & 1.27 & 5.22 & 20.3 & 51.82 & 21.4 \\
\hline & 5th Quintile & 0 & 3.42 & 3.53 & 19.1 & 73.96 \\
\hline
\end{tabular}




\begin{tabular}{|c|c|c|c|c|c|c|}
\hline \multirow{14}{*}{$\underset{\Xi}{\stackrel{\vec{\sigma}}{\Xi}}$} & \multicolumn{6}{|c|}{ State in 1995} \\
\hline & State in 1994 & 1st Quintile & 2nd Quintile & 3rd Quintile & 4th Quintile & 5th Quintile \\
\hline & 1st Quintile & 68.84 & 18.2 & 8.05 & 4.24 & 0.67 \\
\hline & 2nd Quintile & 17.92 & 42.29 & 26.35 & 10.29 & 3.15 \\
\hline & 3rd Quintile & 5.66 & 17.79 & 47.58 & 23.95 & 5.02 \\
\hline & 4th Quintile & 3.19 & 8.88 & 15.85 & 51.05 & 21.03 \\
\hline & 5th Quintile & 1.96 & 1.71 & 3.2 & 18.64 & 74.49 \\
\hline & \multicolumn{6}{|c|}{ State in 2001} \\
\hline & State in 2000 & 1st Quintile & 2nd Quintile & 3rd Quintile & 4th Quintile & 5th Quintile \\
\hline & 1st Quintile & 69.26 & 18.82 & 5.83 & 3.76 & 2.33 \\
\hline & 2nd Quintile & 14.83 & 54.54 & 24.01 & 4.8 & 1.82 \\
\hline & 3rd Quintile & 2.49 & 21.25 & 52.9 & 19.4 & 3.96 \\
\hline & 4th Quintile & 1.31 & 4.49 & 20.02 & 58.22 & 15.96 \\
\hline & 5th Quintile & 0.44 & 2.32 & 2.39 & 15.13 & 79.72 \\
\hline \multirow{14}{*}{ 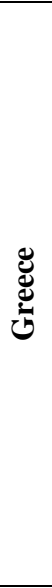 } & \multicolumn{6}{|c|}{ State in 1995} \\
\hline & State in 1994 & 1st Quintile & 2nd Quintile & 3rd Quintile & 4th Quintile & 5th Quintile \\
\hline & 1st Quintile & 54.34 & 27.71 & 12.62 & 2.85 & 2.5 \\
\hline & 2nd Quintile & 20.63 & 35.96 & 32.26 & 6.08 & 5.06 \\
\hline & 3rd Quintile & 5.79 & 20.71 & 42.39 & 23.9 & 7.21 \\
\hline & 4th Quintile & 3.52 & 7.7 & 24.04 & 43.16 & 21.59 \\
\hline & 5th Quintile & 0.81 & 3.63 & 8.96 & 20.96 & 65.64 \\
\hline & \multicolumn{6}{|c|}{ State in 2001} \\
\hline & State in 2000 & 1st Quintile & 2nd Quintile & 3rd Quintile & 4th Quintile & 5th Quintile \\
\hline & 1st Quintile & 69.46 & 23.48 & 5.31 & 1.3 & 0.45 \\
\hline & 2nd Quintile & 11.78 & 57.39 & 22.8 & 7.14 & 0.89 \\
\hline & 3rd Quintile & 4.7 & 15.7 & 61.55 & 15.34 & 2.7 \\
\hline & 4th Quintile & 0 & 2.38 & 19.38 & 57.24 & 21 \\
\hline & 5th Quintile & 0 & 0.56 & 2.85 & 11.94 & 84.65 \\
\hline \multirow{14}{*}{ 宽 } & \multicolumn{6}{|c|}{ State in 1995} \\
\hline & State in 1994 & 1st Quintile & 2nd Quintile & 3rd Quintile & 4th Quintile & 5th Quintile \\
\hline & 1st Quintile & 54.57 & 30.02 & 12.97 & 2.2 & 0.25 \\
\hline & 2nd Quintile & 18.99 & 42.66 & 29.77 & 7.53 & 1.04 \\
\hline & 3rd Quintile & 6.21 & 17.02 & 44.84 & 28.03 & 3.91 \\
\hline & 4th Quintile & 0.43 & 3.11 & 13.34 & 58.36 & 24.75 \\
\hline & 5th Quintile & 0.47 & 0.29 & 1.43 & 17.12 & 80.7 \\
\hline & \multicolumn{6}{|c|}{ State in 2001} \\
\hline & State in 2000 & 1st Quintile & 2nd Quintile & 3rd Quintile & 4th Quintile & 5th Quintile \\
\hline & 1st Quintile & 49.63 & 30.21 & 11.28 & 8.39 & 0.49 \\
\hline & 2nd Quintile & 25.07 & 40.72 & 21.78 & 12.09 & 0.33 \\
\hline & 3rd Quintile & 9.25 & 20.89 & 47.33 & 18.07 & 4.46 \\
\hline & 4th Quintile & 4.18 & 5.96 & 21.67 & 48.66 & 19.53 \\
\hline & 5th Quintile & 0 & 1.48 & 1.28 & 17.65 & 79.59 \\
\hline \multirow{14}{*}{ 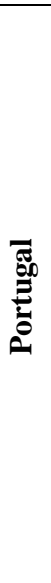 } & \multicolumn{6}{|c|}{ State in 1995} \\
\hline & State in 1994 & 1st Quintile & 2nd Quintile & 3rd Quintile & 4th Quintile & 5th Quintile \\
\hline & 1st Quintile & 59.43 & 27.21 & 10.27 & 2.9 & 0.2 \\
\hline & 2nd Quintile & 19.05 & 50.16 & 25.92 & 4.88 & 0 \\
\hline & 3rd Quintile & 6.08 & 14.46 & 54.58 & 22.67 & 2.22 \\
\hline & 4th Quintile & 2.36 & 7.44 & 15.25 & 63.39 & 11.56 \\
\hline & 5th Quintile & 0.04 & 0.25 & 2.08 & 10.65 & 86.98 \\
\hline & \multicolumn{6}{|c|}{ State in 2001} \\
\hline & State in 2000 & 1st Quintile & 2nd Quintile & 3rd Quintile & 4th Quintile & 5th Quintile \\
\hline & 1st Quintile & 78.36 & 12.12 & 4.91 & 2.64 & 1.96 \\
\hline & 2nd Quintile & 15.2 & 56.42 & 24.64 & 3.64 & 0.11 \\
\hline & 3rd Quintile & 5.45 & 11.07 & 59.26 & 16.97 & 7.25 \\
\hline & 4th Quintile & 0.08 & 6.86 & 19.58 & 65.75 & 7.73 \\
\hline & 5th Quintile & 0 & 0.54 & 2.73 & 11.48 & 85.25 \\
\hline
\end{tabular}




\begin{tabular}{|c|c|c|c|c|c|c|}
\hline \multirow{14}{*}{ 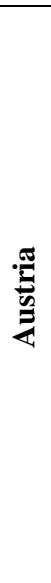 } & \multicolumn{6}{|c|}{ State in 1995} \\
\hline & State in 1994 & 1st Quintile & 2nd Quintile & 3rd Quintile & 4th Quintile & 5th Quintile \\
\hline & 1st Quintile & 59.34 & 29.58 & 6.42 & 2.93 & 1.73 \\
\hline & 2nd Quintile & 22.45 & 39.77 & 25.53 & 9.03 & 3.21 \\
\hline & 3rd Quintile & 12.81 & 29.32 & 27.53 & 24.62 & 5.72 \\
\hline & 4th Quintile & 4.69 & 6.97 & 22.91 & 41.81 & 23.62 \\
\hline & 5th Quintile & 0.78 & 4.17 & 3.99 & 21.47 & 69.59 \\
\hline & \multicolumn{6}{|c|}{ State in 2001} \\
\hline & State in 2000 & 1st Quintile & 2nd Quintile & 3rd Quintile & 4th Quintile & 5th Quintile \\
\hline & 1st Quintile & 76.91 & 14.99 & 5.19 & 2.2 & 0.72 \\
\hline & 2nd Quintile & 15.42 & 58.33 & 17.17 & 6.42 & 2.66 \\
\hline & 3rd Quintile & 8.74 & 18.23 & 54.11 & 15.35 & 3.57 \\
\hline & 4th Quintile & 2.48 & 2.98 & 12.26 & 64.18 & 18.1 \\
\hline & 5th Quintile & 0 & 1.25 & 1.99 & 16.55 & 80.21 \\
\hline \multirow{14}{*}{ 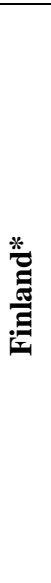 } & \multicolumn{6}{|c|}{ State in 1997} \\
\hline & State in 1996 & 1st Quintile & 2nd Quintile & 3rd Quintile & 4th Quintile & 5th Quintile \\
\hline & 1st Quintile & 61.68 & 24.64 & 7.23 & 4.79 & 1.67 \\
\hline & 2nd Quintile & 12.84 & 52.25 & 25.39 & 5.87 & 3.65 \\
\hline & 3rd Quintile & 6.06 & 24.29 & 43.99 & 18.55 & 7.1 \\
\hline & 4th Quintile & 1.88 & 6.31 & 23.27 & 51.2 & 17.34 \\
\hline & 5th Quintile & 1.03 & 2.06 & 7.08 & 18.4 & 71.42 \\
\hline & \multicolumn{6}{|c|}{ State in 2001} \\
\hline & State in 2000 & 1st Quintile & 2nd Quintile & 3rd Quintile & 4th Quintile & 5th Quintile \\
\hline & 1st Quintile & 57.17 & 27.26 & 11.38 & 2.4 & 1.79 \\
\hline & 2nd Quintile & 23.31 & 40.69 & 25.82 & 6.31 & 3.88 \\
\hline & 3rd Quintile & 2.56 & 21.84 & 47.24 & 26.16 & 2.21 \\
\hline & 4th Quintile & 3.59 & 4.35 & 16.45 & 54.82 & 20.8 \\
\hline & 5th Quintile & 1.01 & 1.05 & 5.45 & 18.9 & 73.6 \\
\hline
\end{tabular}


Table 7. Long-Term Transition Rates Among Income Quintiles

\begin{tabular}{|c|c|c|c|c|c|c|}
\hline \multirow{7}{*}{ 己ٍ } & \multicolumn{6}{|c|}{ State in 2001} \\
\hline & State in 1994 & 1st Quintile & 2nd Quintile & 3rd Quintile & 4th Quintile & 5th Quintile \\
\hline & 1st Quintile & 49.18 & 26.64 & 17.65 & 4.77 & 1.75 \\
\hline & 2nd Quintile & 17.11 & 35.18 & 21.54 & 21.24 & 4.92 \\
\hline & 3rd Quintile & 10.45 & 20.09 & 31.31 & 30.1 & 8.06 \\
\hline & 4th Quintile & 2.17 & 9.51 & 19.12 & 41.76 & 27.45 \\
\hline & 5th Quintile & 0.89 & 1.54 & 4.41 & 18.09 & 75.07 \\
\hline \multirow{7}{*}{ 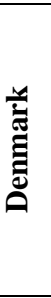 } & \multicolumn{6}{|c|}{ State in 2001} \\
\hline & State in 1994 & 1st Quintile & 2nd Quintile & 3rd Quintile & 4th Quintile & 5th Quintile \\
\hline & 1st Quintile & 34.28 & 19.16 & 29.47 & 11.98 & 5.11 \\
\hline & 2nd Quintile & 37.9 & 27.27 & 19.87 & 3.4 & 11.56 \\
\hline & 3rd Quintile & 12.53 & 21.67 & 35.49 & 13.91 & 16.39 \\
\hline & 4th Quintile & 5.09 & 21.54 & 21.54 & 29.22 & 22.6 \\
\hline & 5th Quintile & 4.32 & 4.18 & 6.77 & 26.77 & 57.95 \\
\hline \multirow{7}{*}{ 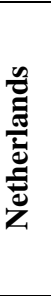 } & \multicolumn{6}{|c|}{ State in 2001} \\
\hline & State in 1994 & 1st Quintile & 2nd Quintile & 3rd Quintile & 4th Quintile & 5th Quintile \\
\hline & 1st Quintile & 38.12 & 26.95 & 18.29 & 13.26 & 3.39 \\
\hline & 2nd Quintile & 12.11 & 38.31 & 30.35 & 15.8 & 3.43 \\
\hline & 3rd Quintile & 2.14 & 16.75 & 35 & 29.83 & 16.27 \\
\hline & 4th Quintile & 0.5 & 5.11 & 20.57 & 47.97 & 25.85 \\
\hline & 5th Quintile & 0.57 & 0.79 & 4.99 & 18.01 & 75.64 \\
\hline \multirow{7}{*}{ 国 } & \multicolumn{6}{|c|}{ State in 2001} \\
\hline & State in 1994 & 1st Quintile & 2nd Quintile & 3rd Quintile & 4th Quintile & 5th Quintile \\
\hline & 1st Quintile & 35.55 & 24.66 & 19.16 & 13.85 & 6.79 \\
\hline & 2nd Quintile & 27.91 & 30.03 & 19.87 & 14.48 & 7.71 \\
\hline & 3rd Quintile & 12.77 & 30.39 & 26.03 & 21.53 & 9.27 \\
\hline & 4th Quintile & 3.89 & 5.09 & 25.16 & 41.98 & 23.88 \\
\hline & 5th Quintile & 1.41 & 3.82 & 3.17 & 21.92 & 69.68 \\
\hline \multirow{7}{*}{ 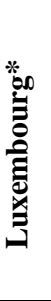 } & \multicolumn{6}{|c|}{ State in 2001} \\
\hline & State in 1995 & 1st Quintile & 2nd Quintile & 3rd Quintile & 4th Quintile & 5th Quintile \\
\hline & 1st Quintile & 39.78 & 43.6 & 12.45 & 2.23 & 1.95 \\
\hline & 2nd Quintile & 9.22 & 47.23 & 33.76 & 9.79 & 0 \\
\hline & 3rd Quintile & 1.92 & 7.45 & 45.24 & 34.12 & 11.28 \\
\hline & 4th Quintile & 0 & 1.69 & 11.55 & 52.6 & 34.16 \\
\hline & 5th Quintile & 0 & 0.47 & 2.5 & 18.11 & 78.92 \\
\hline \multirow{7}{*}{ 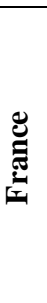 } & \multicolumn{6}{|c|}{ State in 2001} \\
\hline & State in 1994 & 1st Quintile & 2nd Quintile & 3rd Quintile & 4th Quintile & 5th Quintile \\
\hline & 1st Quintile & 41.02 & 39.8 & 14.52 & 3.44 & 1.22 \\
\hline & 2nd Quintile & 17.76 & 31.3 & 35.78 & 12.34 & 2.81 \\
\hline & 3rd Quintile & 3.08 & 12.51 & 36.12 & 38.81 & 9.48 \\
\hline & 4th Quintile & 4.49 & 6.1 & 14.61 & 39.2 & 35.6 \\
\hline & 5th Quintile & 1.8 & 2.38 & 7.64 & 18.61 & 69.57 \\
\hline \multirow{7}{*}{ 光 } & \multicolumn{6}{|c|}{ State in 2001} \\
\hline & State in 1994 & 1st Quintile & 2nd Quintile & 3rd Quintile & 4th Quintile & 5th Quintile \\
\hline & 1st Quintile & 31.65 & 29.99 & 24.19 & 9.52 & 4.65 \\
\hline & 2nd Quintile & 20.84 & 34.5 & 23.85 & 15.73 & 5.08 \\
\hline & 3rd Quintile & 9.87 & 16.13 & 35.33 & 24.23 & 14.45 \\
\hline & 4th Quintile & 3.33 & 6.72 & 16.38 & 41.7 & 31.87 \\
\hline & 5th Quintile & 2.61 & 0.68 & 3.44 & 20.79 & 72.49 \\
\hline
\end{tabular}


Table 7 (Continued)

\begin{tabular}{|c|c|c|c|c|c|c|}
\hline \multirow{7}{*}{ 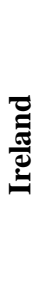 } & \multicolumn{6}{|c|}{ State in 2001} \\
\hline & State in 1994 & 1st Quintile & 2nd Quintile & 3rd Quintile & 4th Quintile & 5th Quintile \\
\hline & 1st Quintile & 23.22 & 25.8 & 19.31 & 18.45 & 13.21 \\
\hline & 2nd Quintile & 26.38 & 18.19 & 29.47 & 21.17 & 4.79 \\
\hline & 3rd Quintile & 4.58 & 22.97 & 31.95 & 21.36 & 19.15 \\
\hline & 4th Quintile & 1.9 & 1.9 & 21.14 & 29.63 & 45.44 \\
\hline & 5th Quintile & 1.66 & 2.13 & 3.05 & 18.02 & 75.14 \\
\hline \multirow{7}{*}{$\stackrel{\frac{\lambda}{\Xi}}{\Xi}$} & \multicolumn{6}{|c|}{ State in 2001} \\
\hline & State in 1994 & 1st Quintile & 2nd Quintile & 3rd Quintile & 4th Quintile & 5th Quintile \\
\hline & 1st Quintile & 34.25 & 32.69 & 18.18 & 10.38 & 4.5 \\
\hline & 2nd Quintile & 9.86 & 28.73 & 33.17 & 20.98 & 7.26 \\
\hline & 3rd Quintile & 6.14 & 16.23 & 33.14 & 29.08 & 15.41 \\
\hline & 4th Quintile & 1.85 & 9.92 & 16.51 & 40.51 & 31.21 \\
\hline & 5th Quintile & 0.34 & 3.64 & 6.57 & 18.32 & 71.12 \\
\hline \multirow{7}{*}{ 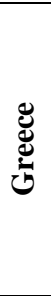 } & \multicolumn{6}{|c|}{ State in 2001} \\
\hline & State in 1994 & 1st Quintile & 2nd Quintile & 3rd Quintile & 4th Quintile & 5th Quintile \\
\hline & 1st Quintile & 31.48 & 27.25 & 23.5 & 11.12 & 6.65 \\
\hline & 2nd Quintile & 16.57 & 22.14 & 33.15 & 21.74 & 6.4 \\
\hline & 3rd Quintile & 3.02 & 10.31 & 37.28 & 39.92 & 9.47 \\
\hline & 4th Quintile & 6.35 & 5.85 & 24.07 & 38.51 & 25.23 \\
\hline & 5th Quintile & 0 & 5.12 & 5.7 & 23.27 & 65.91 \\
\hline \multirow{7}{*}{ 芯 } & \multicolumn{6}{|c|}{ State in 2001} \\
\hline & State in 1994 & 1st Quintile & 2nd Quintile & 3rd Quintile & 4th Quintile & 5th Quintile \\
\hline & 1st Quintile & 37.71 & 29.67 & 19.02 & 10.89 & 2.71 \\
\hline & 2nd Quintile & 13.03 & 37.04 & 29.02 & 15.73 & 5.17 \\
\hline & 3rd Quintile & 11.81 & 12.1 & 34.08 & 30.96 & 11.05 \\
\hline & 4th Quintile & 2.91 & 2.69 & 11.37 & 44.95 & 38.08 \\
\hline & 5th Quintile & 0 & 2.45 & 2.53 & 6.99 & 88.03 \\
\hline \multirow{7}{*}{ 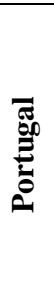 } & \multicolumn{6}{|c|}{ State in 2001} \\
\hline & State in 1994 & 1st Quintile & 2nd Quintile & 3rd Quintile & 4th Quintile & 5th Quintile \\
\hline & 1st Quintile & 41.37 & 30.01 & 14.73 & 12.8 & 1.1 \\
\hline & 2nd Quintile & 19.74 & 28.82 & 32.53 & 16.56 & 2.36 \\
\hline & 3rd Quintile & 10.66 & 23.19 & 28.22 & 27.17 & 10.77 \\
\hline & 4th Quintile & 6.52 & 7.48 & 16.13 & 42.45 & 27.42 \\
\hline & 5th Quintile & 0.13 & 0.13 & 7.46 & 13.92 & 78.35 \\
\hline \multirow{7}{*}{ 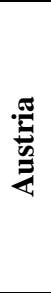 } & \multicolumn{6}{|c|}{ State in 2001} \\
\hline & State in 1994 & 1st Quintile & 2nd Quintile & 3rd Quintile & 4th Quintile & 5th Quintile \\
\hline & 1st Quintile & 44.36 & 31.77 & 14.32 & 5.9 & 3.66 \\
\hline & 2nd Quintile & 18.58 & 25.33 & 31.05 & 20.15 & 4.89 \\
\hline & 3rd Quintile & 16.56 & 24.2 & 21.41 & 26.93 & 10.89 \\
\hline & 4th Quintile & 1.19 & 11.24 & 14.32 & 47.7 & 25.55 \\
\hline & 5th Quintile & 2.87 & 6 & 7.32 & 16.83 & 66.99 \\
\hline \multirow{7}{*}{ 葛 } & \multicolumn{6}{|c|}{ State in 2001} \\
\hline & State in 1996 & 1st Quintile & 2nd Quintile & 3rd Quintile & 4th Quintile & 5th Quintile \\
\hline & 1st Quintile & 42.09 & 24.27 & 14.33 & 13.82 & 5.49 \\
\hline & 2nd Quintile & 12.53 & 32.91 & 33.12 & 18.1 & 3.34 \\
\hline & 3rd Quintile & 8.4 & 17.93 & 35.97 & 24.36 & 13.33 \\
\hline & 4th Quintile & 1.27 & 7.9 & 20 & 38.27 & 32.56 \\
\hline & 5th Quintile & 3.27 & 1.82 & 7.38 & 20.52 & 67.01 \\
\hline
\end{tabular}


Table 8 Immobility Ratio (IR) and Average Jump (AJ) for 1-year and 7-year Transition Rates of Earnings Quintiles (\%)

\begin{tabular}{|c|c|c|c|c|c|c|}
\hline Country & & Period & IR & $\begin{array}{c}\text { IR/ } \\
\text { IR(perfect mobility) }\end{array}$ & $\mathbf{A J}$ & $\begin{array}{c}\mathbf{A J} / \\
\mathbf{A J}(\text { perfect mobility) }\end{array}$ \\
\hline \multirow{3}{*}{ Germany } & \multirow{2}{*}{1 -year } & 1994-1995 & 0.937 & 1.802 & 0.438 & 0.274 \\
\hline & & 2000-2001 & 0.952 & 1.831 & 0.392 & 0.245 \\
\hline & 8 -year & 1994-2001 & 0.825 & 1.587 & 0.747 & 0.467 \\
\hline \multirow{3}{*}{ Denmark } & \multirow{2}{*}{1 -year } & 1994-1995 & 0.888 & 1.707 & 0.641 & 0.401 \\
\hline & & 2000-2001 & 0.880 & 1.693 & 0.606 & 0.379 \\
\hline & 8 -year & 1994-2001 & 0.735 & 1.414 & 1.000 & 0.625 \\
\hline \multirow{3}{*}{ Netherlands } & \multirow{2}{*}{ 1-year } & 1994-1995 & 0.938 & 1.803 & 0.465 & 0.291 \\
\hline & & $2000-2001$ & 0.934 & 1.795 & 0.412 & 0.257 \\
\hline & 8 -year & 1994-2001 & 0.831 & 1.598 & 0.751 & 0.469 \\
\hline \multirow{3}{*}{ Belgium } & \multirow{2}{*}{1 -year } & 1994-1995 & 0.880 & 1.692 & 0.629 & 0.393 \\
\hline & & $2000-2001$ & 0.924 & 1.777 & 0.403 & 0.252 \\
\hline & 8-year & 1994-2001 & 0.797 & 1.533 & 0.888 & 0.555 \\
\hline \multirow{3}{*}{ Luxembourg* } & \multirow{2}{*}{1 -year } & 1995-1996 & 0.968 & 1.861 & 0.332 & 0.207 \\
\hline & & $2000-2001$ & 0.979 & 1.882 & 0.298 & 0.186 \\
\hline & 8 -year & $1995-2001$ & 0.911 & 1.753 & 0.574 & 0.359 \\
\hline \multirow{3}{*}{ France } & \multirow{2}{*}{1 -year } & 1994-1995 & 0.921 & 1.771 & 0.511 & 0.319 \\
\hline & & $2000-2001$ & 0.948 & 1.823 & 0.405 & 0.253 \\
\hline & 8 -year & $1994-2001$ & 0.861 & 1.657 & 0.742 & 0.464 \\
\hline \multirow{3}{*}{ UK } & \multirow{2}{*}{1 -year } & 1994-1995 & 0.927 & 1.783 & 0.490 & 0.306 \\
\hline & & $2000-2001$ & 0.925 & 1.778 & 0.506 & 0.317 \\
\hline & 8 -year & $1994-2001$ & 0.800 & 1.538 & 0.836 & 0.522 \\
\hline \multirow{3}{*}{ Ireland } & \multirow{2}{*}{1 -year } & 1994-1995 & 0.925 & 1.778 & 0.516 & 0.323 \\
\hline & & $2000-2001$ & 0.909 & 1.748 & 0.531 & 0.332 \\
\hline & 8 -year & $1994-2001$ & 0.777 & 1.495 & 0.980 & 0.613 \\
\hline \multirow{3}{*}{ Italy } & \multirow{2}{*}{1 -year } & 1994-1995 & 0.888 & 1.708 & 0.579 & 0.362 \\
\hline & & $2000-2001$ & 0.928 & 1.785 & 0.472 & 0.295 \\
\hline & 8 -year & 1994-2001 & 0.790 & 1.519 & 0.860 & 0.538 \\
\hline \multirow{3}{*}{ Greece } & \multirow{2}{*}{1 -year } & 1994-1995 & 0.867 & 1.667 & 0.694 & 0.434 \\
\hline & & $2000-2001$ & 0.943 & 1.814 & 0.403 & 0.252 \\
\hline & 8 -year & $1994-2001$ & 0.790 & 1.520 & 0.904 & 0.565 \\
\hline \multirow{3}{*}{ Spain } & \multirow{2}{*}{1 -year } & 1994-1995 & 0.920 & 1.770 & 0.528 & 0.330 \\
\hline & & $2000-2001$ & 0.882 & 1.695 & 0.617 & 0.386 \\
\hline & 8 -year & $1994-2001$ & 0.826 & 1.589 & 0.744 & 0.465 \\
\hline \multirow{3}{*}{ Portugal } & \multirow{2}{*}{1 -year } & 1994-1995 & 0.923 & 1.774 & 0.460 & 0.288 \\
\hline & & $2000-2001$ & 0.928 & 1.784 & 0.397 & 0.248 \\
\hline & 8 -year & $1994-2001$ & 0.819 & 1.574 & 0.792 & 0.495 \\
\hline & 1 year & 1995-1996 & 0.875 & 1.683 & 0.689 & 0.431 \\
\hline Austria & 1-year & $2000-2001$ & 0.924 & 1.776 & 0.429 & 0.268 \\
\hline & 7-year & $1995-2001$ & 0.790 & 1.519 & 0.861 & 0.538 \\
\hline & & 1996-1997 & 0.891 & 1.713 & 0.584 & 0.365 \\
\hline Finland & 1-year & $2000-2001$ & 0.908 & 1.746 & 0.578 & 0.361 \\
\hline & 6-year & $1996-2001$ & 0.803 & 1.544 & 0.840 & 0.525 \\
\hline
\end{tabular}


Table 9. Mobility Index for different time horizons over time: Year 1994-2001 (Index*100)

\begin{tabular}{|c|c|c|c|c|c|c|c|c|c|c|c|c|c|c|}
\hline \multirow{2}{*}{ Time Horizon } & \multicolumn{14}{|c|}{ Mobility Index } \\
\hline & $\mathbf{G}$ & $\overline{D k}$ & Nl & $\mathbf{B e}$ & $\mathbf{L u}$ & Fr & UK & Ir & It & $\mathbf{G r}$ & Sp & $\mathbf{P t}$ & $\overline{\mathrm{Au}}$ & $\mathbf{F i}$ \\
\hline 1994-1995 & 18.85 & 26.65 & 19.33 & 27.01 & & 22.50 & 21.12 & 21.43 & 25.52 & 29.52 & 21.51 & 20.64 & & \\
\hline 1994-1996 & 22.25 & 31.44 & 20.16 & 28.22 & & 24.34 & 23.87 & 27.59 & 27.92 & 30.24 & 24.89 & 25.57 & & \\
\hline 1994-1997 & 24.19 & 35.45 & 22.64 & 31.08 & & 25.88 & 26.04 & 29.88 & 30.40 & 31.51 & 24.96 & 27.28 & & \\
\hline 1994-1998 & 25.12 & 38.86 & 25.88 & 29.97 & & 25.09 & 29.19 & 33.11 & 32.91 & 33.18 & 25.67 & 28.32 & & \\
\hline 1994-1999 & 26.48 & 38.50 & 27.55 & 33.30 & & 27.92 & 30.48 & 33.46 & 33.26 & 32.39 & 27.45 & 30.32 & & \\
\hline $1994-2000$ & 28.11 & 40.51 & 30.47 & 35.07 & & 29.12 & 33.83 & 35.55 & 34.27 & 35.86 & 30.33 & 32.26 & & \\
\hline 1994-2001 & 30.54 & 42.69 & 31.77 & 37.20 & & 29.95 & 35.10 & 38.36 & 35.39 & 37.81 & 29.60 & 31.97 & & \\
\hline 1995-1996 & 20.15 & 26.72 & 17.54 & 22.53 & 14.39 & 18.51 & 20.35 & 21.99 & 23.42 & 22.52 & 22.16 & 17.96 & 28.61 & \\
\hline $1995-1997$ & 22.82 & 30.28 & 21.48 & 26.17 & 17.04 & 20.60 & 23.30 & 25.11 & 27.30 & 28.16 & 22.67 & 21.68 & 31.17 & \\
\hline $1995-1998$ & 24.30 & 33.18 & 25.34 & 25.56 & 17.20 & 19.66 & 26.74 & 27.43 & 30.02 & 31.79 & 24.31 & 23.82 & 32.13 & \\
\hline 1995-1999 & 25.55 & 34.69 & 27.30 & 28.53 & 18.82 & 22.30 & 29.23 & 30.06 & 30.57 & 32.90 & 25.28 & 27.10 & 34.68 & \\
\hline $1995-2000$ & 27.80 & 37.04 & 31.45 & 31.41 & 20.46 & 24.55 & 31.26 & 33.41 & 32.20 & 32.37 & 27.17 & 29.30 & 36.01 & \\
\hline $1995-2001$ & 28.69 & 39.72 & 31.92 & 33.20 & 22.42 & 25.00 & 31.79 & 36.47 & 33.69 & 33.12 & 27.23 & 30.44 & 35.65 & \\
\hline 1996-1997 & 19.67 & 26.43 & 18.43 & 23.82 & 14.65 & 18.06 & 20.65 & 20.25 & 24.31 & 23.81 & 21.54 & 18.09 & 21.80 & 26.39 \\
\hline 1996-1998 & 21.50 & 33.17 & 22.37 & 24.26 & 15.75 & 18.38 & 24.74 & 24.19 & 27.80 & 30.97 & 24.21 & 21.96 & 24.91 & 30.39 \\
\hline 1996-1999 & 23.77 & 36.41 & 26.33 & 26.93 & 17.43 & 20.73 & 27.68 & 27.18 & 29.81 & 30.26 & 25.46 & 25.43 & 28.53 & 34.59 \\
\hline $1996-2000$ & 27.08 & 40.07 & 29.61 & 29.79 & 18.91 & 22.76 & 30.25 & 32.42 & 30.21 & 31.27 & 28.58 & 27.05 & 30.03 & 35.78 \\
\hline $1996-2001$ & 28.30 & 39.86 & 31.16 & 30.68 & 20.11 & 22.83 & 32.29 & 32.22 & 32.63 & 30.93 & 28.57 & 30.13 & 32.77 & 36.54 \\
\hline $1997-1998$ & 18.76 & 29.22 & 20.50 & 22.13 & 13.70 & 15.70 & 20.63 & 22.10 & 23.38 & 24.15 & 21.23 & 16.47 & 20.97 & 25.79 \\
\hline $1997-1999$ & 21.45 & 29.81 & 24.22 & 26.07 & 16.46 & 18.82 & 24.50 & 25.83 & 26.17 & 25.85 & 23.94 & 22.26 & 25.19 & 29.70 \\
\hline $1997-2000$ & 23.56 & 32.87 & 27.86 & 26.64 & 18.47 & 21.48 & 26.84 & 29.89 & 27.90 & 26.66 & 27.15 & 25.47 & 28.20 & 32.23 \\
\hline $1997-2001$ & 26.36 & 35.09 & 30.39 & 29.98 & 20.17 & 22.30 & 28.88 & 30.98 & 30.85 & 27.87 & 28.60 & 28.62 & 29.74 & 34.53 \\
\hline 1998-1999 & 16.91 & 25.97 & 19.75 & 23.88 & 11.30 & 16.16 & 21.73 & 22.33 & 21.82 & 20.49 & 21.91 & 15.35 & 19.56 & 26.02 \\
\hline $1998-2000$ & 20.72 & 32.51 & 24.17 & 25.45 & 13.75 & 19.82 & 24.97 & 27.86 & 24.49 & 23.98 & 23.38 & 24.12 & 24.56 & 31.11 \\
\hline $1998-2001$ & 22.86 & 33.33 & 25.81 & 27.63 & 16.04 & 20.05 & 27.85 & 28.90 & 27.39 & 25.34 & 26.40 & 26.77 & 26.33 & 32.48 \\
\hline 1999-2000 & 17.82 & 28.55 & 21.46 & 23.17 & 13.38 & 17.26 & 21.51 & 24.99 & 21.25 & 16.56 & 23.69 & 18.26 & 20.54 & 25.89 \\
\hline $1999-2001$ & 20.69 & 28.77 & 24.38 & 25.62 & 14.51 & 18.36 & 25.07 & 29.14 & 24.71 & 21.11 & 26.45 & 22.27 & 23.99 & 28.21 \\
\hline $2000-2001$ & 17.44 & 27.08 & 19.00 & 20.71 & 13.07 & 17.28 & 21.67 & 23.37 & 20.53 & 18.68 & 26.08 & 17.17 & 19.16 & 25.27 \\
\hline
\end{tabular}


Aaberge, Rolf, Bjorklund, Anders, Jantti, Markus, Palme, Marten, Pedersen, Peder J., Smith, Nina, and Wannemo, Tom. 2002. Income inequlaity and income mobility in the Scandinavian countries compared to the United States. Review of Income and Wealth, 48(4).

Atkinson, Anthony, B., Bourguignon, Francois, and Morrisson, C. (Eds.). (1992). Empirical studies of earnings mobility: Suisse : Harwood Academic Publishers.

Brukhauser, Richard V., Holtz-Eakin, Douglas, and Rhody, Stephen E. 1998. Mobility and inequality in the 1980s: a cross-national comparison of the Unite States and Germany. In Jenkins, Kapteyn andVan Praag (Eds.), The distribution of welfare and household production (pp. 111-175). Cambridge: Cambridge University Press.

Brukhauser, Richard V., and Poupore, John G. 1997. A cross-national comparison of permanent inequality in the United States and Germany. Review of Economics and Statistics, 79, 10-17.

Creedy, J., and Wilhelm, M. 2002. Income Mobility, Inequality and Social Welfare. Australian Economic Papers, 41(2), 140-150.

Dickens, Richard. 1999. Caught in a trap? Wage mobility in Great Britain: 1975-1994. Economica(67), 477-497.

Duncan, Greg J., and Morgan, James N. 1981. Persistence an change in economic status and the role of changing family composition. In Hill, Hill andMorgan (Eds.), Five thousand American families: patterns of economic progress (Vol. 9, pp. 1-44). Ann Arbor: Institute for Social Resarch, University of Michigan.

Fields, Gary S., Leary, Jesse, and Ok, Efe. 2003. Stochastic dominance in mobility analysis. Economic Letters, 75(3), 333-339.

Fields, Gary S., and Ok, Efe. 1999. The measurement of income mobility: an introduction to the literature. In Silber (Ed.), Handbook of Income Inequality Measurement. Boston: Kluwer Academic Publishing.

Friedman, M. 1962. Capitalism and Freedom. Chicago: University of Chicago Press.

Fritzell, Johan. 1990. The dynamics of income distributions: economic mobility in Sweden in comparizon with the United States. Social Science Research, 17-46.

Gottschalk, Peter, and Spolaore, Enrico. 2002. On the evaluation of economic mobility. Review of Economic Studies, 68, 191-208.

OECD. 1996. Earnings inequality, low paid employment and earnings mobility. In Employment Outlook (pp. 59-99). Paris: OECD.

OECD. 1997. Earnings mobility: taking a longer view. In Employment Outlook. Paris: OECD.

OECD. 2004. Employment Outlook. Paris: OECD.

OECD. 2006. Labour Market Performance since 1994 and Future Challenges. In Employment Outlook. 


\title{
Maastricht Graduate School of Governance
}

\author{
Working Paper Series
}

List of publications

\begin{tabular}{|c|c|c|}
\hline 2009 & & \\
\hline No. & Author(s) & Title \\
\hline 001 & $\begin{array}{l}\text { Roelen, K., } \\
\text { Gassmann, F. } \\
\text { and C. de } \\
\text { Neubourg }\end{array}$ & $\begin{array}{l}\text { Child Poverty in Vietnam - providing insights using a country- } \\
\text { specific and multidimensional model }\end{array}$ \\
\hline 002 & $\begin{array}{l}\text { Siegel, M. and } \\
\text { Lücke, M. }\end{array}$ & $\begin{array}{l}\text { What Determines the Choice of Transfer Channel for Migrant } \\
\text { Remittances? The Case of Moldova }\end{array}$ \\
\hline 003 & $\begin{array}{l}\text { Sologon, D. } \\
\text { and } \\
\text { O’Donoghue, } \\
\text { C. }\end{array}$ & Earnings Dynamics and Inequality in EU 1994 - 2001 \\
\hline 004 & $\begin{array}{l}\text { Sologon, D. } \\
\text { and } \\
\text { O’Donoghue, } \\
\text { C. }\end{array}$ & Policy, Institutional Factors and Earnings Mobility \\
\hline 005 & $\begin{array}{l}\text { Muñiz Castillo, } \\
\text { M.R. and D. } \\
\text { Gasper }\end{array}$ & $\begin{array}{l}\text { Looking for long-run development effectiveness: An autonomy- } \\
\text { centered framework for project evaluation }\end{array}$ \\
\hline 006 & $\begin{array}{l}\text { Muñiz Castillo, } \\
\text { M.R. and D. } \\
\text { Gasper }\end{array}$ & $\begin{array}{l}\text { Exploring human autonomy } \\
\text { effectiveness: Project logic and its effects } \\
\text { on individual autonomy }\end{array}$ \\
\hline 007 & $\begin{array}{l}\text { Tirivayi, } \mathrm{N} \text { and } \\
\text { W. Groot }\end{array}$ & $\begin{array}{l}\text { The Welfare Effects of Integrating HIV/AIDS Treatment with } \\
\text { Cash or In Kind Transfers }\end{array}$ \\
\hline 008 & $\begin{array}{l}\text { Tomini, S., } \\
\text { Groot, W. and } \\
\text { Milena Pavlova }\end{array}$ & $\begin{array}{l}\text { Paying Informally in the Albanian Health Care Sector: A Two- } \\
\text { Tiered Stochastic Frontier Bargaining Model }\end{array}$ \\
\hline 009 & $\begin{array}{l}\text { Wu, T., and } \\
\text { Lex Borghans }\end{array}$ & $\begin{array}{l}\text { Children Working and Attending School Simultaneously: } \\
\text { Tradeoffs in a Financial Crisis }\end{array}$ \\
\hline 010 & $\begin{array}{l}\text { Wu, T., } \\
\text { Borghans, L. } \\
\text { and Arnaud } \\
\text { Dupuy }\end{array}$ & $\begin{array}{l}\text { No School Left Behind: Do Schools in Underdeveloped Areas } \\
\text { Have Adequate Electricity for Learning? }\end{array}$ \\
\hline 2008 & & \\
\hline No. & Author(s) & Title \\
\hline 001 & Roelen, K. and & Measuring Child Poverty and Well-Being: a literature review \\
\hline
\end{tabular}




\begin{tabular}{|c|c|c|}
\hline & Gassmann, F. & \\
\hline 002 & $\begin{array}{l}\text { Hagen-Zanker, } \\
\text { J. }\end{array}$ & Why do people migrate? A review of the theoretical literature \\
\hline 003 & $\begin{array}{l}\text { Arndt, C. and } \\
\text { C. Omar }\end{array}$ & The Politics of Governance Ratings \\
\hline 004 & $\begin{array}{l}\text { Roelen, K., } \\
\text { Gassmann, F. } \\
\text { and C. de } \\
\text { Neubourg }\end{array}$ & $\begin{array}{l}\text { A global measurement approach versus a country-specific } \\
\text { measurement approach. Do they draw the same picture of child } \\
\text { poverty? The case of Vietnam }\end{array}$ \\
\hline 005 & $\begin{array}{l}\text { Hagen-Zanker, } \\
\text { J., M. Siegel } \\
\text { and C. de } \\
\text { Neubourg }\end{array}$ & Strings Attached: The impediments to Migration \\
\hline 006 & $\begin{array}{l}\text { Bauchmüller, } \\
\text { R. }\end{array}$ & $\begin{array}{l}\text { Evaluating causal effects of Early Childhood Care and Education } \\
\text { Investments: A discussion of the researcher's toolkit }\end{array}$ \\
\hline 007 & $\begin{array}{l}\text { Wu, T., } \\
\text { Borghans, L. } \\
\text { and A. Dupuy }\end{array}$ & $\begin{array}{l}\text { Aggregate Shocks and How Parents Protect the Human Capital } \\
\text { Accumulation Process: An Empirical Study of Indonesia }\end{array}$ \\
\hline 008 & $\begin{array}{l}\text { Hagen-Zanker, } \\
\text { J. and Azzarri, } \\
\text { C. }\end{array}$ & Are internal migrants in Albania leaving for the better? \\
\hline 009 & $\begin{array}{l}\text { Rosaura Muñiz } \\
\text { Castillo, M. }\end{array}$ & $\begin{array}{l}\text { Una propuesta para analizar proyectos con ayuda internacional:De } \\
\text { la autonomía individual al desarrollo humano }\end{array}$ \\
\hline 010 & $\mathrm{Wu}, \mathrm{T}$. & Circular Migration and Social Protection in Indonesia \\
\hline \multicolumn{3}{|c|}{2007} \\
\hline 001 & $\begin{array}{l}\text { Notten, G. and } \\
\text { C. de Neubourg }\end{array}$ & $\begin{array}{l}\text { Relative or absolute poverty in the US and EU? The battle of the } \\
\text { rates }\end{array}$ \\
\hline 002 & $\begin{array}{l}\text { Hodges, A. A. } \\
\text { Dufay, K. } \\
\text { Dashdorj, K.Y. } \\
\text { Jong, T. } \\
\text { Mungun and U. } \\
\text { Budragchaa }\end{array}$ & $\begin{array}{l}\text { Child benefits and poverty reduction: Evidence from Mongolia's } \\
\text { Child Money Programme }\end{array}$ \\
\hline 003 & $\begin{array}{l}\text { Hagen-Zanker, } \\
\text { J. and Siegel, } \\
\text { M. }\end{array}$ & The determinants of remittances: A review of the literature \\
\hline 004 & Notten, G. & $\begin{array}{l}\text { Managing risks: What Russian households do to smooth } \\
\text { consumption }\end{array}$ \\
\hline
\end{tabular}




\begin{tabular}{|c|c|c|}
\hline 005 & $\begin{array}{l}\text { Notten, G. and } \\
\text { C. de Neubourg }\end{array}$ & $\begin{array}{l}\text { Poverty in Europe and the USA: Exchanging official measurement } \\
\text { methods }\end{array}$ \\
\hline 006 & $\begin{array}{l}\text { Notten, G and } \\
\text { C. de Neubourg }\end{array}$ & $\begin{array}{l}\text { The policy relevance of absolute and relative poverty headcounts: } \\
\text { Whats in a number? }\end{array}$ \\
\hline 007 & $\begin{array}{l}\text { Hagen-Zanker, } \\
\text { J. and M. } \\
\text { Siegel }\end{array}$ & $\begin{array}{l}\text { A critical discussion of the motivation to remit in Albania and } \\
\text { Moldova }\end{array}$ \\
\hline 008 & $\mathrm{Wu}$, Treena & $\begin{array}{l}\text { Types of Households most vulnerable to physical and economic } \\
\text { threats: Case studies in Aceh after the Tsunami }\end{array}$ \\
\hline 009 & Siegel, M. & Immigrant Integration and Remittance Channel Choice \\
\hline 010 & $\begin{array}{l}\text { Muñiz Castillo, } \\
\text { M. }\end{array}$ & Autonomy and aid projects: Why do we care? \\
\hline $\begin{array}{l}2006 \\
\text { No. }\end{array}$ & Author(s) & Title \\
\hline 001 & $\begin{array}{l}\text { Gassmann, F. } \\
\text { and } \\
\text { G. Notten }\end{array}$ & $\begin{array}{l}\text { Size matters: Poverty reduction effects of means-tested and } \\
\text { universal child benefits in Russia }\end{array}$ \\
\hline 002 & $\begin{array}{l}\text { Hagen-Zanker, } \\
\text { J. and } \\
\text { M.R. Muñiz } \\
\text { Castillo }\end{array}$ & $\begin{array}{l}\text { Exploring multi-dimensional wellbeing and remittances in El } \\
\text { Salvador }\end{array}$ \\
\hline 003 & Augsburg, B. & $\begin{array}{l}\text { Econometric evaluation of the SEWA Bank in India: Applying } \\
\text { matching techniques based on the propensity score }\end{array}$ \\
\hline 004 & $\begin{array}{l}\text { Notten, G. and } \\
\text { D. de } \\
\text { Crombrugghe }\end{array}$ & Poverty and consumption smoothing in Russia \\
\hline $\begin{array}{l}2005 \\
\text { No. }\end{array}$ & Author(s) & Title \\
\hline 001 & Gassmann, F. & $\begin{array}{l}\text { An Evaluation of the Welfare Impacts of Electricity Tariff } \\
\text { Reforms And Alternative Compensating Mechanisms In Tajikistan }\end{array}$ \\
\hline 002 & Gassmann, F. & $\begin{array}{l}\text { How to Improve Access to Social Protection for the Poor? } \\
\text { Lessons from the Social Assistance Reform in Latvia }\end{array}$ \\
\hline
\end{tabular}

